Aus der Abteilung Neurodegeneration und Neurorestaurationsforschung

(Prof. Dr. med. J. B. Schulz)

im Zentrum Neurologische Medizin

der Medizinischen Fakultät der Universität Göttingen

\title{
Einfluss des GDNF-Rezeptors RET auf die akute MPTP-Toxizität in der Maus
}

\author{
INAUGURAL-DISSERTATION \\ zur Erlangung des Doktorgrades \\ der Medizinischen Fakultät \\ der Georg-August-Universität zu Göttingen
}

vorgelegt von

Sebastian Kowsky

aus

Bremen

Göttingen 2010 
Dekan: Prof. Dr. med. C. Frömmel

I. Berichterstatter: Prof. Dr. med. J. B. Schulz

II. Berichterstatter/in: Priv.-Doz. Dr. med. D. Liebetanz

III. Berichterstatter/in: Prof. Dr. med. J. Staiger

Tag der mündlichen Prüfung: 17.10.2011 


\section{Inhaltsverzeichnis}

\section{Abkürzungsverzeichnis}

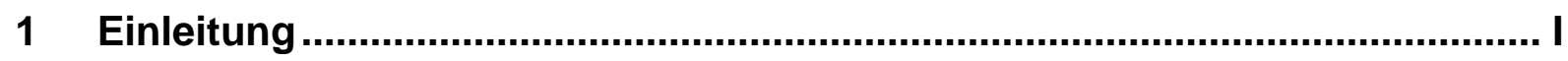

1.1 Das idiopathische Parkinson-Syndrom............................................ 1

1.1.1 Mögliche Ursachen und Entstehung des IPS ................................ 2

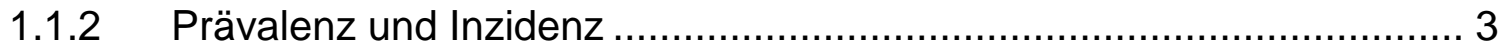

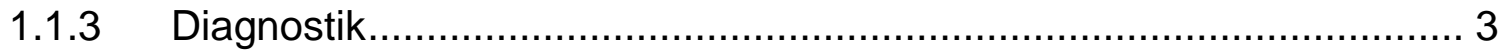

1.2 Anatomie und Organisation der Basalganglien ...................................... 4

1.2.1 Neurotransmitter der Basalganglien ......................................... 5

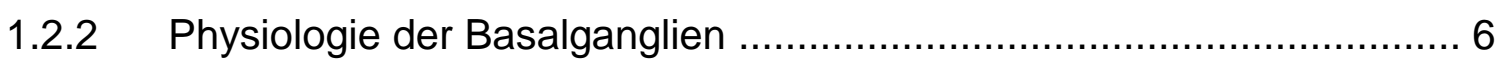

1.2.3 Pathophysiologie der Basalganglien beim IPS .............................. 7

1.3 Aktuelle Therapie des IPS ...................................................... 10

1.4 Experimentelles Modell zur Erforschung des IPS ................................. 11

1.4.1 1-Methyl-4-Phenyl-1,2,3,6-Tetrahydropyridin (MPTP) ...................... 12

1.4.2 Wirkung von MPTP auf die mitochondriale Atmungskette ................. 13

1.4.3 MPTP und oxidativer Stress ..................................................... 13

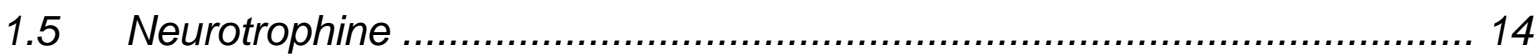

1.5.1 Glial cell line-derived neurotrophic factor (GDNF) ......................... 14

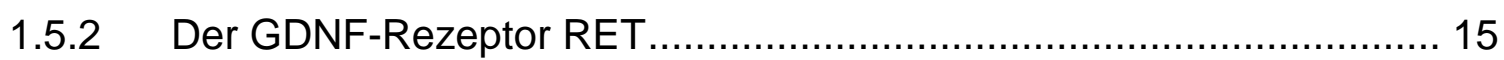

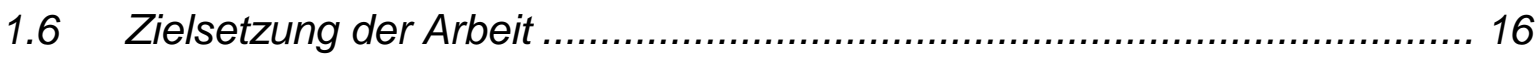

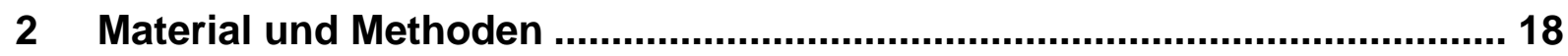

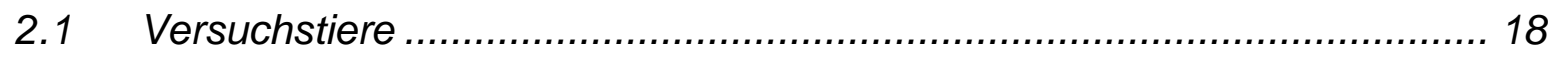

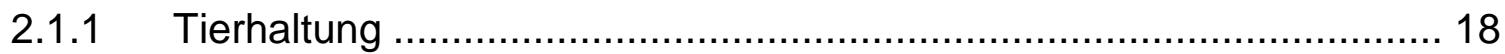

2.1.2 Versuchsgruppen ............................................................... 18

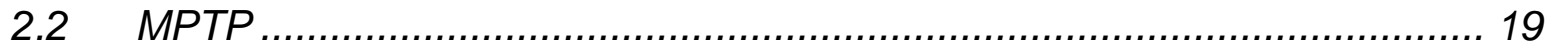

2.2.1 Herstellung der MPTP-Injektionslösung ...................................... 19

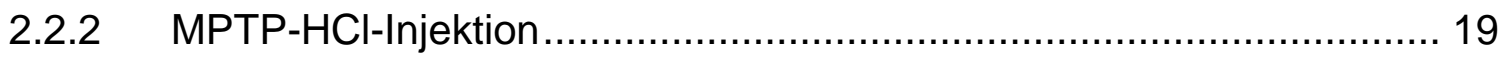

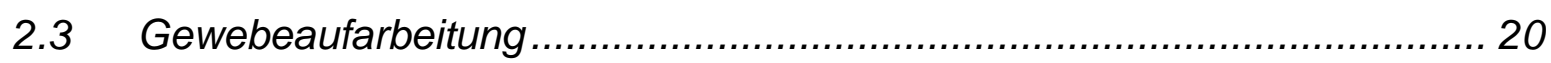

2.3.1 Gewebeentnahme .......................................................... 20

2.3.2 Gewebefixierung zur immunozytochemischen Aufarbeitung .............. 21 
2.3.3 Gewebeaufarbeitung des Striatums zur Bestimmung der Katecholaminkonzentrationen 22

2.4 Bestimmung der Katecholaminkonzentrationen mittels HPLC ................. 22

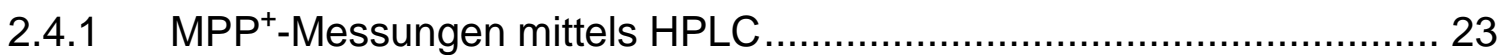

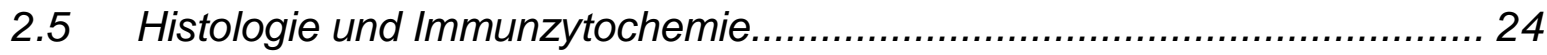

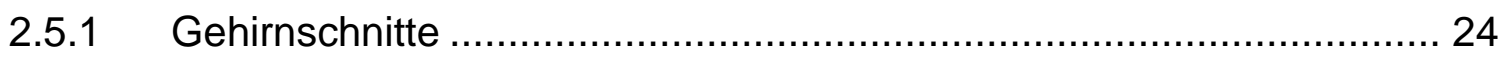

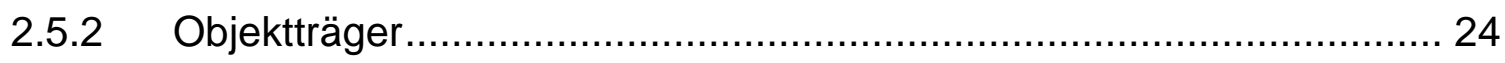

2.5.3 Tyrosinhydroxylase (TH)-Färbung der SNpc ................................. 25

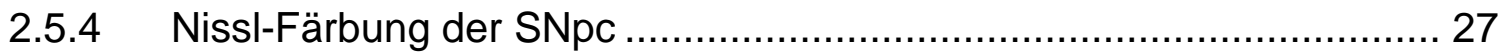

2.5.5 Stereologische Quantifizierung von TH- und Nissl-positiven Zellen der

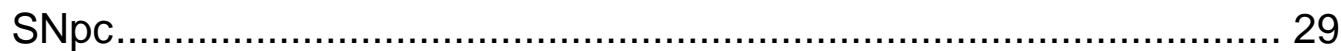

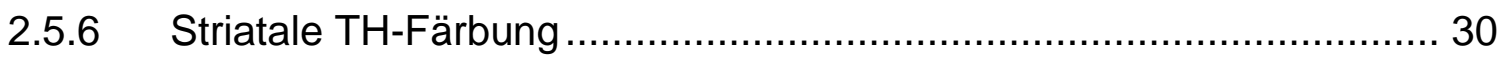

2.6 Optische Dichte und nigrostriatale Projektionen rostral der SNpc............. 32

2.6.1 Bestimmung der optischen Dichte von TH-positiven Fasern des

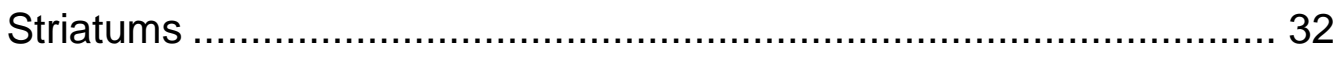

2.6.2 Bestimmung der Anzahl und Fläche nigrostriataler Projektionen rostral

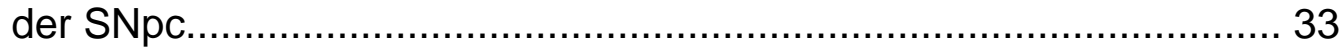

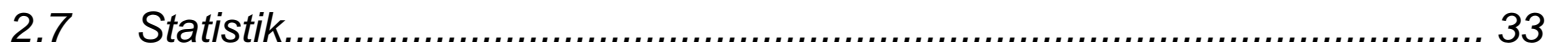

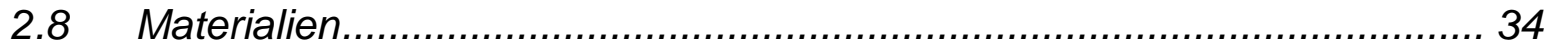

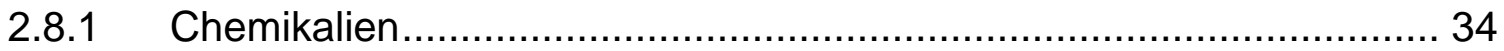

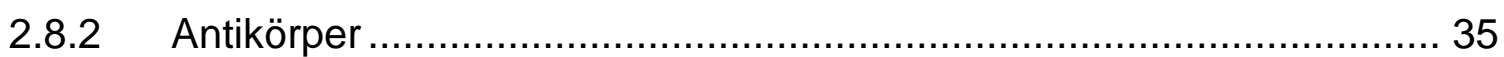

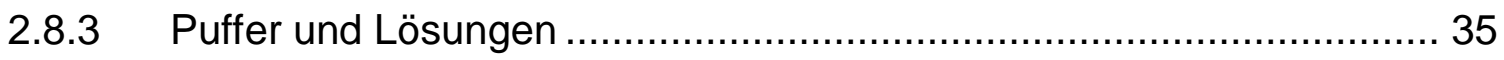

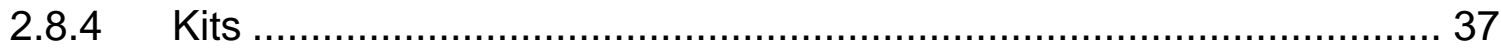

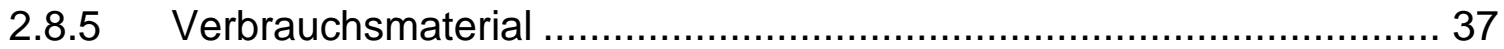

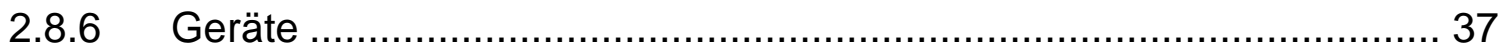

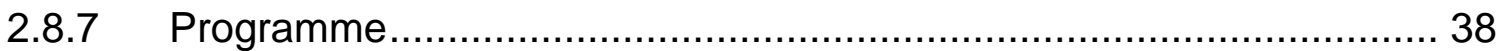

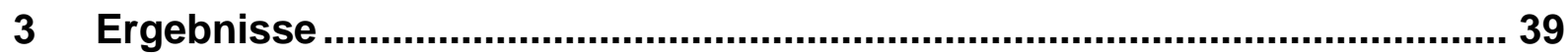

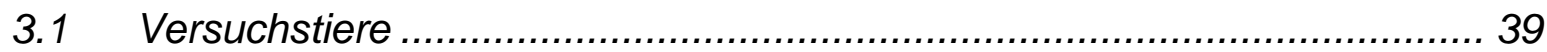

3.2 Der Effekt von MPTP auf dopaminerge Neurone der SNpc ..................... 39

3.2.1 Der Effekt von MPTP auf TH-positive Zellen der SNpc ...................... 39

3.2.2 Der Effekt von MPTP auf Nissl-positive Zellen der SNpc ................... 41

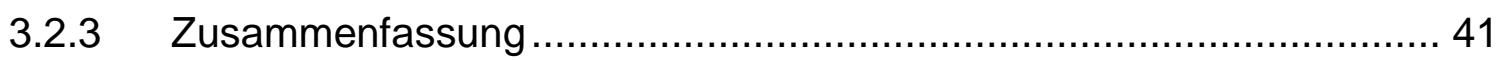


3.3 Der Effekt von MPTP auf die optische Dichte des Striatums und auf die nigrostriatalen Projektionen rostral der SNpc.

3.3.1 Ergebnisse der optischen Dichte TH-positiver Fasern des Striatums.. 42

3.3.2 Auswertung TH-positiver nigrostriataler Projektionen rostral der SNpc...

3.3.3 Zusammenfassung 44 45

3.4 Veränderungen der Katecholaminkonzentrationen nach MPTP-Behandlung

3.4.1 Dopamin 46

3.4.2 DOPAC und HVA 46

3.4.3 Dopaminumsatz 48

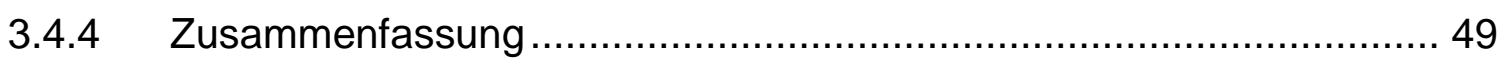

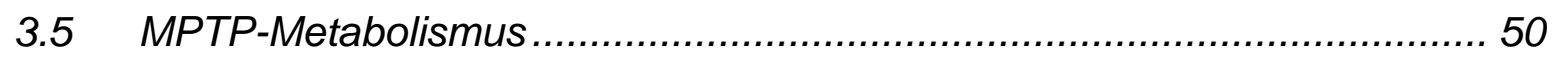

4 Diskussion

4.1 RET-defiziente Mäuse zeigen kein Defizit in der Entwicklung von dopaminergen Neuronen.

4.2 RET-defiziente Mäuse zeigen keine erhöhte MPTP-Toxizität 52

4.3 GDNF und der Rezeptor RET schützen nicht vor MPTP-induzierter Toxizität dopaminerger Neurone und ihrer striatalen Projektionen 53

4.4 Das MPTP-Modell 56

4.5 Klinische Studien mit GDNF 56

4.6 Axonales Sprouting nach MPTP-Injektion ....................................... 58

4.7 Mögliche weitere Therapieoptionen des IPS ...................................... 58

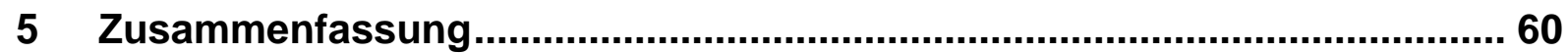

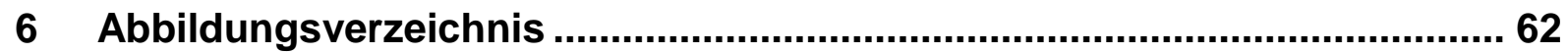

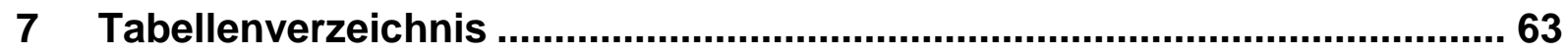

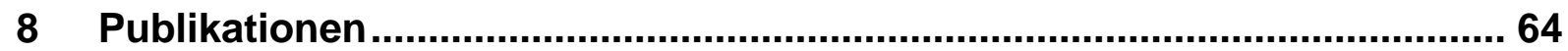

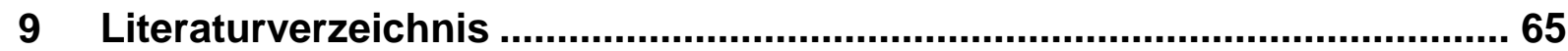




\section{Abkürzungsverzeichnis}

\begin{tabular}{|c|c|}
\hline Abb. & Abbildung \\
\hline ACh & Acetylcholin \\
\hline ARTN & Artemin \\
\hline ATP & Adenosintriphosphat \\
\hline$A U$ & arbitrary units \\
\hline BDNF & Brain-derived neurotrophic factor \\
\hline CDNF & Conserved dopamine neurotrophic factor \\
\hline COMT & Catecholamin-O-Methyltransferase \\
\hline CPP & zellpenetrierendes Peptid \\
\hline Cre & Causes recombination protein \\
\hline $\mathrm{DAB}$ & 3,3'-Diaminobenzidin \\
\hline DAT & Dopamintransporter \\
\hline DNS & Desoxyribonukleinsäure \\
\hline DOPAC & 3,4-Dihydroxyphenylessigsäure \\
\hline Dyn & Dynorphin \\
\hline Enk & Enkephalin \\
\hline GABA & ү-Aminobuttersäure \\
\hline GDNF & Glial cell line-derived neurotrophic factor \\
\hline GFL & GDNF-family ligands \\
\hline GFRa & GDNF-family receptor- $\alpha$ \\
\hline GPe & Globus pallidus externus \\
\hline GPi & Globus pallidus internus \\
\hline GPI & Glycosylphosphatidylinositol \\
\hline $\mathrm{H}_{2} \mathrm{O}$ & Wasser \\
\hline $\mathrm{H}_{2} \mathrm{O}_{2}$ & Wasserstoffperoxid \\
\hline HPLC & High pressure liquid chromatography \\
\hline HVA & Homovanillinsäure \\
\hline i.p. & intraperitoneal \\
\hline IPS & idiopathisches Parkinson-Syndrom \\
\hline KG & Körpergewicht \\
\hline L-DOPA & L-3,4-Dihydroxyphenylalanin \\
\hline
\end{tabular}




\begin{tabular}{|c|c|}
\hline MANF & Mesencephalic astrocyte-derived neurotrophic factor \\
\hline MAO-B & Monoaminooxidase-B \\
\hline $\min$ & Minuten \\
\hline $\mathrm{MPP}^{+}$ & 1-Methyl-4-Phenylpyridinium \\
\hline MPTP & 1-Methyl-4-Phenyl-1,2,3,6-Tetrahydropyridin \\
\hline MPTP-HCl & 1-Methyl-4-Phenyl-1,2,3,6-Tetrahydropyridin-Hydrochlorid \\
\hline MRT & Magnetresonanztomographie \\
\hline MSN & Medium-spiny-neurons \\
\hline $\mathrm{Na}_{2} \mathrm{HPO}_{4}$ & Dinatriumhydrogenphosphat \\
\hline $\mathrm{NaCl}$ & Natriumchlorid \\
\hline $\mathrm{NADH}$ & Nikotinamidadenindinukleotid (reduziert) \\
\hline $\mathrm{NaH}_{2} \mathrm{PO}_{4}$ & Natriumdihydrogenphosphat \\
\hline NC & Nucleus caudatus \\
\hline NCAM & Neural cell adhesion molecule \\
\hline NGS & Normal Goat Serum \\
\hline NMDA & N-Methyl-D-Aspartat \\
\hline NRTN & Neurturin \\
\hline NST & Nucleus subthalamicus \\
\hline NTF & Neurotrophine \\
\hline 6-OHDA & 6-Hydroxydopamin \\
\hline PB & Phosphatpuffer \\
\hline PBS & Phosphat-gepufferte Salzlösung \\
\hline PET & Positron Emission Tomography \\
\hline PFA & Paraformaldehyd \\
\hline PI3K & Phosphatidylinositol-3-Kinase \\
\hline PPN & Nucleus pedunculopontinus \\
\hline PSPN & Persephin \\
\hline $\mathrm{Pu}$ & Putamen \\
\hline Ras-MAPK & Ras-mitogen activated protein kinase \\
\hline RET & Rearranged during transfection \\
\hline $\mathrm{ROI}$ & Region of interest \\
\hline ROS & Reactive oxygen species \\
\hline s & Sekunden \\
\hline SNpc & Substantia nigra pars compacta \\
\hline
\end{tabular}




$\begin{array}{ll}\text { SNr } & \text { Substantia nigra pars reticulata } \\ \text { SPECT } & \text { Single Photon Emission Computed Tomography } \\ \text { SuP } & \text { Substanz P } \\ \text { Tab. } & \text { Tabelle } \\ \text { TBS } & \text { Tris-gepufferte Salzlösung } \\ \text { TH } & \text { Tyrosinhydroxylase } \\ \text { THS } & \text { Tiefe-Hirnstimulation } \\ \text { Tris } & \text { Tris(hydroxymethyl)-aminomethan } \\ \text { UPDRS } & \text { Unified Parkinson's Disease Rating Scale } \\ \text { VA } & \text { Nucleus ventralis anterior } \\ \text { VL } & \text { Nucleus ventralis lateralis } \\ \text { VMAT2 } & \text { vesikulärer Monoamintransporter-2 } \\ \text { ZNS } & \text { Zentralnervensystem }\end{array}$




\section{Einleitung}

\subsection{Das idiopathische Parkinson-Syndrom}

Das bereits schon im Altertum bekannte Krankheitsbild der „Schüttellähmung“ wurde 1817 von dem Londoner Arzt James Parkinson detailliert beschrieben und später nach inm benannt. In seinem Werk „An Essay on the Shaking Palsy" beschrieb er die klassischen Kernbestandteile der „Paralysis agitans“ und legte damit den Grundstein für die Definition des uns heute bekannten Krankheitsbildes des idiopathischen Parkinson-Syndroms (IPS).

Das IPS ist mit 75\% die am häufigsten auftretende Form und wird auch als primäres Parkinson-Syndrom bezeichnet. Es kann sporadisch oder erblich auftreten. Neben dem IPS wird zwischen zwei weiteren Gruppen unterschieden: 1) das sekundäre Parkinson-Syndrom, das auf erkennbaren strukturellen, metabolischen oder toxischen Ursachen beruht und 2) das atypische Parkinson-Syndrom, welches im Rahmen anderer neurodegenerativer Erkrankungen auftritt. Dazu zählen die Multisystematrophie, die progressive supranukleäre Blickparese, die kortikobasale Degeneration und die Demenz mit Lewy-Körpern. Diese Arbeit bezieht sich auf das IPS.

Beim IPS handelt es sich um eine chronisch progrediente neurodegenerative Erkrankung, die durch eine Degeneration von dopaminergen Neuronen in der Substantia nigra pars compacta (SNpc) charakterisiert ist. Die Erkrankung führt zu Störungen der willkürlichen und unwillkürlichen Motorik, mit den Kardinalsymptomen Akinese, Tremor, Rigor und posturale Instabilität. Diese Symptome können in unterschiedlichem Ausmaß auftreten. Der Untergang der Dopamin produzierenden Neurone findet vor allem im venterolateralen Bereich der SNpc statt (Fearnley und Lees 1991) und führt zu einer Verminderung von Dopamin in den striatalen Projektionen. Oft kommt es zur Ausbildung fakultativer Begleitsymptome. Diese können aus sensorischen Symptomen (Dysästhesien und Schmerzen), vegetativen Symptomen (Störungen von Blutdruck, Temperaturregulation, Harnblasenfunktion und sexuellen Funktionen) sowie psychischen Symptomen (z.B. Depressionen) 
bestehen. Kognitive Symptome wie frontale Störungen und Demenz werden bei ca. $30-40 \%$ der Patienten beobachtet und steigen mit zunehmendem Alter (Mayeux et al. 1992).

\subsubsection{Mögliche Ursachen und Entstehung des IPS}

Wesentliches neuropathologisches Charakteristikum des IPS ist neben dem Untergang von dopaminergen Neuronen das Auftreten von intrazytoplasmatischen Lewy-Körpern. Diese eosinophilen Einschlüsse bestehen aus zahlreichen Lipiden und Proteinen, ihr Hauptbestandteil ist das fibrilläre a-Synuklein (Engelender et al. 1999; Gibb und Lees 1988; Spillantini et al. 1997). In Untersuchungen konnte gezeigt werden, dass sich die Lewy-Pathologie in einem typischen zeitlichen Muster im Gehirn ausbreitet, bei dem der Bulbus olfactorius und die Medulla oblongata vor der SNpc befallen werden (Braak et al. 2003). Zusätzlich treten diese im Locus coeruleus, Nucleus basalis Meynert sowie dem dorsalen Vaguskern und Kortex auf (Gibb und Lees 1988).

Die Ausbildung eines IPS ist nach gegenwärtigem Forschungsstand die Folge eines Zusammenspiels aus genetischer Prädisposition und Umwelteinflüssen (Maher et al. 2002; Sveinbjornsdottir et al. 2000; Warner und Schapira 2003). In 5-10\% der Fälle beruht die Ursache des IPS auf autosomal-dominant bzw. autosomal-rezessiv vererbten Genmutationen (Fahn und Sulzer 2004; Gasser 2005). Bisher wurden 13 genetische Mutationen (PARK1-13) identifiziert, unter denen fünf Mutationen eine eindeutige Assoziation mit der Erkrankung aufweisen (Thomas und Beal 2007). Mutationen für $\alpha$-Synuklein (PARK1/PARK4) und für LRRK2 (PARK8) führen zu späten dominanten Parkinson-Syndromen (Singleton et al. 2003; Zimprich et al. 2004), während Mutationen von Parkin (PARK2), PINK1 (PARK6) und DJ-1 (PARK7) frühe rezessive Formen der Erkrankung hervorrufen (Thomas und Beal 2007).

Faktoren wie oxidativer Stress mit der Ausbildung von reaktiven Sauerstoffradikalen (reactive oxygen species, ROS), sowie inflammatorische Prozesse und mitochondriale Dysfunktion gelten als wesentliche Auslöser des IPS und unterhalten den Erkrankungsprozess (Jenner und Olanow 2006; Larkin 1999). 
Weitere mögliche Pathomechanismen sind Exzitotoxizität, Apoptose, Proteinaggregation und Proteinfehlbildung (Dauer und Przedborski 2003; Olanow 2007; Schulz 2006; Tatton et al. 1998).

\subsubsection{Prävalenz und Inzidenz}

Das IPS ist die zweithäufigste neurodegenerative Erkrankung nach dem Morbus Alzheimer (Cummings 1999). Das durchschnittliche Erkrankungsalter liegt zwischen dem 50. und 60. Lebensjahr. Ein Erkrankungsbeginn vor dem 30. Lebensjahr ist selten.

Die Inzidenz des IPS wird in Europa mit ca. 16-19 : 100.000 Einwohnern pro Jahr angegeben (Twelves et al. 2003) und nimmt mit steigendem Alter zu. In einer USStudie betrug die Inzidenz für das IPS ca. 10 : 100.000. Dabei kommt es zu einem kontinuierlichen Anstieg der Inzidenz in der Altersverteilung. Sie beträgt in der Gruppe der 30- bis 49- Jährigen ca. $1: 100.000$ und steigt in der Gruppe der 70- bis 79-Jährigen auf ca. $100: 100.000$ an (Bower et al. 1999). In der Gruppe der über 65Jährigen beträgt die Prävalenz in Europa $1.800: 100.000$ und steigt bei den über 85-Jährigen auf $2.600: 100.000$ an (DeRijk et al. 2000).

\subsubsection{Diagnostik}

Der Hauptteil der Parkinsondiagnostik beruht auf anamnestischen und klinischen Diagnosekriterien (Hughes et al. 2001). Es ist vor allem in den Anfangsstadien der Erkrankung schwer, eine klinische Diagnose zu stellen. In mindestens $15 \%$ der Fälle entsprechen Patienten mit einem IPS nicht den klinischen Kriterien und werden fehldiagnostiziert (Schrag et al. 2002). Die klinischen Diagnosekriterien basieren auf den Kardinalsymptomen Akinese, Tremor, Rigor und posturale Instabiliät (Sian et al. 1999). Kommt es zum Auftreten von Akinese und einem der drei weiteren Kardinalsymptome, gilt die Diagnose als klinisch gesichert (Gelb et al. 1999). Zudem wird das positive Ansprechen auf L-3,4-Dihydroxyphenylalanin (L-DOPA) als ein bestätigendes diagnostisches Kriterium gesehen. Der Krankheitsverlauf eines Patienten mit IPS wird über die Unified Parkinson's Disease Rating Scale (UPDRS) 
beurteilt. Im L-DOPA-Test ist ein Anstieg von 30\% im motorischen UPDRS-III-Score als positiv zu werten (Diener und Putzki 2008). Das IPS beginnt einseitig und/oder mit persistierender Asymmetrie im Krankheitsverlauf.

Bildgebende Verfahren wie die Magnetresonanztomographie (MRT), die Single Photon Emission Computed Tomography (SPECT) und das Positron Emission Tomography (PET) sind hilfreich, um Veränderungen im Stoffwechsel von IPSPatienten darzustellen und es von anderen Parkinson-Syndromen abzugrenzen (Benamer et al. 2000; Schulz et al. 1994; Schulz et al. 1999; Schwarz et al. 1993; Varrone et al. 2001). Eine definitive Diagnose kann letztlich erst neuropathologisch gesichert werden.

\subsection{Anatomie und Organisation der Basalganglien}

Die motorischen Symptome des IPS werden durch den Dopaminmangel in den Basalganglien hervorgerufen. Die Kerne der Basalganglien sind anatomisch und funktionell zwischen dem Großhirnkortex und dem Thalamus lokalisiert. Sie bilden in Ihrer Einheit ein komplexes System, welches auf die Ausführung und Koordination der Bewegungsabläufe Einfluss nimmt.

Die Basalganglien bestehen beim Menschen aus dem Striatum, das sich aus dem Putamen ( $\mathrm{Pu}$ ) und dem Nucleus caudatus (NC) zusammensetzt, dem Globus pallidus (GP), der sich in ein externes (GPe) und ein internes (GPi) Segment unterteilt, der SNpc und Substantia nigra pars reticulata (SNr) sowie dem Nucleus subthalamicus (NST). Bei Nagern sind die beiden Strukturen NC und Pu nicht von einander abgrenzbar und werden zusammen als Striatum bezeichnet.

Bewegungsimpulse, die im Limbischen System entstehen, werden über den Assoziationskortex zum Kleinhirn und den Basalganglien weitergeleitet. Während das Kleinhirn an der Feinsteuerung der Motorik beteiligt ist, modulieren die Basalganglien die Amplitude von Bewegungen und bahnen bzw. unterdrücken Bewegungsimpulse. Diese motorischen Informationen laufen über ein direktes sowie indirektes Projektionssystem im Nucleus ventralis lateralis (VL) und Nucleus ventralis anterior (VA) des Thalamus zusammen und werden von dort an den Motorkortex weitergeleitet (Lang und Lozano 1998). 


\subsubsection{Neurotransmitter der Basalganglien}

Neurotransmitter regulieren die Aktivität der einzelnen Basalganglienkerne. Dopamin kann rezeptorspezifisch sowohl exzitatorisch als auch inhibitorisch wirken. Glutamat wirkt exzitatorisch, Y-Aminobuttersäure (GABA) inhibitorisch. Enkephalin (Enk), Substanz P (SuP) und Dynorphin (Dyn) sind Neuropeptide, die als Kotransmitter GABA-erger Neurone fungieren (Alexander und Crutcher 1990; Obeso et al. 2000). Acetylcholin (ACh) fungiert als Transmitter von striatalen Interneuronen und nimmt modulierenden Einfluss auf die "Medium-spiny-neurons" (MSN) des Striatums (Kawaguchi et al. 1995; Zhou et al. 2002).

Dopamin ist der vorherrschende Neurotransmitter des nigrostriatalen Systems. Es entstammt der Katecholaminbiosynthese und wird über mehrere Vorstufen aus der Aminosäure Phenylalanin gebildet. In der Leber erfolgt die Umsetzung von Phenylalanin zu L-Tyrosin, welches anschließend durch die dopaminergen Neurone aufgenommen wird. Dort erfolgt die Umwandlung durch das Enzym Tyrosinhydroxylase (TH) zu L-DOPA. L-DOPA wird wiederum durch die DOPADecarboxylase in Dopamin umgewandelt. Der geschwindigkeitsbestimmende Schritt in dieser Synthesekette wird durch die TH vermittelt. Anschließend wird Dopamin über den vesikulären Monoamintransporter-2 (VMAT2) in die Speichervesikel der nigralen Neurone aufgenommen (Riddle et al. 2005).

Durch Eintreffen eines entsprechenden Nervenimpulses erfolgt die exozytotische Freisetzung des Dopamins in den synaptischen Spalt. Die Stimulation präsynaptischer Rezeptoren moduliert die Neurotransmitter-Freisetzung. Im Striatum übt Dopamin seine Wirkung über postsynaptische D1- und D2-Rezeptoren aus (Kebabian und Calne 1979). Dabei bewirkt die Stimulation von D1-Rezeptoren eine Aktivierung und die Stimulation von D2-Rezeptoren eine Hemmung der nachgeschalteten Nervenzelle (Cepeda et al. 1993; Gerfen et al. 1990).

Im Anschluss erfolgt die Beendigung der Dopaminwirkung durch Wiederaufnahme (Re-uptake) und enzymatischen Abbau. Die präsynaptische Wiederaufnahme in die dopaminergen Neurone erfolgt über den Dopamintransporter (DAT). Der Abbau des Dopamins erfolgt durch die Enzyme Monoaminooxidase-B (MAO-B) und Catecholamin-O-Methyltransferase (COMT). Dabei entstehen über Zwischenstufen die Dopamin-Metabolite 3,4-Dihydroxyphenylessigsäure (DOPAC) und Homovanillinsäure (HVA). 


\subsubsection{Physiologie der Basalganglien}

Die wichtigste Eingangsstruktur (Input-Region) der Basalganglien ist das Striatum. Die Aktivität wird durch dopaminerge Impulse der SNpc moduliert (Abb. 1). Zudem erhält das Striatum zahlreiche glutamaterge Afferenzen von ausgedehnten Arealen des Kortex. Diese sind der prämotorische- und supplementär-motorische Kortex, der primär-motorische Kortex und der Assoziationskortex. Afferenzen von Thalamuskernen werden bahnende Funktionen zugeschrieben (Alexander und Crutcher 1990). Die inhibitorischen, GABA-ergen MSN machen etwa 95\% der striatalen Neurone aus. Innen stehen ca. 2\% cholinerge Interneurone gegenüber (Smith und Bolam 1990). Es können zwei Subpopulationen der MSN unterschieden werden. Die erste Neuronenpopulation stellt den Anfang des direkten Projektionssystems dar und exprimiert GABA, SuP und Dyn. Diese monosynaptische Projektion wirkt inhibitorisch auf die Ausgangskerne der Basalganglien, GPi und SNr. Der Anfang des indirekten Projektionssystems wird über die zweite Subpopulation der MSN gebildet. Diese exprimieren GABA sowie Enk und projizieren zum GPe, dessen GABA-erge Neurone zum NST projizieren. Das indirekte Projektionssystem wirkt somit über den NST glutamaterg exzitatorisch auf den GPi und die SNr. GPi und SNr stellen die Output-Region der Basalganglien dar. Sie besitzen eine tonische Daueraktivität, welche durch das direkte Projektionssystem herabgesetzt und durch das indirekte gesteigert wird. Der GPi und die SNr projizieren GABA-erg zu den intralaminären Thalamuskernen, insbesondere zum VL und VA sowie zum Nucleus pedunculopontinus (PPN) und zum Colliculus superior. Von dem VL und VA aus erfolgt die glutamaterge und somit exzitatorische Projektion zum Motorkortex (Alexander und Crutcher 1990; DeLong 1990; Joel und Weiner 1997; Lang und Lozano 1998; Schiel 2004).

Aus der SNpc projizieren dopaminerge Neurone über das mediale Vorderhirnbündel in das Striatum und enden an den MSN und an Interneuronen. Im direkten Projektionssystem wird die dopaminerge Wirkung über D1-Rezeptoren (aktivierend) vermittelt, im indirekten Projektionssystem über D2-Rezeptoren (inhibierend). Die Rolle der dopaminergen Projektionen besteht im Erhalt eines Gleichgewichtes zwischen den antagonistischen Einflüssen des direkten und indirekten Projektionssystems. 
Zusammenfassend fördert das direkte Projektionssystem motorische Funktionen während das indirekte Projektionssystem diese hemmt (Schiel 2004).

\subsubsection{Pathophysiologie der Basalganglien beim IPS}

Durch die striatale Dopaminverarmung kommt es im direkten Projektionssystem zu einer abgeschwächten D1-vermittelten Inhibition des GPi. Gleichzeitig kommt es im indirekten Projektionssystem zu einer verminderten Inhibition des GPe, der dadurch seinen ebenfalls inhibitorischen Effekt auf den NST verliert. Es folgt somit eine verstärkte Aktivierung des GPi und der SNr durch den NST (Bergman et al. 1990; Wichmann et al. 1994). Das Resultat ist eine Inhibition des Thalamus und eine verminderte thalamokortikale Aktivierung (Abb. 2). Die vermehrte Hemmung des Hirnstamms wird vor allem für die Ausbildung von Symptomen, die sich auf Körperhaltung und Gang auswirken, verantwortlich gemacht (Lang und Lozano 1998; Wichmann und DeLong 1993).

Zur klinischen Manifestation des IPS kommt es bei einer Degeneration von ca. 50\% der dopaminergen Neurone in der SNpc bzw. einer Verminderung des Dopamingehalts von 70-80\% im Striatum (Bernheimer et al. 1973). Die im Vergleich zur Neuropathologie späten Funktionseinbußen werden damit erklärt, dass einerseits der striatale Dopaminumsatz als Zeichen eines präsynaptischen Kompensationsmechanismus zunimmt und andererseits die postsynaptische Dopaminrezeptorendichte und Dopaminrezeptorensensitivität ansteigt (Hefti et al. 1980; Rinne et al. 1990; Rinne et al. 1993). 


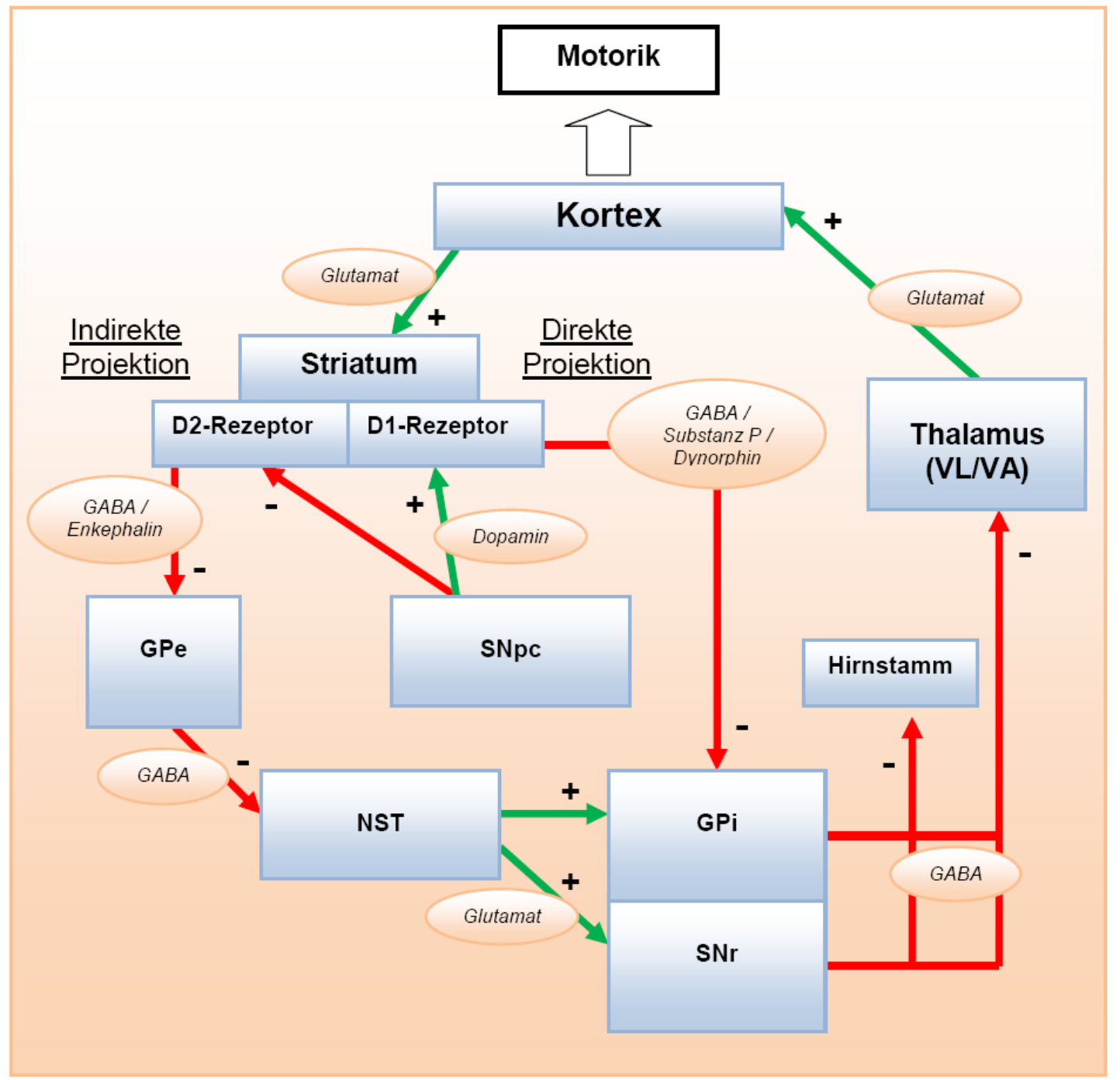

Abb. 1 Modifizierte Darstellung der Basalganglien nach Lang und Lozano (1998), S.1132

Die Abbildung zeigt den Regelkreis der Basalganglien bei Personen mit einer normalen motorischen Funktion.

Eingangsstruktur der Basalganglien ist das Striatum, welches zahlreiche Afferenzen von ausgedehnten Arealen des Kortex erhält. Vom Striatum ziehen inhibitorische Fasern des direkten Projektionsweges zum Globus pallidus internus (GPi) und der Substantia nigra pars reticulata (SNr). Striatale Fasern des indirekten Projektionssystems wirken inhibitorisch auf den Globus pallidus externus (GPe), der wiederum hemmenden Einfluss auf den Nucleus subthalamicus (NST) hat. Dieser sendet exzitatorische Efferenzen zu den Ausgangskernen der Basalganglien GPi und SNr, welche wiederum hauptsächlich hemmenden Einfluss auf den venterolateralen und venteroanterioren Anteil des Thalamus sowie den Hirnstamm ausüben. Weitere Efferenzen wie z.B. der Nucleus pedunculopontius (PPN) sind nicht abgebildet. Exzitatorische thalamokortikale Efferenzen zu motorischen Kortexarealen werden somit beeinflusst. Dopamin wirkt modulierend auf das Striatum über den D1-Rezeptor (exzitatorisch) und den D2-Rezeptor (inhibitorisch).

Grüne Pfeile symbolisieren exzitatorische Wege und inhibitorische Wege werden mit roten Pfeilen abgebildet. Rund umrandete Substanzen bezeichnen die Neurotransmitter und deren Neuropeptide. 


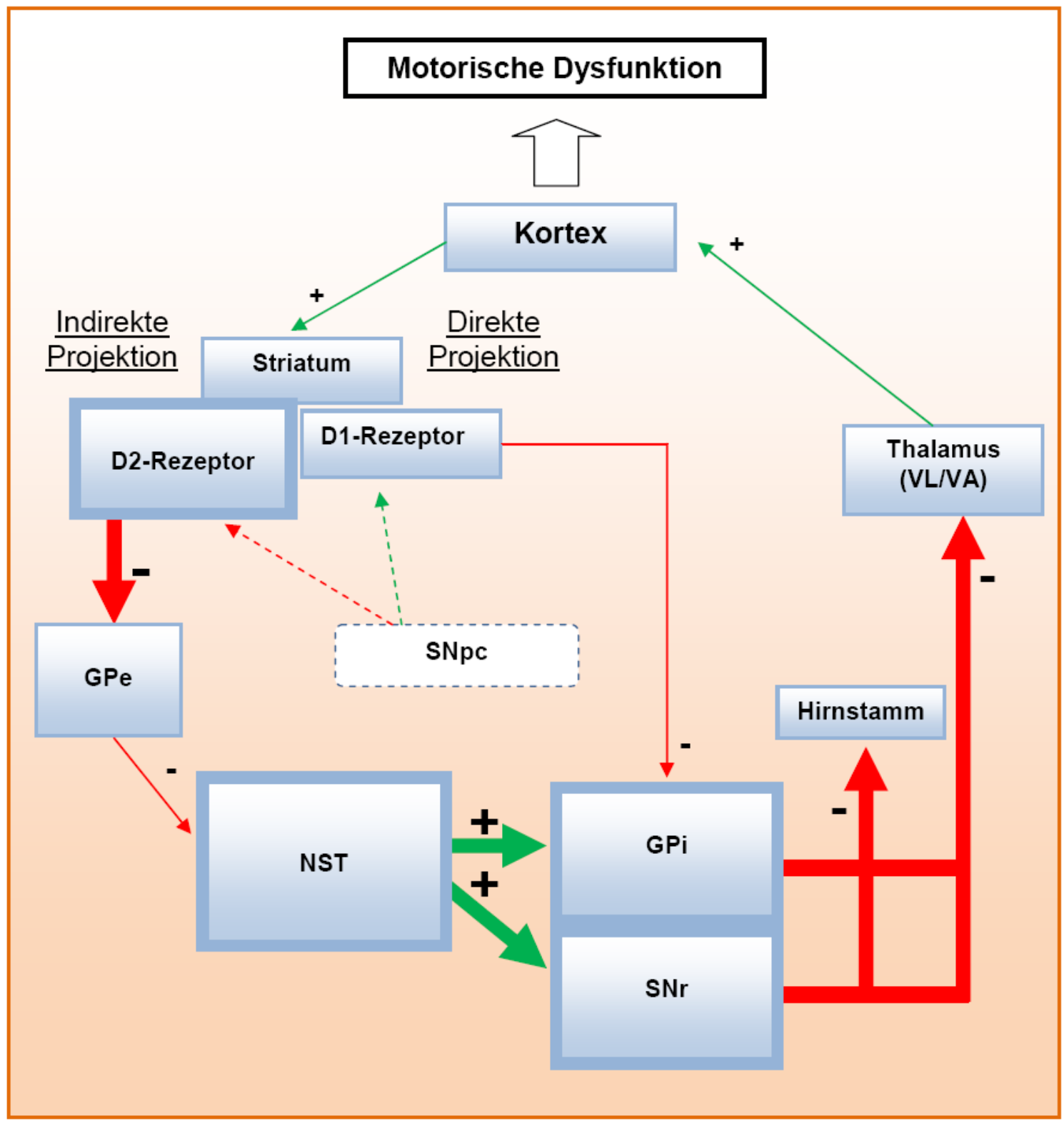

Abb. 2 Modifizierte Darstellung der Basalganglien beim IPS nach Lang und Lozano (1998), S.1132

Die Abbildung zeigt den veränderten Regelkreis der Basalganglien bei Patienten mit IPS. Dabei kommt es zu einem Verlust von dopaminergen Neuronen der SNpc und einem Mangel des Neurotransmitters Dopamin. Es folgt ein Ungleichgewicht zwischen der verminderten Hemmung des Globus pallidus internus (GPi) und der Substantia nigra pars reticulata ( $\mathrm{SNr}$ ) durch das direkte Projektionssystem und der gesteigerten Aktivität des Nucleus subthalamicus (NST) auf den GPi und die SNr im indirekten Projektionssystem. Das Resultat ist eine verminderte thalamokortikale Aktivierung, bedingt durch die Überaktivität der Hemmung vom GPi und SNr auf den Thalamus und Hirnstamm. Es kommt zur Ausbildung der typischen Symptome Akinese, Tremor, Rigor und posturale Instabilität.

Grüne Pfeile symbolisieren exzitatorische Wege und inhibitorische Wege werden mit roten Pfeilen abgebildet. Die Breite der Pfeile steht für die allgemeine Aktivität der einzelnen Verknüpfungen. Die Rahmengröße der einzelnen Hirnregionen steht für die Aktivität dieser Region im Vergleich zur normalen Funktion (Abb. 1). 


\section{$1.3 \quad$ Aktuelle Therapie des IPS}

Die derzeitige Therapie des IPS beschränkt sich auf die Behandlung der Symptome und die Aufrechterhaltung einer weitgehend normalen physiologischen Funktion. Ein wichtiger Stützpfeiler dieser Therapie ist die Substitution von L-DOPA, welches die Blut-Hirn-Schranke passieren kann. Die Ergänzung dieses Medikaments durch einen peripher wirksamen Decarboxylasehemmer (Benserazid oder Carpidopa) verhindert den peripheren Abbau des L-DOPA. L-DOPA wird nach Aufnahme in die dopaminergen Neurone von der DOPA-Decarboxylase zu Dopamin umgewandelt und kann dem entstandenen Mangel entgegenwirken (Cotzias et al. 1969; Fahn et al. 2004). Im Verlauf der Erkrankung kommt es zu einer verringerten Wirkung und Wirkdauer des L-DOPA. Dabei ist entscheidend, dass sich die neurodegenerativen Prozesse vor allem präsynaptisch abspielen. Postsynaptisch bleibt die Rezeptorendichte und Sensibilität zunächst erhalten. Erst im Verlauf der Erkrankung kommt es auch dort zu funktionellen Veränderungen, so dass ein Wirkverlust von LDOPA auftritt (Bravi et al. 1994). Dadurch nimmt der Substitutionsbedarf überproportional zu (Fahn 1999; Rascol et al. 2002) und unerwünschte zentrale sowie periphere Nebenwirkungen steigen an (Javoy-Agid und Agid 1980; Rascol et al. 2003; Thanvi und Lo 2004).

Eine weitere Therapieoption sind Dopaminagonisten (z.B. Bromcriptin). Bei Patienten unter 70 Jahren ohne wesentliche Komorbidität sollte die Therapie mit einem Dopaminagonisten begonnen werden (Oertel et al. 2006). Durch die Kombination von Dopaminagonisten mit L-DOPA kann L-DOPA gespart und das Auftreten von Wirkungsfluktuationen verzögert werden (Diener und Putzki 2008).

MAO-B- und COMT-Inhibitoren verhindern den enzymatischen Abbau von Dopamin und verlängern die Wirkungszeit des Dopamins im synaptischen Spalt und an postsynaptischen Rezeptoren. Hierzu zählen MAO-B-Inhibitoren wie das Selegilin oder Rasagilin, die den oxidativen Abbau von Dopamin blockieren. Dies führt zu einer verminderten Bildung von freien Radikalen. Aufgrund der schwachen Wirksamkeit von Selegilin als Monotherapeutikum (Elizan et al. 1989) wird es vor allem in Kombination mit L-DOPA eingesetzt und verstärkt dessen Wirkung (Gerlach et al. 1996). Hierdurch kann in der Kombinationstherapie bei $50 \%$ der Patienten eine Dosisreduktion von L-DOPA um $10 \%$ bis $15 \%$ erreicht werden, ohne dass es zu einer Verschlechterung der motorischen Symptome kommt (Heinonen und Rinne 
1989). COMT-Inhibitoren (z.B. Entacapon und Tolcapon) sind in Kombination mit LDOPA bei einem Vorliegen von motorischen Wirkungsfluktuationen zugelassen. In den meisten Fällen kann somit eine L-DOPA-Reduktion von 20\% erreicht werden (Merello et al. 1994; Myllyla et al. 2001; Ruottinen und Rinne 1996).

Anticholinergika (z.B. Biperiden und Bornaprin) führen zu einer Blockade von striatalen Muskarinrezeptoren und wirken hemmend auf das Überwiegen des cholinergen Einflusses der Basalganglien beim IPS. Sie greifen regulierend in ein Ungleichgewicht zwischen den Neurotransmittern ACh und Dopamin ein. Trotz fehlender kontrollierter Studien sind Anticholinergika insbesondere bei vorherrschendem Ruhetremor als klinisch nützlich einzustufen (Diener und Putzki 2008). Bei dieser Substanzklasse kommt es jedoch oft zu unangenehmen peripheren und zentralen Nebenwirkungen (Brocks 1999).

Amantadin ist ein nicht-kompetitiver Hemmer des N-Methyl-D-Aspartat (NMDA)Rezeptors an Glutamat-gesteuerten lonenkanälen der Basalganglien (Kornhuber und Weller 1997). Amantadin kann bei sehr geringen Symptomen und bei L-DOPAassoziierten Dyskinesien eingesetzt werden (Crosby 2003).

Die funktionelle Tiefe-Hirnstimulation (THS) kommt überwiegend bei Patienten zum tragen, die an einem starken Tremor oder komplizierten L-DOPA-induzierten Spätsymptomen leiden (Volkmann 2004).

Hoffnungen beruhen auf der Entwicklung neuroprotektiver Therapien. Bis heute gibt es jedoch keine Therapie, die der Degeneration von dopaminergen Neuronen überzeugend entgegenwirkt.

\section{$1.4 \quad$ Experimentelles Modell zur Erforschung des IPS}

Tierexperimentelle Untersuchungen spielen im Bereich der IPS-Forschung eine große Rolle. Diese ermöglichen die pathologischen Prozesse des IPS darzustellen und tragen zur Entwicklung neuer Therapieoptionen bei. Das Toxin 1-Methyl-4Phenyl-1,2,3,6-Tetrahydropyridin (MPTP) führt beim Menschen und im Tierexperiment zu einem selektiven Untergang der dopaminergen Neurone und vereint dadurch eine Vielzahl der pathologischen Vorgänge des IPS. 


\subsubsection{1-Methyl-4-Phenyl-1,2,3,6-Tetrahydropyridin (MPTP)}

Anfang der achtziger Jahre kam es in den USA bei jungen Drogenabhängigen nach einer intravenösen Injektion eines mit MPTP verunreinigten Heroin-Analogons zu ausgeprägten Parkinson-Symptomen (Langston et al. 1983). Diese Symptome zeigten ein gutes Ansprechen auf eine L-DOPA Therapie (Langston und Ballard 1984). In post-mortem-Untersuchungen zeigte sich eine Degeneration von dopaminergen Neuronen in der SNpc (Langston et al. 1999) sowie ein Verlust von Dopamin und seiner Metabolite in den nigrostriatalen Projektionen (Heikkila et al. 1985).

Die Entdeckung und Anwendung des Neurotoxins MPTP gilt bisher als eines der besten und wichtigsten tierexperimentellen Instrumente zur Auslösung des IPS (Bloem et al. 1990; Dauer und Przedborski 2003; Heikkila et al. 1985; Przedborski und Jackson-Lewis 1998; Przedborski et al. 2000; Przedborski und Vila 2003; Schulz und Falkenburger 2004). Ähnlich wie beim IPS des Menschen kommt es bei Primaten nach MPTP-Behandlung zu einem Verlust der dopaminergen Neurone in der SNpc (Varastet et al. 1994). Zusätzlich können sämtliche klinische Symptome des IPS beobachtet werden (Bloem et al. 1990; Burns et al. 1983; Markey et al. 1984). Es kommt nach systemischer MPTP-Injektion bei Primaten zur Ausbildung von neuronalen Einschlusskörperchen, welche Lewy-Körpern ähneln (Beal 2001; Forno et al. 1993; Kowall et al. 2000). MPTP-Versuche mit Mäusen zeigen im Gegensatz zu Primaten kaum klinische Symptome (Beal 2001). Es kommt jedoch ebenso zum dopaminergen Zellverlust der SNpc, vergleichbar dem IPS des Menschen (German et al. 1996). Die höchste Sensitivität und Toxizität unter den Mäusen zeigen Tiere des C57BL/6-Stammes und werden deshalb gewöhnlich bei tierexperimentellen Untersuchungen mit MPTP und in dieser Arbeit eingesetzt. Zudem wurde ein altersabhängiger Unterschied in der Neurotoxizität beobachtet, bei dem ältere Mäuse empfindlicher auf MPTP reagieren als jüngere Tiere (Sugama et al. 2003).

Das MTPT-Modell hat im Wesentlichen dazu beigetragen, den Untergang von dopaminergen Neuronen und Therapieansätze zu erforschen. 


\subsubsection{Wirkung von MPTP auf die mitochondriale Atmungskette}

MPTP ist eine lipophile Substanz. Diese Eigenschaft erleichtert die Passage der BlutHirn-Schranke und zellulärer Membranen (Markey et al. 1984; O'Callaghan et al. 1990). Nach der Aufnahme von MPTP kommt es in den Astrozyten durch die MAO-B zur Umwandlung des MPTP in seinen aktiven Metaboliten 1-Methyl-4Phenylpyridinium (MPP ${ }^{+}$) (Marini et al. 1992; Ransom et al. 1987; Salach et al. 1984; Singer et al. 1986). Der aktive und toxische Metabolit $\mathrm{MPP}^{+}$wird von Gliazellen freigesetzt (Russ et al. 1996) und über den DAT in die dopaminergen Neurone aufgenommen (Javitch et al. 1985; Mayer et al. 1986). Dort inhibiert MPP ${ }^{+}$spezifisch die NADH-Ubichinon-Reduktase (Komplex-I) der mitochondrialen Atmungskette (Cleeter et al. 1992; Nicklas et al. 1987; Ramsay et al. 1991). Es kommt zu einer Hemmung der Zellatmung mit verminderter Synthese von Adenosintriphosphat (ATP). Dieser Mangel wird für den neurotoxischen Effekt von MPTP und die Generierung von ROS verantwortlich gemacht (Chan et al. 1991; Cosi und Marien 1998; Scotcher et al. 1990).

\subsubsection{MPTP und oxidativer Stress}

Als oxidativer Stress wird eine Stoffwechsellage bezeichnet, bei der es zu einer vermehrten Ausbildung von ROS kommt. ROS entstehen z.B. im Rahmen von physiologischen Stoffwechselvorgängen der mitochondrialen Atmungskette (Rossetti et al. 1988). Untersuchungen an Gehirnen von Parkinson-Patienten post-mortem belegen einen Zusammenhang zwischen der Schädigung des mitochondrialen Komplex-I und oxidativem Stress (Bindoff et al. 1989; Janetzky et al. 1994; Schapira et al. 1990) mit einem Anstieg von ROS im Nervengewebe (Fahn und Cohen 1992).

MPTP führt zu oxidativem Stress und der damit verbundenen Degeneration dopaminerger Neurone in der SNpc (Pennathur et al. 1999). Neben einem Mangel an ATP wird dieser Vorgang möglicherweise durch eine $\mathrm{MPP}^{+}$bedingte massive Freisetzung von Dopamin aus den Vesikeln der Nervenendigungen unterstützt (Chiueh und Rauhala 1998). Das freigesetzte Dopamin wird im synaptischen Spalt enzymatisch und nicht-enzymatisch metabolisiert und setzt dabei weitere Radikale frei (Johnson 1988). Dies führt zu destruktiven Schäden an der 
Desoxyribonukleinsäure (DNS) sowie zu Zellfunktionsstörungen bis hin zum Zelltod (Bowling und Beal 1995; Dexter et al. 1994; Schulz et al. 2000; Yoritaka et al. 1996). Weiter gibt es Hinweise, dass apoptotische Vorgänge, vermittelt durch Bax, c-Jun-Nterminale Kinase und p53, an der Toxizität des MPTP beteiligt sind (Eberhardt und Schulz 2003; Hartmann et al. 2000; Przedborski und Vila 2003; Saporito et al. 1999; Saporito et al. 2000; Trimmer et al. 1996; Vila et al. 2001).

\section{$1.5 \quad$ Neurotrophine}

Neurotrophine (NTF) sind Komponenten eines komplexen Signalnetzwerkes, die insbesondere für die Entwicklung und das Überleben des Nervensystems von Bedeutung sind (Krieglstein 2004; Levi-Montalcini 1987).

Während der Entwicklung werden zunächst zu viele Neurone produziert. Neurotrophe Faktoren regulieren die Anzahl durch einen ontogenetisch programmierten Zelltod (Andressoo und Saarma 2008). Welche genaue Rolle die NTF bei der Entwicklung von dopaminergen Neuronen spielen bleibt nicht vollständig geklärt. Die ihnen zugeschriebenen neuroprotektive Eigenschaften sind in den Fokus der Forschung gerückt.

\subsubsection{Glial cell line-derived neurotrophic factor (GDNF)}

GDNF wurde anfangs beschrieben als ein neurotropher Faktor, der am Überleben und an der Ausdifferenzierung von dopaminergen Neuronen beteiligt ist (Lin et al. 1993). GDNF und drei weitere neurotrophe Faktoren: Neurturin (NRTN), Artemin (ARTN) und Persephin (PSPN) gehören zu den GDNF-family ligands (GFL). GFL wirken über eine RET (Rearranged during transfection)-Tyrosinkinase durch die primäre Bindung am Glykosylphosphatidylinositol (GPI)-vermittelten GDNF-family receptor-a (GFRa1-4) (Airaksinen und Saarma 2002; Baloh et al. 2000; Sariola und Saarma 2003).

Es wurde beobachtet, dass GDNF am Überleben von Motorneuronen, noradrenergen Neuronen, sensorischen sowie autonomen Neuronen beteiligt ist (Arenas et al. 1995; Henderson et al. 1994; Trupp et al. 1995). In vitro gilt GDNF als 
Überlebensfaktor für mesenzephale dopaminerge Neurone und schützt diese vor toxischen Einflüssen (Krieglstein 2004).

GDNF wurde schnell zum Gegenstand von neuen Therapiestrategien des IPS und genießt seitdem eine große Aufmerksamkeit (Kirik et al. 2004). Versuche mit 6Hydroxydopamin (6-OHDA) und Axotomie-induziertem Verlust dopaminerger Neurone zeigten eindeutige neuroprotektive Effekte nach GDNF-Applikation (Akerud et al. 2001; Beck et al. 1995; Bilang-Bleuel et al. 1997; Choi-Lundberg et al. 1997). Versuche an Nagern und Primaten zeigten, dass GDNF zu einer Protektion von dopaminergen Neuronen, einer Verbesserung der motorischen Funktionen und zu einer Regeneration der striatalen Faserdichte bei MPTP-Gabe führte (Gash et al. 1996; Kordower et al. 2000; Schober et al. 2007; Tomac et al. 1995).

Hingegen zeigten Versuche mit adenoviral vermittelter Freisetzung von GDNF im Striatum und anschließender MPTP-Gabe keinen protektiven Effekt (Eberhardt et al. 2000). Die Kombination von GDNF mit einem zellpenetrierenden Peptid (CPP) im MPTP-Mausmodell führte ebenfalls zu keiner Neuroprotektion dopaminerger Neurone (Dietz et al. 2006).

Erste klinische Untersuchungen mit intraputaminaler GDNF-Infusion an IPSerkrankten Patienten führten zu deutlichen klinischen Verbesserungen (Gill et al. 2003; Slevin et al. 2005). Eine randomisierte Doppelblind-Studie an IPS-erkrankten Patienten zeigte jedoch in der Auswertung keine signifikante motorische Verbesserung der UPDRS und wurde teilweise bei einigen Patienten aufgrund von Komplikationen abgebrochen (Lang et al. 2006). Eine mehrfache intraventrikuläre Verabreichung von GDNF führte zur Verschlechterung eines an IPS-erkrankten Patienten und rief schwere Nebenwirkungen hervor (Kordower et al. 1999).

\subsubsection{Der GDNF-Rezeptor RET}

Im Jahre 1996 wurde der transmembrane Tyrosinkinase-Rezeptor RET erstmals als Rezeptor für GDNF identifiziert (Durbec et al. 1996; Trupp et al. 1996). Die einzelnen GFRa1-4 wirken als Ko-Rezeptoren der GFL und besitzen unterschiedliche Ligandenspezifität (Airaksinen und Saarma 2002; Baloh et al. 2000). GDNF bindet zuerst an der GFRa1-Untereinheit und aktiviert dadurch die RET gebundene Tyrosinkinase (Airaksinen und Saarma 2002). Es folgt eine Aktivierung 
unterschiedlicher intrazellulärer Signalkaskaden, die an Überleben, Proliferation und Differenzierung der Zelle beteiligt sind. Die Signalwege Phosphatidylinositol-3-Kinase (PI3K), die Ras-mitogen activated protein kinase (Ras-MAPK) sowie die Tyrosinkinase-Src werden diskutiert, am Überleben und Neuritenwachstum von Neuronen beteiligt zu sein (Airaksinen und Saarma 2002; Kaplan und Miller 2000). Der GFRa1-Ko-Rezeptor ist selbst in einigen Regionen des Nervensystems exprimiert, in denen kein RET detektiert werden konnte. Daher ist anzunehmen, dass GFRa1 auch mit anderen Rezeptoren interagieren kann und der Signalweg komplexer ist als bisher angenommen (Airaksinen und Saarma 2002; Sariola und Saarma 2003).

Mäuse mit einem kompletten Mangel an RET, GDNF oder GFRa1 sterben kurz nach der Geburt infolge von Nierenfehlbildung und einem Verlust an enterischen und parasympathischen Neuronen (Airaksinen und Saarma 2002). In Versuchen mit selektiver Defizienz für RET und GFRa1 in spezifischen Zellpopulationen war es schließlich möglich, ein postnatales Überleben zu erreichen (Baudet et al. 2008; Jain et al. 2006; Kramer et al. 2007; Kramer et al. 2006). In zwei Studien mit einer RETDeletion in dopaminergen Neuronen konnte eine normale Entwicklung und Ausbildung des nigrostriatalen Systems beobachet werden (Jain et al. 2006; Kramer et al. 2007). Während bei Jain et al. kein Neuronenverlust bis zu einem Lebensalter von 12 Monaten festgestellt werden konnte, kam es bei Kramer et al. zu einem progressiven Verlust von dopaminergen Neuronen und ihrer TH-positiven Projektionen ab einer Überlebenszeit von 12 Monaten.

Obwohl GDNF ursprünglich als Überlebensfaktor für dopaminerge Neurone während der Entwicklung beschrieben wurde, zeigten diese Analysen mit RET-defizientenMäusen, dass GFRa1/RET nicht essentiell für die Entwicklung von dopaminergen Neuronen ist. Dies illustriert das komplexe Netzwerk an Regulations- und Kompensationsmechanismen, die an der Modulation und Entwicklung des neuronalen Systems beteiligt sind.

\section{$1.6 \quad$ Zielsetzung der Arbeit}

Das IPS ist durch das steigende Alter unserer Bevölkerung eine häufige Erkrankung. Die Therapieoptionen sind bislang symptomatisch und wirken nur initial. Es ist 
deshalb wichtig, nach kausalen Therapiemethoden zu suchen, die der Degeneration von dopaminergen Neuronen entgegenwirken bzw. zur Regeneration beitragen. Es besteht daher ein Bedarf an experimentellen Modellen mit induziertem Zelltod dopaminerger Neurone. Die Verwendung des Neurotoxins MPTP gilt als eines der wichtigsten neurotoxischen Modelle zur Auslösung des IPS.

NTF können zukünftige Therapieoptionen darstellen, um das Absterben von dopaminergen Neuronen zu verhindern und das Wiederauswachsen von Projektionsbahnen zu fördern. GDNF ist auf diesem Hintergrund Gegenstand vieler Untersuchungen und Diskussionen. In präklinischen Untersuchungen konnte gezeigt werden, dass die Aktivierung des RET-Rezeptors durch GDNF einen wichtigen Bestandteil in der Differenzierung und dem Überleben von dopaminergen Neuronen darstellt. Klinische Untersuchungen mit GDNF-Applikation an Parkinson-erkrankten Patienten führten zu kontroversen Ergebnissen. Es konnte bisher nicht ausreichend geklärt werden, ob und wie weit es sich bei den durch GDNF modulierten Zellfunktionen um einen neuroprotektiven Effekt handelt. Weiterhin bleibt unklar, welche Rolle der GDNF-Rezeptor RET bei dem Überleben von dopaminergen Neuronen spielt.

In dieser Arbeit wurde untersucht, ob die selektive Ablation des RET-Rezeptors in dopaminergen Neuronen eine MPTP-induzierte Degeneration dieser Neurone und inrer striatalen Projektionen verändert. Da Tiere mit einem kompletten Verlust an RET nicht lebensfähig sind, wurden in dieser Arbeit Mäuse mit einer selektiven RETDefizienz in dopaminergen Neuronen verwendet. Hierzu wurden Mäuse mit gefloxten Allelen für RET mit einer Mauslinie verkreuzt, die die Cre (Causes recombination protein)-Rekombinase unter Kontrolle des DAT-Promotors exprimierten. Die Nachkommen weisen somit eine gewebespezifische Deletion des RET-Rezeptors in dopaminergen Neuronen auf.

Für diese Arbeit wurde das MPTP-Mausmodell gewählt. Hierfür wurden die Versuchstiere an fünf aufeinanderfolgenden Tagen mit MPTP behandelt und anschließend nach 14 Tagen getötet. Post mortem wurde der Einfluss des GDNFRezeptors RET auf die akute MPTP-Toxizität in der Maus, durch die Quantifizierung dopaminerger Neurone, nigrostriataler Projektionen und Katecholaminkonzentrationen im Striatum, untersucht. 


\section{Material und Methoden}

\section{$2.1 \quad$ Versuchstiere}

Alle Versuchstiere basierten auf einem C57BL/6-Hintergrund, waren männlich und 12 bis 16 Wochen alt.

Um eine selektive Deletion des RET-Rezeptors in dopaminergen Neuronen der SNpc zu erreichen, wurden Mäuse mit einem gefloxten Allel für RET $\left(R E T^{\mid x}\right)$ mit einer Mauslinie verkreuzt, die die Cre-Rekombinase unter Kontrolle des DAT-Promotors exprimierten (DAT-Cre). Das Resultat war eine gewebespezifische Deletion des RET-Rezeptors (DAT-RET ${ }^{|x| x}$ ) in dopaminergen Neuronen (Kramer et al. 2007; Kramer et al. 2006). Alle DAT-RET $T^{|x| x}$ waren fruchtbar und lebensfähig. Als Kontrollen dienten DAT-Cre- und RET ${ }^{\mathrm{Ix}}$-Mäuse.

\subsubsection{Tierhaltung}

Die Haltung der Mäuse erfolgte in Tierkäfigen mit je 4-5 Tieren einer Versuchsgruppe. Wasser und Futter standen ad libitum zur Verfügung. Die Umgebungstemperatur betrug konstant $25^{\circ} \mathrm{C}\left( \pm 1.0^{\circ} \mathrm{C}\right)$, die Luftfeuchtigkeit lag bei $60 \% \quad( \pm 5 \%)$. Der Tag-Nacht-Zyklus wurde in zwölfstündigen Intervallen (Helligkeitsphase von 6.00 Uhr bis $18.00 \mathrm{Uhr}$ ) durch ein Lichtprogramm geregelt. Die durchgeführten Tierversuche waren von dem Regierungspräsidium Braunschweig (Aktenzeichen: 33.42502/01-15.05) genehmigt.

\subsubsection{Versuchsgruppen}

Die Versuchstiere wurden innerhalb ihres Genotyps DAT-RET ${ }^{|x| \mid x}$, DAT-Cre und $\mathrm{RET}^{\mathrm{Ix}}$ in eine mit Natriumchlorid ( $\mathrm{NaCl}$ )- und eine MPTP-behandelte Versuchsgruppe eingeteilt. Es wurden 4-7 Versuchstiere pro Gruppe verwendet. Die entsprechenden 
Genotypen waren nicht erkennbar. Zur späteren Auswertung waren die Tiere mit nummerierten Ohrmarkierungen gekennzeichnet. Die jeweiligen Käfige wurden entsprechend mit $\mathrm{NaCl}$ oder MPTP gekennzeichnet.

\section{$2.2 \quad$ MPTP}

\subsubsection{Herstellung der MPTP-Injektionslösung}

Material: MPTP-HCl (1-Methyl-4-Phenyl-1,2,3,6-Tetrahydropyridin-Hydrochlorid)

Herstellung: Die Herstellung der MPTP-HCl-Injektionslösung erfolgte unter strengen Sicherheitsvorkehrungen (Abzug, Schutzkleidung und Atemmaske) (Przedborski et al. 2001). Das Trockenpulver wurde bei $4^{\circ} \mathrm{C}$ gelagert. Zur Injektion wurde eine freie Basen-Konzentration von $30 \mathrm{mg} / \mathrm{kg}$ Körpergewicht (KG) angesetzt. Nach Berechnung der anteiligen freien Base, wurden $100 \mathrm{mg}$ MPTP mit 27,55 ml 0.9\% $\mathrm{NaCl}$ verdünnt. Die Herstellung erfolgte an jedem Injektionstag neu.

\subsubsection{MPTP-HCl-Injektion}

Versuchsprinzip: Die Injektion erfolgte an fünf aufeinander folgenden Tagen, in einem 24-Stunden-Intervall (Abb. 3). Die Injektion erfolgte ebenfalls unter strengen Sicherheitsvorkehrungen (Abzug, Schutzkleidung und Atemmaske) (Przedborski et al. 2001). Die Tiere wurden vor jeder Injektion gewogen und mit $30 \mathrm{mg} / \mathrm{kg}$ MPTP injiziert. Die Injektion der $\mathrm{NaCl}$-Mäuse erfolgte jeweils am gleichen Tag mit einem äquivalenten Volumen 0,9\% NaCl-Lösung.

\begin{tabular}{|l|r}
\hline 5 Tage MPTP-Injektion & 14 Tage \\
\hline
\end{tabular}

Abb. 3 Schematische Darstellung des Injektionszyklus Versuchsdurchführung: Für die Injektion wurde das Versuchstier auf 
dem Boden des Käfigeinsatzes mit der Hand am Schwanz fixiert. Mit Daumen und Zeigefinger wurde das Nackenfell des Tieres gegriffen. Die Maus wurde in Rücklage gebracht und der Kopf abgesenkt. Dies führte zu einem kranialen Absinken und besseren Schutz der inneren Organe bei der intraperitonealen (i.p.) Injektion. Die Injektion erfolgte ca. 0,5-0,6 cm oberhalb des Leistenbandes im linken unteren Quadranten. Zur Injektion wurde eine $1 \mathrm{ml}$ Injektionsspritze mit einer 0,45x12 mm Injektionskanüle verwendet. Anschließend wurde der Käfig speziell als MPTP-Käfig gekennzeichnet. Um mögliche MPTP-Verunreinigungen von Arbeitsflächen und Instrumenten zu vermeiden, wurden diese mit einer Natriumhypochlorit-Lösung $\left(\right.$ Danklorix ${ }^{\circledR}$ ) gesäubert und anschließend desinfiziert.

\section{$2.3 \quad$ Gewebeaufarbeitung}

\subsubsection{Gewebeentnahme}

Die Tiere wurden 14 Tage nach MPTP- bzw. NaCl-Behandlung durch Dekapitation getötet (Abb. 4). Die Schädelkalotte wurde entlang der Sutura sagittalis eröffnet und durch zwei weitere seitliche Schnitte aufgeklappt. Nach Entfernen der Dura mater wurde das Gehirn entnommen. Die Präparation erfolgte auf einer umgedrehten Petrischale, welche mit einem feuchten Filterpapier bedeckt war. Die komplette Einheit wurde konstant durch Eis gekühlt.

Die Präparation wurde von ventral durchgeführt. Es wurde der linke frontale Quadrant enfernt, begrenzt von der Mediosaggitalebene und einer koronaren Ebene durch den kaudal des optischen Nervs gelegenen Hypothalamus (Resektionsanteil 1 in Abb. 4). Mit Hilfe eines Auflichtmikroskopes wurde das Striatum aus diesem Resektionsanteil heraus präpariert und in abgewogenen 1,5 ml Reaktionsgefäßen auf Trockeneis schockgefroren. Die striatalen Proben wurden bis zur weiteren Aufarbeitung (2.3.3) und Messung der Katecholaminkonzentrationen (2.4) bei $-80^{\circ} \mathrm{C}$ aufbewahrt.

Der Resektionsanteil 2 diente zur Untersuchung der dopaminergen Neurone der SNpc (2.5.5), der striatalen Faserdichte (optische Dichte) und der nigrostriatalen 
Projektionen rostral der SNpc (2.6). Dieser wurde zur histologischen Aufarbeitung in eine Fixierlösung überführt (2.3.2).

A)

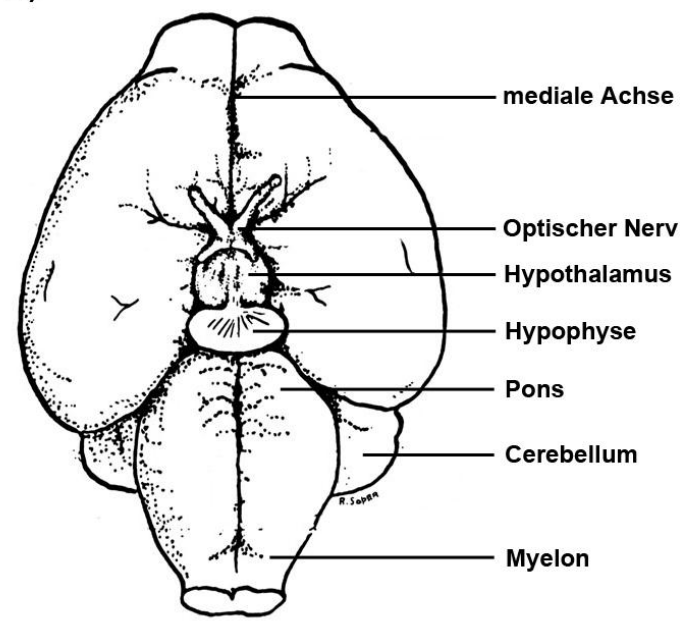

B)

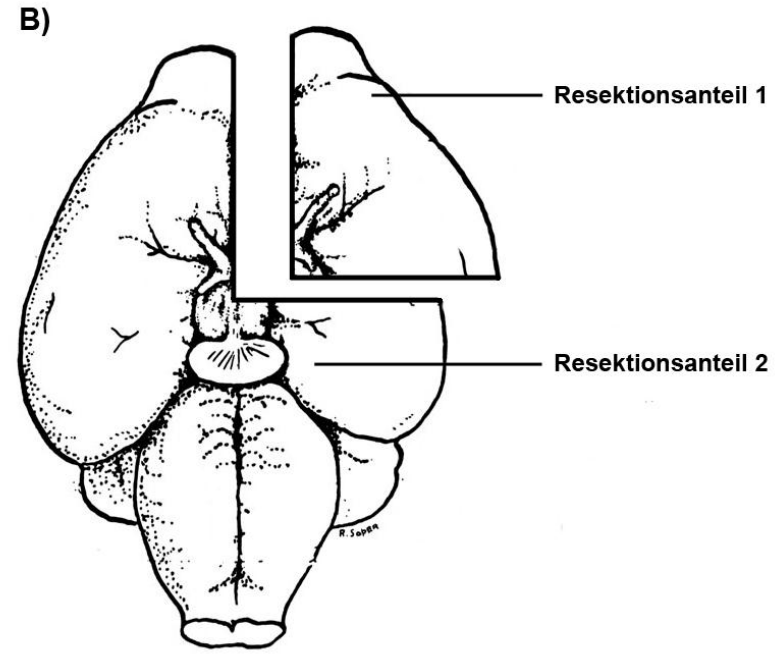

Abb. 4 Modifizierte Darstellung des Mausgehirns von ventral (A) mit Resektionsanteilen der Gewebeentnahme (B)

(Quelle: www.informatics.jax.org/greenbook/figures/figure13-11.shtml)

(A) Die Abbildung dient der allgemeinen Übersicht der unter 2.3.1 aufgeführten Gewebeentnahme. (B) Der Resektionsanteil 1 diente der striatalen Gewebeentnahme und anschließender Quantifizierung der Katecholaminkonzentrationen. Der Resektionsanteil 2 diente der Auswertung der dopaminergen Neurone in der SNpc, der striatalen Faserdichte (optische Dichte) und der nigrostriatalen Projektionen rostral der SNpc.

\subsubsection{Gewebefixierung zur immunozytochemischen Aufarbeitung}

Vorbereitung der Paraformaldehyd-Lösung (PFA): Zur Herstellung der Fixierlösung wurden $8 \mathrm{~g}$ PFA pro $100 \mathrm{ml}$ destillierten $\mathrm{H}_{2} \mathrm{O}$ für 20-30 min auf $60^{\circ} \mathrm{C}$ erhitzt. Um die Lösung aufzuklaren, wurden unter ständigem Rühren ein bis zwei Tropfen konzentrierter Natronlauge (4N) hinzugefügt. Die Lösung wurde abgedeckt und über Nacht abgekühlt. Um eine 0,1 M 4\% PFA-Lösung zu erhalten, wurde die Lösung im Anschluss mit 0,2 M Phosphatpuffer (PB) im Verhältnis 1:1 verdünnt und der $\mathrm{pH}$ Wert auf $\mathrm{pH} 7,4$ eingestellt. 
Vorbereitung der Sucrose-Lösung: Für die Herstellung der 30\% Sucrose-Lösung wurden $30 \mathrm{~g}$ Sucrose auf $100 \mathrm{ml}$ 0,1 M PB angesetzt.

PB 0,2 M: $\quad 21,8 \mathrm{~g} / / \mathrm{Na}_{2} \mathrm{HPO}_{4}, 6,28 \mathrm{~g} / / \mathrm{NaH}_{2} \mathrm{PO}_{4}, \mathrm{pH} 7,2-7,4$

PB 0,1 M: $\quad 10,9 \mathrm{~g} / / \mathrm{Na}_{2} \mathrm{HPO}_{4}, 3,14 \mathrm{~g} / \mathrm{l} \mathrm{NaH} \mathrm{PO}_{4}, \mathrm{pH} 7,2-7,4$

Durchführung: Zur weiteren Untersuchung wurde der Resektionsanteil 2 (Abb. 4) in $4 \%$ PFA für 24 Stunden bei $4^{\circ} \mathrm{C}$ fixiert. Anschließend folgte die Überführung in $30 \%$ Sucrose für 48 Stunden bei $4^{\circ} \mathrm{C}$. Zur schnellen Gefrierfixation wurde ein Gefäß mit 2-Methylbutan mittels Trockeneis auf $-40^{\circ} \mathrm{C}$ herunter gekühlt und die einzelnen Resektionsanteile für 30 Sekunden schockgefroren. Diese wurden bis zur weiteren Aufarbeitung bei $-80^{\circ} \mathrm{C}$ gelagert.

\subsubsection{Gewebeaufarbeitung des Striatums zur Bestimmung der Katecholamin- konzentrationen}

Die Striata aus dem Resektionsanteil 1 wurden in einzeln abgewogene $1,5 \mathrm{ml}$ Reaktionsgefäße überführt und erneut gewogen. Die einzelnen Gewichte wurden von einander subtrahiert und gewichtsadaptiert in einem Verhältnis von 1:3 mit $0,1 \mathrm{M}$ Perchlorsäure (eiskalt) versetzt. Nach dem Zusetzen der Perchlorsäure wurden die Striata durch Ultraschall bei $4^{\circ} \mathrm{C}$ für ca. 10 Sekunden homogenisiert. Um eine quantitative Proteinfällung zu erreichen, wurden die Proben für 30 Minuten bei $4^{\circ} \mathrm{C}$ gelagert. Anschließend erfolgte eine erneute Ultraschallhomogenisierung für weitere 10 Sekunden. Nach einer Ruhezeit von 20 Minuten wurde der gelöste Zellbestandteil bei $4^{\circ} \mathrm{C}$ und 13.000 Umdrehungen pro Minute für 20 Minuten abzentrifugiert. Die auf diesem Wege gewonnenen Überstände konnten direkt mittels der High pressure liquid chromatography (HPLC) analysiert werden.

\subsection{Bestimmung der Katecholaminkonzentrationen mittels HPLC}

Versuchsprinzip: Mit der HPLC ist es möglich, die einzelnen Katecholamine des Striatums aufzutrennen und deren Konzentrationen $\mathrm{zu}$ bestimmen. Die 
Konzentrationen von Dopamin und seinen Metaboliten DOPAC und HVA sind ein $\mathrm{Maß}$ für die Integrität nigrostriataler Terminalen.

Versuchsdurchführung: Zur Messung von Dopamin und seinen Metaboliten DOPAC und HVA mittels HPLC (Gynkotek P580A) wurden $20 \mu$ Proben auf eine ReversePhase-Säule (Bischoff Pronto SIL 120-3-C18 AQ) gegeben und durch elektrochemische Detektion bei $400 \mathrm{mV}$ gemessen (ESA Coulchem II). Als Fließmittel wurde ein Puffer verwendet, welcher sich aus $935 \mathrm{ml}$ destilliertem Wasser, $105 \mathrm{ml}$ Methanol, 6,937 g Natriumacetat, 0,048 g NatriumEthylendiamintetraessigsäure, $7,355 \mathrm{~g}$ Zitronensäure und 0,105 g NatriumOctansulfonsäure zusammensetzt. Der pH-Wert des Puffers wurde auf $\mathrm{pH} 2,5$ eingestellt und durch einem Bottle-top-Filter (Satorius $1130750 \mathrm{~N}$ Poren 0,2 $\mu \mathrm{m}$ ) gefiltert. Die Flussgeschwindigkeit lag bei $1 \mathrm{ml}$ pro Minute.

Für jedes Katecholamin wurde eine typische Retentionszeit ermittelt, welche es ermöglichte, die Zugehörigkeit der Signalkurven zu den einzelnen Katecholaminen festzustellen. Die Berechnung erfolgte dann über das Flächenintegral der identifizierten Signalkurven in Bezug zu den aus der Eichung erhaltenen Referenzkurven (Software: Chromeleon 6.60; Gynkotek). Der bestimmte Katecholamingehalt der Proben konnte anschließend mit denen bei der Aufbereitung gemessenen striatalen Gewichten verrechnet werden. Die somit ermittelten Konzentrationen wurden in $\mathrm{ng} / \mathrm{mg}$ Nassgewebe angegeben.

\subsection{1 $\quad$ MPP $^{+}-$Messungen mittels HPLC}

Versuchsprinzip: Die Toxizität von MPTP beruht auf dem aktiven Metabolit MPP'. Um mögliche Unterschiede im MPTP-Metabolismus auszuschließen, wurden Tiere der verschiedenen Genotypen DAT-Cre, RET ${ }^{\mid x}$ und DAT-RET ${ }^{|x| x}$ mit $30 \mathrm{mg} / \mathrm{kg}$ KG MPTP i.p. injiziert (siehe 2.2.2). Die Detektion von $\mathrm{MPP}^{+}$im Striatum erfolgte mittels HPLC 90 Minuten nach MPTP-Injektion.

Versuchsdurchführung: Die verwendeten Striata wurden wie unter 2.3.1 und 2.3.3 entnommen und aufgearbeitet. $20 \mu \mathrm{l}$ Proben wurden auf eine Reverse-Phase-Säule (Nucleosil-100 C18, Knauer) gegeben und durch UV-Absorption bei $300 \mathrm{~nm}$ (UVD340U, Dionex) gemessen. Als Fließmittel wurden 697/1000 ml Acetonitril in 
Phosphatpuffer $(\mathrm{pH} \mathrm{2,5)}$ verwendet. Die Flussgeschwindigkeit lag bei $0,5 \mathrm{ml}$ pro Minute. Die gewonnen Daten wurden mittels der Software Chromeleon 6.60 (Gynkotek) ausgewertet und die ermittelten Konzentrationen in $\mathrm{ng} / \mathrm{mg}$ Nassgewebe angegeben. Zur Kalibrierung wurden Lösungen mit bekannter $\mathrm{MPP}^{+}-$Konzentration gemessen.

\subsection{Histologie und Immunzytochemie}

\subsubsection{Gehirnschnitte}

Mit einem Gefriermikrotom (Leica CM 3050s) wurden $30 \mu \mathrm{m}$ dicke Gehirnschnitte der SNpc und des Striatums angefertigt (Resektionsanteil 2) und bis zur weiteren Färbung in Phosphat-gepufferter Salzlösung (Phosphate-buffered saline; PBS: $10,9 \mathrm{~g} \mathrm{Na}_{2} \mathrm{HPO}_{4}, 3,14 \mathrm{~g} \mathrm{NaH}_{2} \mathrm{PO}_{4}, 9 \mathrm{~g} \mathrm{NaCl}, 1 \mathrm{~g} \mathrm{Natriumazid}, 1000 \mathrm{ml}$ destilliertes $\mathrm{H}_{2} \mathrm{O}$; pH $\left.7,2-7,4\right)$ bei $4^{\circ} \mathrm{C}$ in 48er-Wellplatten aufbewahrt. Zur besseren Seitendifferenzierung und Ausrichtung unter dem Mikroskop wurde mit einer 0,45×12 mm dicken Injektionskanüle die linke Großhirnhemisphäre markiert. Die genaue Ausrichtung und Orientierung erfolgte nach anatomischen Richtlinien (Paxinos und Franklin 2004).

\subsubsection{Objektträger}

Im Anschluss an die folgende TH-Färbung wurden die Gehirnschnitte auf Objektträger (Menzel Gläser, 76×26 mm) gezogen. Für eine bessere Haftung der Gehirnschnitte bei der Nissl-Färbung der SNpc und Entwässerung der Striata wurden die Objektträger mit einer Gelatineschicht versehen.

Zunächst wurden $5 \mathrm{~g}$ Gelatine in $500 \mathrm{ml}$ zweifach destilliertem $\mathrm{H}_{2} \mathrm{O}$ gelöst und unter ständigem Rühren auf $80^{\circ} \mathrm{C}$ erhitzt. Die Gelatinelösung wurde auf $40^{\circ} \mathrm{C}$ abgekühlt und zum besseren Aufklaren der Lösung mit 0,5 g Chrom-III-Kaliumsulfat versetzt. Nach anschließender Filtration durch einen Bottle-top-Filter wurden die Objektträger für 30 Sekunden in die Gelatinelösung getaucht, 20 Minuten bei Raumtemperatur 
getrocknet und für 15 Minuten in 1\% PFA-Lösung ( $\mathrm{NaCl}$ frei) fixiert. Die Objektträger mussten anschließend für 12 Stunden staubfrei bei $63^{\circ} \mathrm{C}$ getrocknet werden.

\subsubsection{Tyrosinhydroxylase (TH)-Färbung der SNpc}

Versuchsprinzip: Die Darstellung der TH-positiven Zellen der SNpc beruht auf einer Antikörper gebundenen 3,3'-Diaminobenzidin (DAB)-Färbung. Dabei wurde das zunächst farblose Chromogen DAB durch einen Peroxidase-vermittelnden Oxidationsprozess in ein bräunliches Endprodukt umgewandelt. Vor Beginn der Färbung wurde die endogene Peroxidase, welche vorrangig in Erythrozyten und Leukozyten vorkommt, mit Wasserstoffperoxid $\left(\mathrm{H}_{2} \mathrm{O}_{2}\right)$ blockiert. Hierdurch wurde eine Anfärbung vermieden. Die Präinkubation mit Normal Goat Serum (NGS) diente der Blockierung unspezifischer Bindungsstellen. Der primäre Antikörper richtete sich gegen die in dopaminergen Neuronen exprimierte $\mathrm{TH}$ (Chemicon International; Rabbit-Anti-Tyrosine-Hydroxylase-Antibody; polyklonal 1:1000). Der sekundäre Biotin-gekoppelte Antikörper (Vector Laboratories; Biotinylated Anti-Rabbit IgG; 1:200) richtete sich gegen den primären TH-gebundenen Antikörper. Das dritte Reagenz war ein peroxidasegekoppelter Avidin-Biotin-Komplex. Die freien Bindungsstellen des Avidins ermöglichten die Bindung von Biotin (Vector Laboratories; ABC Kit Standard PK-4000). Dieser peroxidasegebundene-AntikörperKomplex wurde anschließend mit DAB gefärbt (Tab. 1).

Es wurden zehn $30 \mu \mathrm{m}$ dicke Gehirnschnitte der SNpc im Abstand von $120 \mu \mathrm{m}$ verwendet. Als Waschmedium diente 0,1 M Tris-gepufferte Salzlösung (Tris-buffered saline; TBS).

Die gefärbten Gehirnschnitte wurden auf die gelatinisierten Objektträger überführt und für 12 Stunden bei Raumtemperatur getrocknet.

Das überschüssige DAB-Reagenz wurde anschließend mit einer NatriumhypochloritLösung (Danklorix ${ }^{\circledR}$ ) inaktiviert. 
Puffer:

0,1 M TBS:

$12,11 \mathrm{~g} / \mathrm{l}$ Tris(hydroxymethyl)-aminomethan, $9 \mathrm{~g} / \mathrm{l} \mathrm{NaCl} ;(\mathrm{pH} 7,2-7,4)$

Tris-Puffer:

$12,11 \mathrm{~g} / \mathrm{l}$ Tris $(\mathrm{pH} 7,6)$

Versuchsdurchführung:

\begin{tabular}{|c|c|c|}
\hline Art des Vorgangs & Inkubationszeit & Zusammensetzung der Lösung \\
\hline Waschen & $3 \times 5 \min$ & $0,1 \mathrm{M}$ TBS \\
\hline Peroxidaseblockung & $5 \min$ & $\begin{array}{l}10 \% \text { Methanol und } 3 \% \mathrm{H}_{2} \mathrm{O}_{2} \text { in } \\
0,1 \mathrm{M} \text { TBS }\end{array}$ \\
\hline Waschen & $3 \times 5 \min$ & $0,1 \mathrm{M}$ TBS \\
\hline Präinkubation & $60 \mathrm{~min}$ & $5 \% \mathrm{NGS}$ in $0,1 \mathrm{M}$ TBS \\
\hline Prim. Antikörper & 48 Stunden & $\begin{array}{l}\text { Rabbit-Anti-Tyrosine-Hydroxylase- } \\
\text { Antibody }(1: 1000) ; 2 \% \text { NGS in } \\
0,1 \text { M TBS bei } 4^{\circ} \mathrm{C}\end{array}$ \\
\hline Waschen & $3 \times 5 \min$ & $0,1 \mathrm{M}$ TBS \\
\hline Sek. Antikörper & $60 \mathrm{~min}$ & $\begin{array}{l}\text { Biotinylated Anti-Rabbit IgG } \\
(1: 200), 2 \% \text { NGS in } 0,1 \mathrm{M} \text { TBS }\end{array}$ \\
\hline Waschen & $3 \times 5 \min$ & $0,1 \mathrm{M}$ TBS \\
\hline Enzymkomplex & $60 \mathrm{~min}$ & $\begin{array}{l}\text { ABC Kit Standard (PK- } 4000) \\
\text { (2 Tropfen A und } 2 \text { Tropfen B pro } \\
10 \mathrm{ml} \text { ) } \\
\text { in } 0,1 \mathrm{M} \text { TBS }\end{array}$ \\
\hline Waschen & $3 \times 5 \min$ & $0,1 \mathrm{M}$ TBS \\
\hline DAB-Färbung & $15 \min$ & $\begin{array}{l}\text { In } 50 \mathrm{ml} \text { Tris-Puffer }(\mathrm{pH} 7,6): 25 \\
\text { mg DAB, } 100 \mu \mathrm{l} \mathrm{NH}{ }_{4} \mathrm{Cl}, 150 \mu \mathrm{l} \\
\text { Glucoseoxidase, } 400 \mu \mathrm{l} \text { Glucose }\end{array}$ \\
\hline
\end{tabular}




\begin{tabular}{|l|l|l}
\hline Waschen & $3 \times 5 \mathrm{~min}$ & $0,1 \mathrm{M}$ TBS
\end{tabular}

Tab. 1 Tabellarische Darstellung der TH-Färbung der SNpc

\subsubsection{Nissl-Färbung der SNpc}

Versuchsprinzip: Bei der Nissl-Färbung handelt es sich um eine Thionin-Färbung, bei der die Zellkörper von Neuronen angefärbt werden. Dabei kommt es zur Anlagerung basischer Farbstoffe an sauer reagierende Zellbestandteile des rauen endoplasmatischen Retikulums (Nisslschollen) (Bohlen und Halbach und Dermietzel 1999). Dadurch werden alle Neurone innerhalb und außerhalb der SNpc angefärbt.

Bei der Anwendung des MPTP-Mausmodell kann es zu einer vorübergehenden Herabregulation der TH in den dopaminergen Neurone kommen, ohne dass eine Degeneration der Zelle vorliegt (Jackson-Lewis et al. 1995). Als ausschließlich NissIpositive Zellen in der SNpc werden Neurone beschrieben, die sich nicht für TH anfärben lassen. Bei der anschließenden stereologischen Zählung (2.5.5) ist zu beachten, dass jede TH-positive Zelle auch Nissl-positiv ist. Da sich auch Gliazellen durch die Nissl-Färbung anfärben lassen, bedarf es Auswahlkriterien zur Bestimmung einer Nissl-positiven Zelle in der SNpc. Diese Auswahlkriterien sind neben der Anfärbung und Lokalisation innerhalb der SNpc, die Größe der Zelle und die Größe des Nucleus. Nissl-positive Zellen der SNpc können das 5-fache an THpositiven Zellen ausmachen (Kramer et al. 2007). Die Auswertung von TH- und NissIpositiven Zellen lässt auf die gesamte Neuronenzahl in der SNpc und Aktivität der TH schließen. Zusätzlich gilt die gleichzeitige Erniedrigung von TH-positiven und Nisslpositiven Zellen als Neurodegenerationsmarker für dopaminerge Neurone.

Versuchsdurchführung: Für die Nissl-Färbung wurden die zuvor TH-gefärbten $30 \mu \mathrm{m}$ dicken Gehirnschnitte auf Objektträger gebunden angefärbt (Tab. 2). Die Gegenfärbung ermöglichte eine gleichzeitige Auszählung der TH- und Nissl-positiven Zellen in der Stereologie (2.5.5). 
Für die NissI-Färbung wurden folgende Lösungen angesetzt:

Chloroform-Lösung: $\quad 480 \mathrm{ml}$ Chloroform; $60 \mathrm{ml}$ 95\% Ethanol; $60 \mathrm{ml}$ Diethylether (Reihenfolge wichtig!)

Färbelösung:

$$
\begin{aligned}
& 455 \mathrm{ml} \text { Standardfärbelösung, } 45 \mathrm{ml} \text { Pufferlösung } \\
& \text { Pufferlösung: } \quad 7 \mathrm{~g} \text { Natriumacetat } \\
& 2 \mathrm{ml} \text { Eisessigsäure } \\
& 1100 \mathrm{ml} \text { destilliertes Wasser } \\
& \text { Standardfärbelösung: } \quad 1 \mathrm{~g} \text { Thionin } \\
& 100 \mathrm{ml} \text { kochendes destilliertes } \\
& \text { Wasser }
\end{aligned}
$$

Formalin-Essig-Lösung: $1 \mathrm{ml}$ Eisessigsäure; $1 \mathrm{ml}$ 39\% Formaldehyd; $100 \mathrm{ml}$ destilliertes Wasser

\begin{tabular}{|l|c|}
\hline Reagenz & Inkubationszeit \\
\hline $95 \%$ Ethanol & $20 \mathrm{~min}$ \\
\hline Chloroform-Lösung & $10 \mathrm{~min}$ \\
\hline $95 \%$ Ethanol & $2 \mathrm{~min}$ \\
\hline $100 \%$ Ethanol & $5 \mathrm{~min}$ \\
\hline Xylol & $5 \mathrm{~min}$ \\
\hline $100 \%$ Ethanol & $2 \mathrm{~min}$ \\
\hline $95 \%$ Ethanol & $2 \mathrm{~min}$ \\
\hline $95 \%$ Ethanol & $2 \mathrm{~min}$ \\
\hline Destilliertes Wasser & $7 \mathrm{~min}$ \\
\hline Färbelösung & $2 \mathrm{~min}$ \\
\hline Destilliertes Wasser & $2 \mathrm{~min}$ \\
\hline Destilliertes Wasser & $2 \mathrm{~min}$ \\
\hline Destilliertes Wasser & \\
\hline
\end{tabular}




\begin{tabular}{|l|c|}
\hline Formalin-Essig-Lösung & $8 \mathrm{~s}$ \\
\hline Destilliertes Wasser & $2 \mathrm{~min}$ \\
\hline Destilliertes Wasser & $2 \mathrm{~min}$ \\
\hline Destilliertes Wasser & $2 \mathrm{~min}$ \\
\hline $95 \%$ Ethanol & $2 \mathrm{~min}$ \\
\hline $95 \%$ Ethanol & $2 \mathrm{~min}$ \\
\hline $95 \%$ Ethanol & $2 \mathrm{~min}$ \\
\hline $100 \%$ n-Butanol & $10 \mathrm{~min}$ \\
\hline Cedernholzöl & $10 \mathrm{~min}$ \\
\hline Xylol & $10 \mathrm{~min}$ \\
\hline Xylol & $10 \mathrm{~min}$ \\
\hline Eindeckeln mit Entellan & \\
\hline
\end{tabular}

Tab. 2 Tabellarische Darstellung der NissI-Färbung der SNpc

\subsubsection{Stereologische Quantifizierung von TH- und Nissl-positiven Zellen der SNpc}

Um die Gesamtzahl der TH- und Nissl-gefärbten Neurone in der SNpc zu bestimmen, wurden anhand der $30 \mu \mathrm{m}$ dicken Gehirnschnitte stereologische Zählungen durchgeführt. Bei der Stereologie wurde nur ein Subset der gefärbten Gehirnschnitte (jeder vierte, im Abstand von $120 \mu \mathrm{m}$ ) sowie ein Bruchteil der gesamten Fläche (ca. 20\%) ausgezählt (West 1993; West et al. 1991). Pro Tier wurden zehn Gehirnschnitte aus dem Bereich der SNpc stereologisch auf TH- und Nissl-positive Zellen untersucht. Als Referenz für die Grenzen der SNpc wurde der Maushirnatlas (Paxinos und Franklin 2004) verwendet. In jedem Schnitt wurde zunächst die Region of interest (ROI), die SNpc, bei niedriger Vergrößerung (10x Objektiv) umfahren. Die Auswahl der auszuzählenden Felder (counting frame, 50x50 $\mu \mathrm{m})$ in jedem Schnitt erfolgte randomisiert durch ein Computerprogramm (Stereolnvestigator, MicroBrightField; USA). Die Felder wurden in einem zufällig platzierten Raster (grid size, 100×125 $\mu \mathrm{m}$ ) angeordnet. Die Zählung erfolgte manuell 
unter Verwendung eines Zeiss Axioskop 2. TH- und Nissl-positive Zellen wurden dabei unterschiedlich markiert. Gezählt wurde mit einem 63x Objektiv und Immersionsöl. Nicht gezählt wurden Zellen, die die rote Grenze des Zählrahmens überschritten. Die Auswertung erfolgte für jede Hemisphäre gleich. Genotyp und Versuchsreihe waren bei Durchführung der Auswertung verblindet.

Am Ende der Auswertung wurde anhand der einzelnen Stichproben die Gesamtneuronenzahl der $\mathrm{TH}$ - und Nissl-positiven Zellen beider Hemisphären computergestützt berechnet (Stereolnvestigator, MicroBrightField; USA).

\subsubsection{Striatale TH-Färbung}

Versuchsprinzip: Die striatale TH-Färbung diente der Quantifizierung von THpositiven Fasern zur Bestimmung der optischen Dichte. Das Versuchsprinzip beruhte ebenfalls auf einer TH-gebundenen DAB-Färbung (Tab. 3). Zur Auswertung des gesamten Striatums wurden $30 \mu \mathrm{m}$ dicke striatale Gehirnschnitte im Abstand von 240 $\mu \mathrm{m}$ (jeder achte Schnitt) verwendet. Der Versuchsaufbau ähnelte der unter (2.5.3) beschriebenen Färbemethode für dopaminerge Neurone in der SNpc. Es wurde ebenfalls ein peroxidasegekoppelter Avidin-Biotin-Komplex verwendet, jedoch mit einem anderen Reagenz (ABC Kit Vectastain Elite Standard PK-6100; Vector). Der Unterschied im Elite Kit liegt in der höheren Affinität zum Antikörper-Komplex. Dadurch kann die Konzentration gesenkt und die Anfärbung des Hintergrundes vermindert werden. Die Inkubation der Striata mit DAB betrug zudem 20 Minuten.

Versuchsdurchführung:

\begin{tabular}{|l|c|l|}
\hline \multicolumn{1}{|c|}{ Art des Vorgangs } & Inkubationszeit & Zusammensetzung der Lösung \\
\hline Waschen & $3 \times 5 \mathrm{~min}$ & $0,1 \mathrm{M}$ TBS \\
\hline Peroxidaseblockung & $5 \mathrm{~min}$ & $\begin{array}{l}10 \% \text { Methanol und } 3 \% \mathrm{H}_{2} \mathrm{O}_{2} \quad \text { in } \\
0,1 \mathrm{M} \text { TBS }\end{array}$ \\
\hline Waschen & $3 \times 5 \mathrm{~min}$ & $0,1 \mathrm{M}$ TBS \\
\hline
\end{tabular}




\begin{tabular}{|c|c|c|}
\hline Präinkubation & $60 \mathrm{~min}$ & $5 \% \mathrm{NGS}$ in $0,1 \mathrm{M}$ TBS \\
\hline Prim. Antikörper & 48 Stunden & $\begin{array}{l}\text { Rabbit-Anti-Tyrosine-Hydroxylase- } \\
\text { Antibody }(1: 1000) ; 2 \% \text { NGS in } \\
0,1 \mathrm{M} \mathrm{TBS} \text { bei } 4^{\circ} \mathrm{C}\end{array}$ \\
\hline Waschen & $3 \times 5 \mathrm{~min}$ & $0,1 \mathrm{M}$ TBS \\
\hline Sek. Antikörper & $60 \mathrm{~min}$ & $\begin{array}{l}\text { Biotinylated Anti-Rabbit IgG } \\
(1: 200), 2 \% \text { NGS in } 0,1 \mathrm{M} \text { TBS }\end{array}$ \\
\hline Waschen & $3 \times 5 \min$ & $0,1 \mathrm{M}$ TBS \\
\hline Enzymkomplex & $60 \mathrm{~min}$ & $\begin{array}{l}\text { ABC Kit Elite Standard (PK-6100) } \\
(2 \text { Tropfen A und } 2 \text { Tropfen B pro } \\
10 \mathrm{ml} \text { ) } \\
\text { in } 0,1 \mathrm{M} \text { TBS }\end{array}$ \\
\hline Waschen & $3 \times 5 \mathrm{~min}$ & $0,1 \mathrm{M}$ TBS \\
\hline DAB-Färbung & $20 \mathrm{~min}$ & $\begin{array}{l}\text { In } 50 \mathrm{ml} \text { Tris-Puffer }(\mathrm{pH} 7,6): 25 \\
\text { mg DAB, } 100 \mu \mathrm{l} \mathrm{NH}{ }_{4} \mathrm{Cl}, 150 \mu \mathrm{l} \\
\text { Glucoseoxidase, } 400 \mu \mathrm{l} \text { Glucose }\end{array}$ \\
\hline Waschen & $3 \times 5 \mathrm{~min}$ & $0,1 \mathrm{M}$ TBS \\
\hline
\end{tabular}

Tab. 3 Tabellarische Darstellung der striatalen TH-Färbung

Die TH-gefärbten striatalen Gehirnschnitte wurden auf gelatinisierte Objektträger überführt und bei Raumtemperatur für 12 Stunden getrocknet. Anschließend wurden die Objektträger durch eine aufsteigende Alkoholreihe entwässert und fixiert (Tab. 4).

\section{Entwässerung:}

\begin{tabular}{|l|c|}
\hline Reagenz & Zeit \\
\hline Destilliertes Wasser & $5 \mathrm{~min}$ \\
\hline $70 \%$ Ethanol & $10 \mathrm{~min}$ \\
\hline $95 \%$ Ethanol & $10 \mathrm{~min}$ \\
\hline
\end{tabular}




\begin{tabular}{|l|c|}
\hline $100 \%$ Ethanol & $10 \mathrm{~min}$ \\
\hline $100 \%$ Ethanol & $10 \mathrm{~min}$ \\
\hline Xylol & $10 \mathrm{~min}$ \\
\hline Xylol & $10 \mathrm{~min}$ \\
\hline Eindeckeln mit Entellan & \\
\hline
\end{tabular}

Tab. 4 Tabellarische Darstellung der Entwässerungsreihe von TH-gefärbten striatalen Gehirnschnitten

\subsection{Optische Dichte und nigrostriatale Projektionen rostral der SNpc}

Das Striatum stellt das terminale Feld der nigrostriatalen Fasern dar. Neben der Faserdichte im Striatum (optische Dichte) wurde zudem die Anzahl und Fläche der nigrostriatalen Fasern nahe ihres Ursprungs, ca. 120-240 $\mu \mathrm{m}$ rostral der SNpc gemessen.

\subsubsection{Bestimmung der optischen Dichte von TH-positiven Fasern des Striatums}

Die Objektträger gebundenen Striata wurden als digitale Bilddateien eingescannt (Durchlicht-Modus, 8-bit) und ausgewertet. Die Auswertung erfolgte mittels Scion Image 4.0.3.2 Software (Scion Corporation; Frederick, Maryland, USA). Das Striatum wurde in jedem einzelnen Schnitt markiert und die mittlere Intensität bestimmt. Da es sich um Durchlichtaufnahmen handelte, entsprechen die gemessenen Werte willkürlichen Einheiten arbitrary units $(\mathrm{AU})=$ optische Dichte. Um Färbeunterschiede zwischen den einzelnen Schnitten auszugleichen, wurde in jedem Schnitt ein äquivalentes Areal der Großhirnrinde gemessen und die mittlere Dichte im Kortex vom Wert für das Striatum subtrahiert (Burke et al. 1990). Pro Versuchstier wurden zwölf TH-gefärbte striatale Gehirnschnitte ausgewertet. Genotyp und Versuchsreihe waren bei Durchführung der Auswertung verblindet. 


\subsubsection{Bestimmung der Anzahl und Fläche nigrostriataler Projektionen rostral der SNpc}

Versuchsprinzip: Zur Evaluation der nigrostriatalen Projektionen wurden pro Versuchstier je drei unilaterale, $30 \mu \mathrm{m}$ dicke Gefrierschnitte im Bereich 120-240 $\mu \mathrm{m}$ rostral der SNpc verwendet. Die quer angeschnittenen nigrostriatalen Projektionen wurden mittels TH-Färbung (siehe 2.5.6) angefärbt.

Versuchsdurchführung: Zur Analyse der TH-gefärbten Projektionen wurden diese in 20 -facher mikroskopischer Vergrößerung (Leica DMI 6000 B) eingescannt (Durchlicht-Modus). Die anschließende Auswertung erfolgte durch das Programm Image J (Version 1.63 B; Wayne Rasband, USA). Durch das Plugin "threshold_colour" (von Gabriel Landini; School of Dentistry, University of Birmingham) wurde der sichtbare Farbbereich auf die TH-gefärbten Projektionen beschränkt und auf 8-Bit reduziert. Das Areal der entsprechenden Projektionsbahnen wurde manuell markiert und die Anzahl der nigrostriatalen Projektionen durch eine automatisierte Partikel-Analyse bestimmt. Eine Erniedrigung der Anzahl und der gemessenen Fläche $\left(\mathrm{mm}^{2}\right)$ von TH-positiven Projektionen lässt auf eine Degeneration schließen. Genotyp und Versuchsreihe waren bei Durchführung der Auswertung verblindet.

\subsection{Statistik}

Daten in Text und Abbildungen entsprechen Mittelwerten \pm Standardabweichung. Zur statistischen Analyse wurde i.d.R. eine ANOVA mit zwei Faktoren durchgeführt. Dabei war der erste Faktor die Behandlung mit $\mathrm{NaCl}$ oder MPTP, und der zweite Faktor der Genotyp. Verwendet wurde die Software GraphPad Prism 4.0 (GraphPad Software, San Diego, USA). Falls nicht anders angegeben wurde die Nullhypothese mit einer Irrtumswahrscheinlichkeit von 0,05 abgewiesen. 


\subsection{Materialien}

\subsubsection{Chemikalien}

\begin{tabular}{|l|l|}
\hline Acetonitril & Sigma-Aldrich, München \\
\hline Ammoniumchlorid & Merck, Darmstadt \\
\hline Cedernholzöl & Sigma-Aldrich, München \\
\hline Chloroform & Sigma-Aldrich, München \\
\hline Chrom-III-Kaliumsulfat & Sigma-Aldrich, München \\
\hline 3,3'-Diaminobenzidin (DAB) & Sigma-Aldrich, München \\
\hline Diethylether & Sigma-Aldrich, München \\
\hline Dinatriumhydrogenphosphat $\left(\mathrm{Na}_{2} \mathrm{HPO}_{4}\right)$ & Roth, Karlsruhe \\
\hline Eisessigsäure & Sigma-Aldrich, München \\
\hline Ethanol & GeReSo GmbH, Dassel-Lauenberg \\
\hline Formaldehyd & Sigma-Aldrich, München \\
\hline Gelatine & Merck, Darmstadt \\
\hline Glucose & Roth, Karlsruhe \\
\hline Glucoseoxidase & Sigma-Aldrich, München \\
\hline Methanol & Roth, Karlsruhe \\
\hline 1-Methyl-4-Phenyl-1,2,3,6- \\
Tetrahydropyridin (MPTP) & Sigma-Aldrich, München \\
\hline 2-Methylbutan & Roth, Karlsruhe \\
\hline Natriumacetat & Roth, Karlsruhe \\
\hline Natriumazid & Sigma-Aldrich, München \\
\hline Natriumchlorid & Roth, Karlsruhe \\
\hline Natriumchlorid-Lösung, isoton $0,9 \%$ & Merck, Darmstadt \\
\hline Natriumdihydrogenphosphat $\left(\mathrm{NaH}_{2} \mathrm{PO}_{4}\right)$ & \\
\hline
\end{tabular}




\begin{tabular}{|l|l|}
\hline Natrium-Ethylendiamintetraessigsäure & Roth, Karlsruhe \\
\hline Natrium-Octansulfonsäure & Roth, Karlsruhe \\
\hline Natronlauge & Roth, Karlsruhe \\
\hline n-Butanol & Merck, Darmstadt \\
\hline Paraformaldehyd (PFA) & Roth, Karlsruhe \\
\hline Perchlorsäure 70\% & Sigma-Aldrich, München \\
\hline Sucrose & Roth, Karlsruhe \\
\hline Thionin-Acetat & Sigma-Aldrich, München \\
\hline Tris & Roth, Karlsruhe \\
\hline Wasserstoffperoxid 30\% & Merck, Darmstadt \\
\hline Xylol & Roth, Karlsruhe \\
\hline Zitronensäure & Sigma-Aldrich, München \\
\hline
\end{tabular}

\subsubsection{Antikörper}

\begin{tabular}{|l|l|}
\hline Biotinylated Anti-Rabbit IgG; 1:200 & Vector Laboratories \\
\hline Normal Goat Serum (NGS) & PAA Laboratories \\
\hline $\begin{array}{l}\text { Rabbit-Anti-Tyrosine-Hydroxylase } \\
\text { Antibody; polyklonal 1:1000 }\end{array}$ & Chemicon international \\
\hline
\end{tabular}

\subsubsection{Puffer und Lösungen}

\begin{tabular}{|l|l|}
\hline Ammoniumchlorid & $40 \mathrm{mg} / 200 \mu \mathrm{l}$ Tris-Puffer \\
\hline Chloroform-Lösung & $480 \mathrm{ml}$ Chloroform \\
& $60 \mathrm{ml}$ 95\% Ethanol \\
& $60 \mathrm{ml}$ Diethylether \\
& Reihenfolge einhalten \\
\hline
\end{tabular}




\begin{tabular}{|c|c|}
\hline Färbelösung & $\begin{array}{l}455 \mathrm{ml} \text { Standardfärbelösung, } 45 \mathrm{ml} \text { Pufferlösung } \\
\text { Pufferlösung: } \\
7 \mathrm{~g} \text { Natriumacetat } \\
2 \mathrm{ml} \text { Eisessigsäure } \\
1100 \mathrm{ml} \text { destilliertes Wasser } \\
\text { Standardfärbelösung: } \\
1 \mathrm{~g} \text { Thionin } \\
100 \mathrm{ml} \text { kochendes destilliertes Wasser }\end{array}$ \\
\hline Formalin-Essig-Lösung: & $\begin{array}{l}1 \mathrm{ml} \text { Eissessigsäure } \\
1 \mathrm{ml} 39 \% \text { Formaldehyd } \\
100 \mathrm{ml} \text { destilliertes Wasser }\end{array}$ \\
\hline Glucose & $200 \mathrm{mg} / 800 \mu \mathrm{l}$ Tris-Puffer \\
\hline Glucoseoxidase & $30 \mathrm{mg} / 10 \mathrm{ml}$ Tris-Puffer \\
\hline $0,1 \mathrm{M}$ PB & $\begin{array}{l}10,9 \mathrm{~g} / \mathrm{l} \text { Dinatriumhydrogenphosphat }\left(\mathrm{Na}_{2} \mathrm{HPO}_{4}\right) \\
3,14 \mathrm{~g} / \mathrm{l} \text { Natriumdihydrogenphosphat }\left(\mathrm{NaH}_{2} \mathrm{PO}_{4}\right) \\
\mathrm{pH} 7,2-7,4\end{array}$ \\
\hline $0,2 \mathrm{M}$ PB & $\begin{array}{l}21,8 \mathrm{~g} / \mathrm{l} \text { Dinatriumhydrogenphosphat }\left(\mathrm{Na}_{2} \mathrm{HPO}_{4}\right) \\
6,28 \mathrm{~g} / \mathrm{l} \text { Natriumdihydrogenphosphat }\left(\mathrm{NaH}_{2} \mathrm{PO}_{4}\right) \\
\mathrm{pH} 7,2-7,4\end{array}$ \\
\hline $0,1 \mathrm{M}$ PBS & $\begin{array}{l}10,9 \mathrm{~g} / \mathrm{l} \text { Dinatriumhydrogenphosphat }\left(\mathrm{Na}_{2} \mathrm{HPO}_{4}\right) \text {, } \\
3,14 \mathrm{~g} / \mathrm{l} \text { Natriumdihydrogenphosphat }\left(\mathrm{NaH}_{2} \mathrm{PO}_{4}\right) \text {, } \\
9 \mathrm{~g} \mathrm{NaCl} \\
0,1 \% \mathrm{Natriumazid} \\
\mathrm{pH} 7,2-7,4\end{array}$ \\
\hline $0,1 \mathrm{M}$ TBS & $12,11 \mathrm{~g} / \mathrm{l} \mathrm{Tris} ; 9 \mathrm{~g} / \mathrm{l} \mathrm{NaCl} ; \mathrm{pH}$ 7,2-7,4 \\
\hline Tris-Puffer & $\begin{array}{l}12,11 \mathrm{~g} / \mathrm{l} \text { Tris } \\
\mathrm{pH} \mathrm{7,6}\end{array}$ \\
\hline
\end{tabular}




\subsubsection{Kits}

\begin{tabular}{|l|l|}
\hline ABC Kit Elite Standard PK-6100 & Vector Laboratories \\
\hline ABC Kit Standard PK 4000 & Vector Laboratories \\
\hline
\end{tabular}

\subsubsection{Verbrauchsmaterial}

\begin{tabular}{|l|l|}
\hline Einbettmedium & Jung, Leica Instruments GmbH, Nussloch \\
\hline Entellan & Merck, Darmstadt \\
\hline Eppendorfgefäße 1,5 ml & Eppendorf, Hamburg \\
\hline Immersionsöl & Merck, Darmstadt \\
\hline Injektionskanüle Sterican & Braun, Melsungen \\
\hline Injektiosnspritze Omnifix & Braun, Melsungen \\
\hline Natriumhypochlorit & $\begin{array}{l}\text { Danklorix } \\
{ }^{\circledR} ;\end{array}$ Colgate Palmolive GmbH, \\
\hline Nitril-Handschuhe, Nitra Tex & Ansell, München \\
\hline Objektträger (76x26 mm) & Menzel, Braunschweig \\
\hline Pipettenspitzen & Sarstedt, Nümbrecht \\
\hline $\begin{array}{l}\text { Spitzen für Multipipette, Combitips } \\
12,5 \text { ml, Combitips plus } 50 \text { ml }\end{array}$ & Eppendorf, Hamburg \\
\hline Wellplatten 12er/ 48er & Corning incorporated, NY, USA \\
\hline
\end{tabular}

\subsubsection{Geräte}

\begin{tabular}{|l|l|}
\hline Feinwaage & Sartorius, Göttingen \\
\hline Gefriermikrotom, CM 3050s & Leica Microsystems GmbH, Nussloch \\
\hline HPLC, P580A & Gynkotek \\
\hline
\end{tabular}




\begin{tabular}{|l|l|}
\hline Magnetrührer & Heidolph Instruments, Schwabach \\
\hline Mikroskop, Axioskop 2 & Zeiss, Jena \\
\hline Mikroskop, DMI 6000 B & Leica Microsystems GmbH, Nussloch \\
\hline Multipipette, Ripette & Ritter, Schwabmünchen \\
\hline pH-Meter & SCHOTT Instruments, Mainz \\
\hline Pipette & Eppendorf, Hamburg \\
\hline Schüttler, Rotamax 120 & Heidolph Instruments, Schwabach \\
\hline Trockenschrank Haraeus & Thermo Scientific, Karlsruhe \\
\hline Ultraschallhomogenisator, Sonoplus & Bandelin, Berlin \\
\hline Zentrifuge 1-15k & Sigma, Osterode \\
\hline
\end{tabular}

\subsubsection{Programme}

\begin{tabular}{|l|l|}
\hline Chromeleon 6.60 & Gynkotek, Germering \\
\hline GraphPad Prism 4.0 & GraphPad Software, San Diego, USA \\
\hline Image J, Version 1.63 B & Wayne Rasband, USA \\
\hline Scion Image 4.0.3.2 & $\begin{array}{l}\text { Scion Corporation; Frederick, Maryland, } \\
\text { MD, USA }\end{array}$ \\
\hline Stereoinvestigator Software & MicroBrightField Bioscience, Magdeburg \\
\hline
\end{tabular}




\section{Ergebnisse}

\subsection{Versuchstiere}

Verwendet wurden C57BL/6-Mäuse der Genotypen DAT-Cre, RET ${ }^{1 \mathrm{x}}$ und DAT$\mathrm{RET}^{\mathrm{Ix} / \mathrm{x}}$. Die Versuchstiere wurden an 5 aufeinander folgenden Tagen mit jeweils 30 mg/kg KG MPTP behandelt und nach 14 Tagen getötet. Die Behandlung der NaClMäuse erfolgte mit einem äquivalenten Volumen 0,9\% NaCl-Lösung.

\subsection{Der Effekt von MPTP auf dopaminerge Neurone der SNpc}

Um den Effekt von MPTP auf die SNpc zu untersuchen, wurden zur Quantifizierung dopaminerger Neurone die TH-positiven Zellen in der SNpc ausgezählt (OpticalFractionator-Methode). Da es zu einer Herunterregulation von TH nach MPTP kommen kann, wurden zusätzlich alle Neurone (Nissl-positive Zellen) in der SNpc ausgezählt (siehe 2.5.5).

\subsubsection{Der Effekt von MPTP auf TH-positive Zellen der SNpc}

Die Auswertung der $\mathrm{NaCl}$-behandelten Tiere ergab keinen signifikanten Unterschied in der Anzahl der TH-positiven Zellen zwischen den einzelnen Genotypen DAT-Cre $(9,130 \pm 942), \operatorname{RET}^{\mid x}(9,650 \pm 556)$ und DAT-RET ${ }^{\mid x / 1 x}(8,580 \pm 460)$.

Die Quantifizierung der MPTP-behandelten Mäuse ergab ebenfalls keinen signifikanten Unterschied in der Anzahl der TH-positiven Zellen zwischen den Genotypen DAT-Cre $(4,256 \pm 370), \operatorname{RET}^{1 x}(4,390 \pm 938)$ und DAT-RET ${ }^{\mid x / x}(4,350 \pm$ 266).

Im Vergleich zu den NaCl-behandelten Genotypen kam es 14 Tage nach der letzten MPTP-Injektion bei allen Genotypen zu einer ca. 50\%-igen signifikanten Erniedrigung der TH-positiven Zellen ( $p<0,001$; ANOVA) (Tab. 5). 


\begin{tabular}{|l|l|l|l|}
\hline Genotyp & Injektion & TH-positive Zellen & Nissl- positive Zellen \\
\hline \multirow{2}{*}{ DAT-Cre } & $\mathrm{NaCl}$ & $9,130 \pm 942$ & $12,720 \pm 1,780$ \\
\cline { 2 - 4 } & MPTP & $4,256 \pm 370$ & $6,563 \pm 732$ \\
\hline RET $^{\mid \mathbf{x}}$ & $\mathrm{NaCl}$ & $9,650 \pm 556$ & $13,640 \pm 1,021$ \\
\cline { 2 - 4 } & MPTP & $4,390 \pm 938$ & $7,570 \pm 562$ \\
\hline \multirow{2}{*}{ DAT-RET } & NaCl & $8,580 \pm 460$ & $11,940 \pm 1,029$ \\
& MPTP & $4,350 \pm 266$ & $6,700 \pm 359$ \\
\cline { 2 - 4 } & & & \\
\hline
\end{tabular}

Tab. 5 Stereologische Quantifizierung von TH-positiven und Nissl-positiven Zellen in der SNpc Zum Nachweis der Degeneration wurden die Gehirnschnitte durch eine TH- und Nissl-Färbung doppelt gefärbt. Die stereologische Auswertung erfolgte mit Hilfe des Stereoinvestigator (MircroBrightField; USA) 14 Tage nach der letzen MPTP-Injektion. Die Werte beziehen sich auf die durchschnittliche Gesamtzahl der gezählten Zellen beider Hemisphären unter Angabe der \pm Standardabweichung. Die Auswertung ergab eine signifikante Erniedrigung von TH-positiven und Nissl-positiven Zellen nach MPTP-Injektion bei allen Genotypen ( $p<0,001$; ANOVA).

Analog zur stereologischen Quantifizierung (Tab. 5) zeigte die photographische Übersicht (Abb. 5) einen deutlichen Untergang von TH-positiven Zellen in der SNpc.
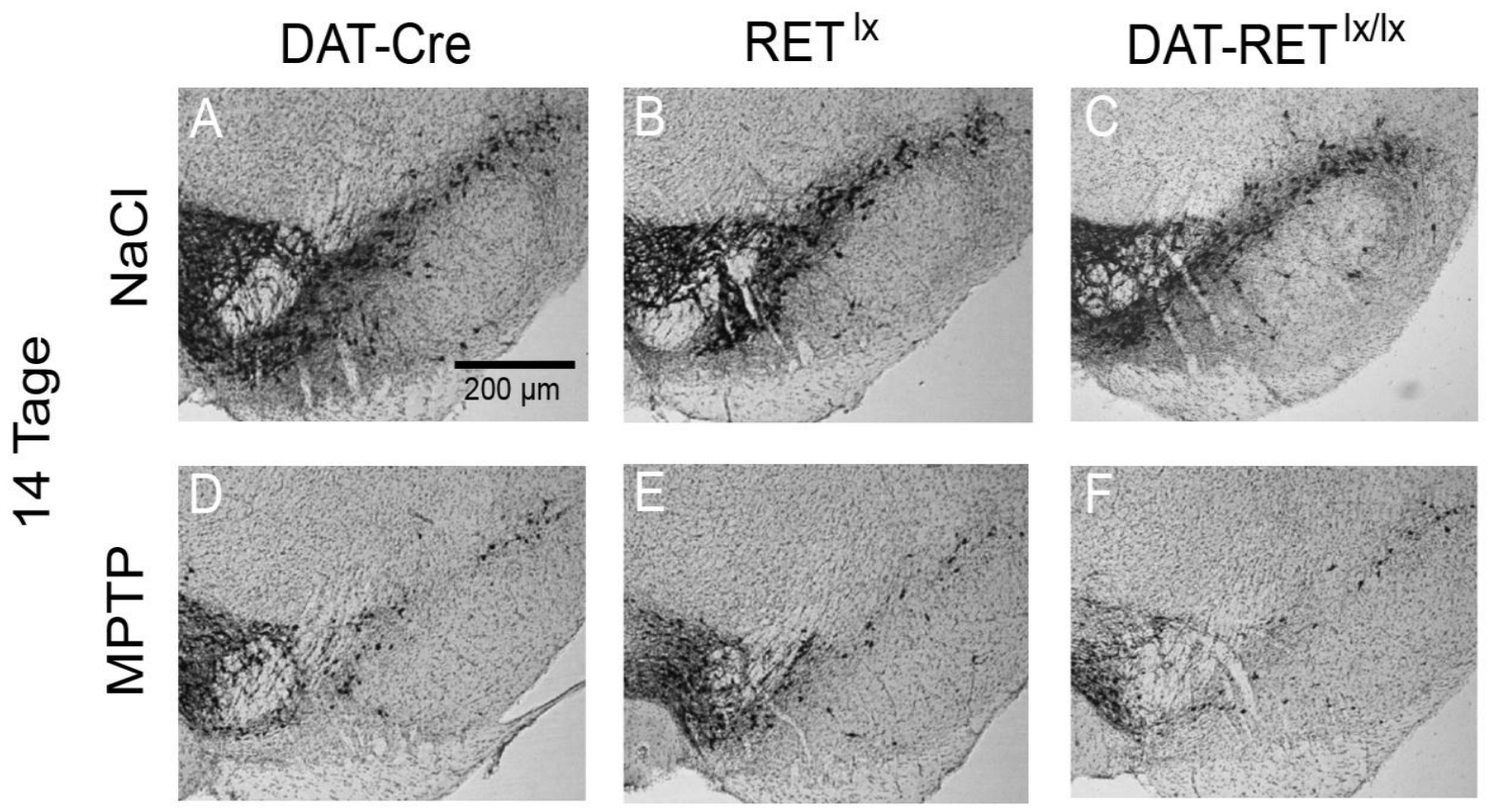

Abb. 5 MPTP-induzierter Verlust von TH-positiv gefärbten Zellen in der SNpc 
Die $30 \mu \mathrm{m}$ dicken Schnitte liegen auf der Höhe des Bregma $(-3,52 \mathrm{~mm})$. Es konnte kein Unterschied in der Anzahl der TH-positiven Zellen der mit NaCl-behandelten Genotypen DAT-Cre, RET ${ }^{1 \mathrm{x}}$ und DATRET $^{|x| x}$ detektiert werden (A-C). 14 Tage nach MPTP-Behandlung kam es zu einer deutlichen Erniedrigung in der Anzahl der TH-positiven Zellen im Vergleich zu NaCl-behandelten Kontrollen (DF). Die Genotypen DAT-Cre, RET $T^{\mid x}$ und DAT-RET ${ }^{|x| x}$ zeigten untereinander nach MPTP- und NaClBehandlung im photographischen Vergleich keinen wesentlichen Unterschied von TH-positiven Zellen in der SNpc.

\subsubsection{Der Effekt von MPTP auf NissI-positive Zellen der SNpc}

Die stereologische Auswertung der Nissl-positiven Zellen der NaCl-behandelten Mäuse ergab keinen signifikanten Unterschied zwischen den einzelnen Genotypen DAT-Cre $(12,720 \pm 1,780), \operatorname{RET}^{\mid x}(13,640 \pm 1,021)$ und DAT-RET $T^{|x| x}(11,940 \pm$ 1,029).

Der Vergleich von Nissl-positiven Zellen der mit MPTP-behandelten Mäuse erbrachte ebenfalls keinen signifikanten Unterschied zwischen den einzelnen Genotypen DATCre $(6,563 \pm 732), \operatorname{RET}^{\mid x}(7,570 \pm 562)$ und DAT-RET $T^{|x| x}(6,700 \pm 359)$.

Im Vergleich zu den NaCl-behandelten Genotypen kommt es 14 Tage nach der letzten MPTP-Injektion bei allen Genotypen zu einer ca. 53\%-igen signifikanten Erniedrigung der Nissl-positiven Zellen ( $p<0,001$; ANOVA) (Tab. 5).

\subsubsection{Zusammenfassung}

Die Auszählung der TH-positiven und Nissl-positiven Zellen der NaCl-behandelten Mäuse zeigte keinen Unterschied zwischen den einzelnen Genotypen. Eine spontane Degeneration der dopaminergen Neurone konnte somit ausgeschlossen werden. Zudem wurde gezeigt, dass eine Deletion für RET (DAT-RET $T^{\mid x / x}$ ) zu keinem Unterschied in der Entwicklung dopaminerger Neurone führt.

14 Tage nach MPTP-Injektion zeigte sich bei allen Genotypen eine signifikante Erniedrigung der TH-positiven und Nissl-positiven Zellen. Die Deletion des RETRezeptors (DAT-RET $T^{\mid x / x}$ ) führte bei den MPTP-behandelten Mäusen zu keiner erhöhten Vulnerabilität im Vergleich zu den MPTP-behandelten Genotypen DAT-Cre und RET ${ }^{\mid x}$. Die gleichzeitige Erniedrigung von TH-positiven Zellen und Nissl-positiven 
Zellen nach MPTP-Behandlung lässt eine Verminderung in der TH-Expression ausschließen und zeigt den degenerativen Effekt der MPTP-Behandlung mit Verlust dopaminerger Neurone in der SNpc. Da es bei RET-defizienten Mäusen zu keiner vermehrten Toxizität nach MPTP-Gabe kam, vermittelt endogenes GDNF über den RET-Rezeptor keine Protektion dopaminerger Neurone.

\subsection{Der Effekt von MPTP auf die optische Dichte des Striatums und auf die nigrostriatalen Projektionen rostral der SNpc}

Der Verlust von dopaminergen Neuronen in der SNpc durch MPTP führt ebenfalls zu einem axonalen Verlust dieser Zellen. Um diesen Effekt zu untersuchen, wurden die optische Dichte im Striatum und die Anzahl und Fläche von nigrostriatalen Projektionen rostral der SNpc bestimmt.

\subsubsection{Ergebnisse der optischen Dichte TH-positiver Fasern des Striatums}

Verwendet wurden zwölf $30 \mu \mathrm{m}$ dicke TH-gefärbte Gehirnschnitte des Striatums. Der Abstand zwischen den Schnitten betrug $240 \mu \mathrm{m}$. Zur Auswertung wurden die THgefärbten Striata eingescannt und die optische Dichte computergestützt (Scion Image 4.0.3.2 Software) gemessen.

Im photographischen Vergleich der TH-gefärbten striatalen Gehirnschnitte konnte kein Unterschied in der Farbintensität für die Gruppe der mit NaCl-behandelten Genotypen festgestellt werden. Hingegen zeigte sich bei allen mit MPTPbehandelten Genotypen (DAT-Cre, RET ${ }^{\mid x}$ und DAT-RET ${ }^{\mid x / x}$ ) ein erheblicher und gleichmäßiger Intensitätsverlust der striatalen Schnitte (Abb. 6).

Die Messung der optischen Dichte (Abb. 7) der mit NaCl-behandelten Genotypen ergab ebenfalls keinen signifikanten Unterschied zwischen DAT-Cre, RET ${ }^{\mathrm{Ix}}$ und DAT$\operatorname{RET}^{|x /| x}($ ANOVA).

Im Vergleich zur NaCl-Gruppe ergab die Auswertung der mit MPTP-behandelten Tiere (Abb. 7) eine deutliche Erniedrigung in der optischen Dichte für die Genotypen DAT-Cre, RET ${ }^{\mid x}$ und DAT-RET $T^{\mid x / x}(p<0,0001$, ANOVA). 


\section{DAT-Cre RET ${ }^{\mid x} \quad$ DAT-RET ${ }^{|x| x}$}
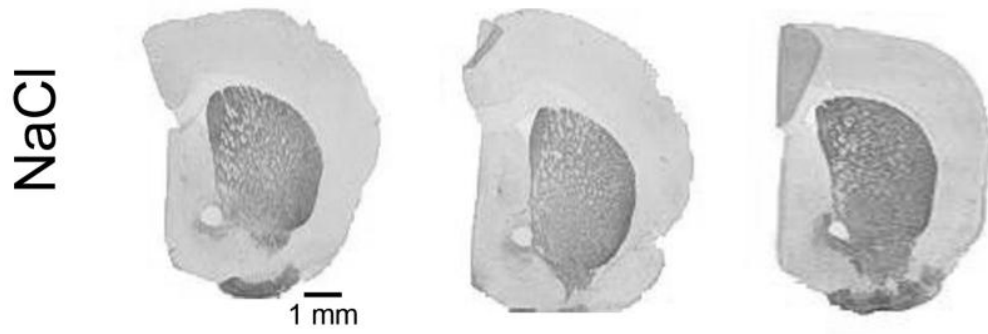

$\stackrel{0}{\stackrel{0}{2}}$
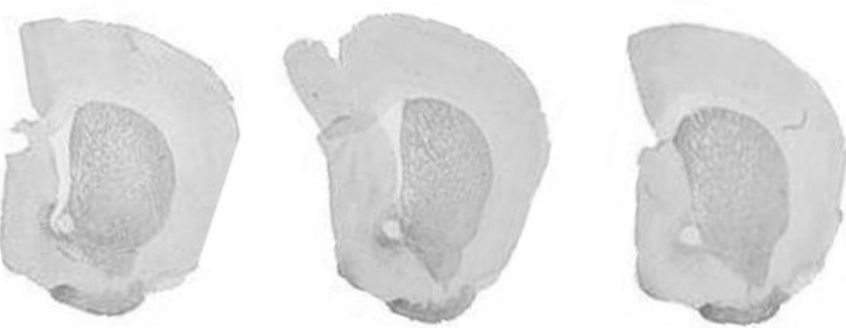

Abb. 6 TH-gefärbte striatale Gehirnschnitte zur Messung der optischen Dichte

Der bildliche Vergleich zeigt eine deutliche Reduktion in der TH-Intensität aller Genotypen 14 Tage nach MPTP-Behandlung. Zwischen den Genotypen DAT-Cre, RET $T^{\mid x}$ und DAT-RET ${ }^{|x| x}$ ergibt sich kein Unterschied in der Intensität nach MPTP-Behandlung.

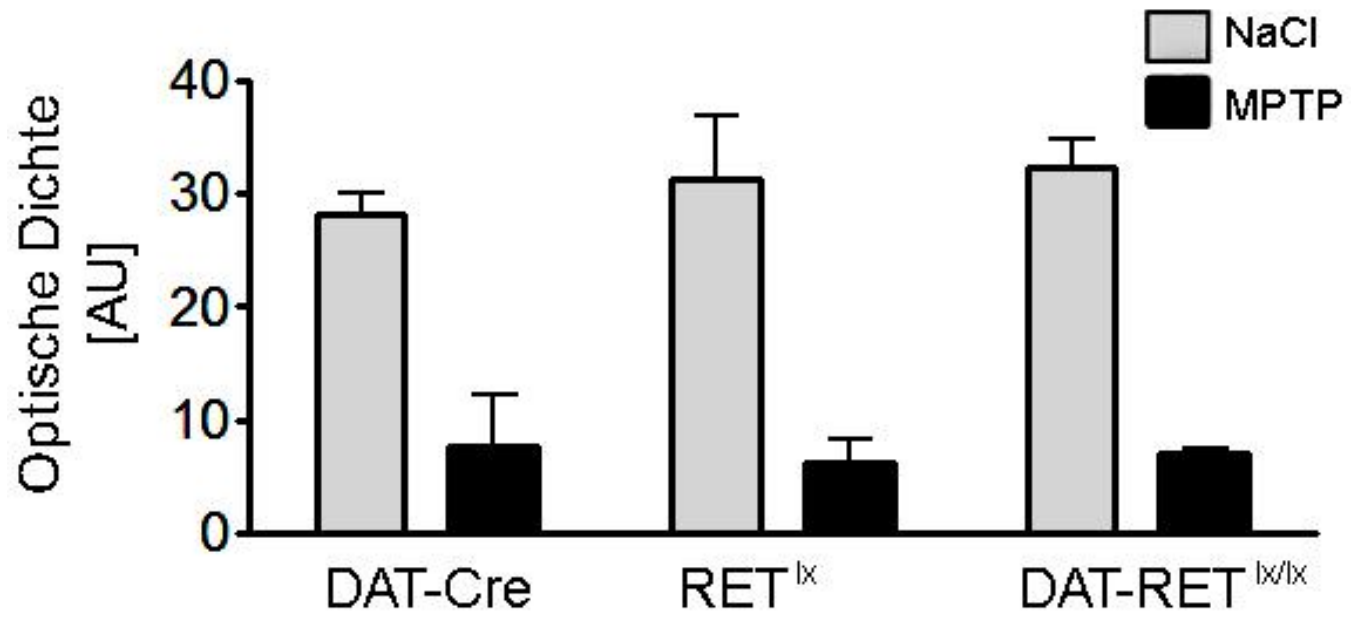

Abb. 7 Bestimmung der optischen Dichte von TH-positiven Fasern des Striatums

Im Vergleich zur NaCl-Gruppe ergab die Auswertung der mit MPTP-behandelten Mäuse 14 Tage nach MPTP-Gabe eine deutliche Erniedrigung der optischen Dichte für die Genotypen DAT-Cre, RET ${ }^{\mathrm{Ix}}$ und $\operatorname{DAT}_{-R^{2}} T^{|x| x}(p<0,0001, A N O V A)$. Werte sind angegeben in willkürlichen Einheiten, arbitrary units $(A U)$. 


\subsubsection{Auswertung TH-positiver nigrostriataler Projektionen rostral der SNpc}

Gemessen wurde die Anzahl und Fläche von nigrostriatalen Projektionen, ausgehend von ihrem Ursprung, ca. 120-240 $\mu$ m rostral der SNpc. Die verwendeten Gehirnschnitte wurden für TH angefärbt und computergestützt ausgewertet.

Die Auswertung der $\mathrm{NaCl}$-behandelten Mäuse ergab keinen Unterschied in der Anzahl und Fläche von nigrostriatalen Projektionen zwischen den Genotypen DATCre, RET ${ }^{\mid x}$ und DAT-RET $T^{|x| x}$ (Abb. 8).

14 Tage nach MPTP-Behandlung konnte eine signifikante Reduktion sowohl in der Anzahl der TH-positiven Projektionen als auch in der Fläche für alle Genotypen beobachtet werden (ANOVA).

(A)

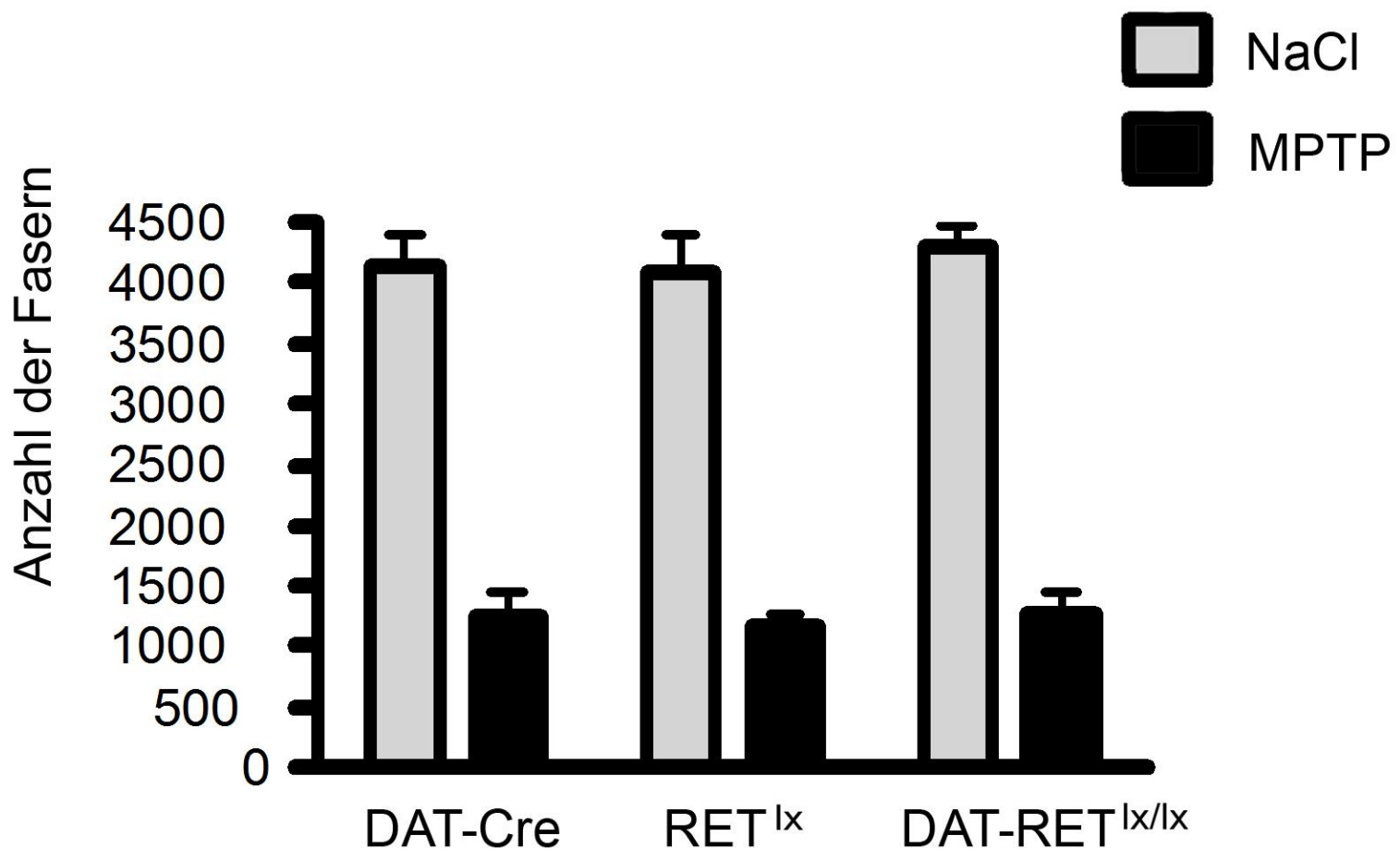


(B)

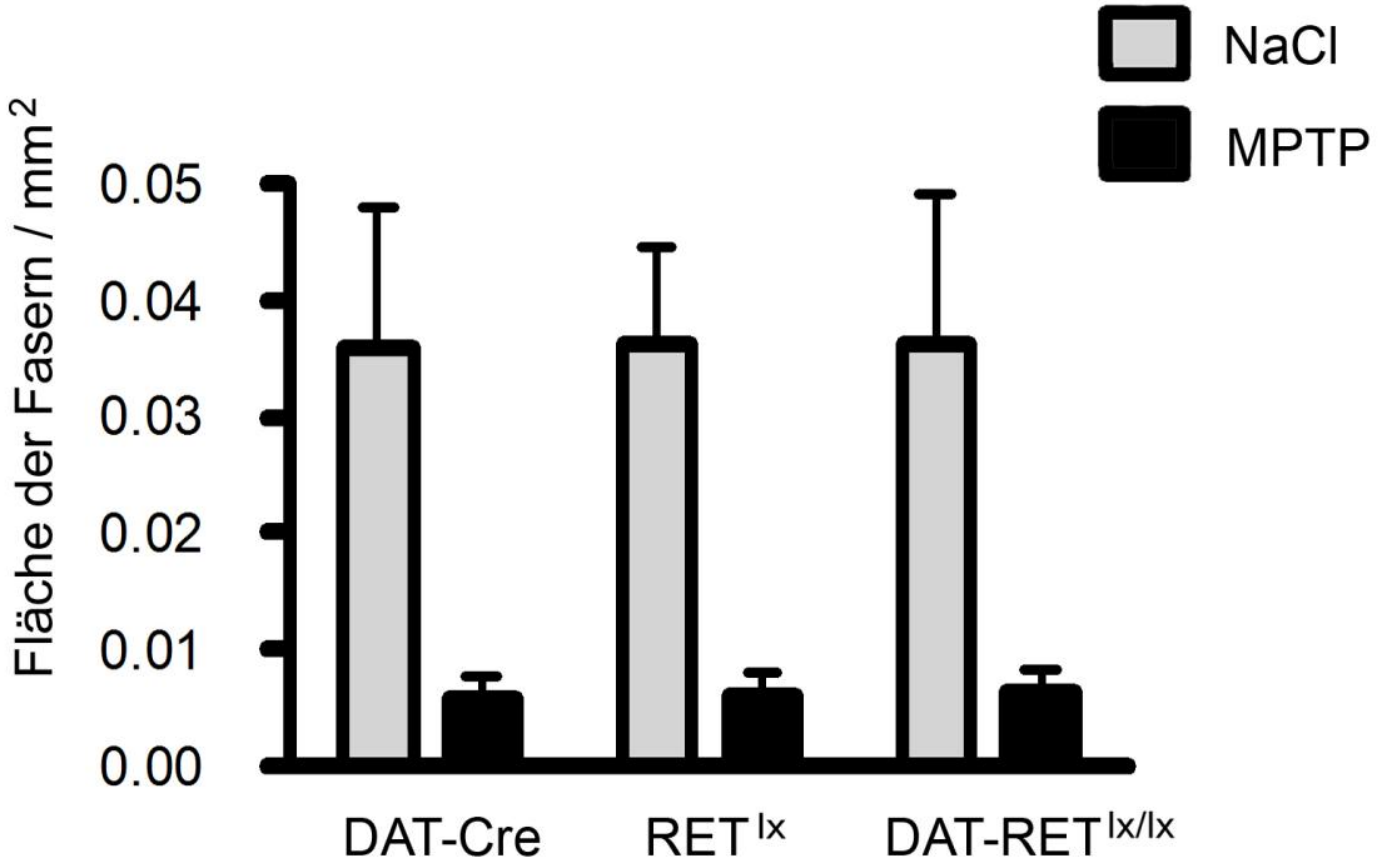

Abb. 8 Bestimmung der Anzahl (A) und Fläche (B) nigrostriataler Projektionen rostral der SNpc Verwendet wurden drei $30 \mu \mathrm{m}$ dicke TH-gefärbte Gehirnschnitte, ca. 120-240 $\mu \mathrm{m}$ rostral der SNpc. 14 Tage nach MPTP-Gabe kam es zu einer gleichmäßigen und deutlichen Erniedrigung in der Anzahl der Fasern $(\mathrm{A})$ und der Fläche in $\mathrm{mm}^{2}(\mathrm{~B})$ aller Genotypen DAT-Cre, RET ${ }^{\mathrm{Ix}}$ und DAT-RET ${ }^{\mathrm{x} / \mathrm{x}}$.

\subsubsection{Zusammenfassung}

$\mathrm{NaCl}$-behandelte Mäuse zeigten sowohl in der optischen Dichte (Abb. 6 und 7) als auch in der Anzahl und Fläche der nigrostriatalen Projektionen (Abb. 8) keinen Unterschied zwischen den Genotypen DAT-Cre, RET ${ }^{\mid x}$ und DAT-RET ${ }^{|x| x}$. Somit führt die Abwesenheit von RET (DAT-RET ${ }^{|x| x}$ ) zu keinem Unterschied in der Ausbildung und Entwicklung von nigrostriatalen Projektionen.

14 Tage nach MPTP-Behandlung ergab die Auswertung der optischen Dichte und der nigrostriatalen Projektionen eine gleichmäßige Erniedrigung aller Genotypen. In beiden Untersuchungen konnte keine erhöhte Vulnerabilität von DAT-RET ${ }^{|x| x}$ gegenüber MPTP im Vergleich zu den Genotypen DAT-Cre und RET ${ }^{1 x}$ detektiert werden. Die Reduktion der optischen Dichte des Striatums und der nigrostriatalen Projektionen rostral der SNpc nach MPTP-Behandlung korreliert mit dem MPTPinduzierten Verlust dopaminerger Neurone der SNpc (3.2.3). Der durch endogenes 
GDNF ausgelöste RET-Signalweg vermittelt keine Protektion nigrostriataler Projektionen gegenüber MPTP-Toxizität.

\subsection{Veränderungen der Katecholaminkonzentrationen nach MPTP- Behandlung}

Die Bestimmung der striatalen Konzentrationen von Dopamin und seiner Metabolite DOPAC und HVA erfolgte mittels HPLC 14 Tage nach der letzten MPTP-Injektion. Angegeben sind die Werte in ng/mg Nassgewebe. Eine Abnahme von striatalen Katecholaminkonzentrationen gilt als zusätzlicher Neurodegenerationsmarker bei Verlust von dopaminergen Neuronen in der SNpc.

\subsubsection{Dopamin}

Die Bestimmung der Dopaminkonzentrationen der $\mathrm{NaCl}$-behandelten Mäuse ergab keinen Unterschied zwischen den Genotypen. 14 Tage nach MPTP-Behandlung kam es bei allen Genotypen zu einer signifikanten Erniedrigung von Dopamin im Striatum (ANOVA). Die RET-defizienten Mäuse (DAT-RET ${ }^{\mid x / x}$ ) zeigten keine erhöhte Vulnerabilität gegenüber MPTP im Vergleich zu den Genotypen DAT-Cre und RET ${ }^{\mathrm{Ix}}$ (Abb. 9).

\subsubsection{DOPAC und HVA}

Die Konzentrationen der Dopaminmetabolite DOPAC und HVA von $\mathrm{NaCl}$ behandelten Mäusen zeigten keinen Unterschied zwischen den einzelnen Genotypen DAT-Cre, RET ${ }^{\mid x}$ und DAT-RET $T^{\mid x / x}$ (Abb. 9).

Es kam 14 Tage nach MPTP-Behandlung zu einer signifikanten Erniedrigung der DOPAC- und HVA-Konzentrationen (ANOVA). Diese Werte korrelieren mit den erniedrigten Dopaminkonzentrationen nach MPTP-Behandlung (Abb. 9). 
A) DOPAMIN

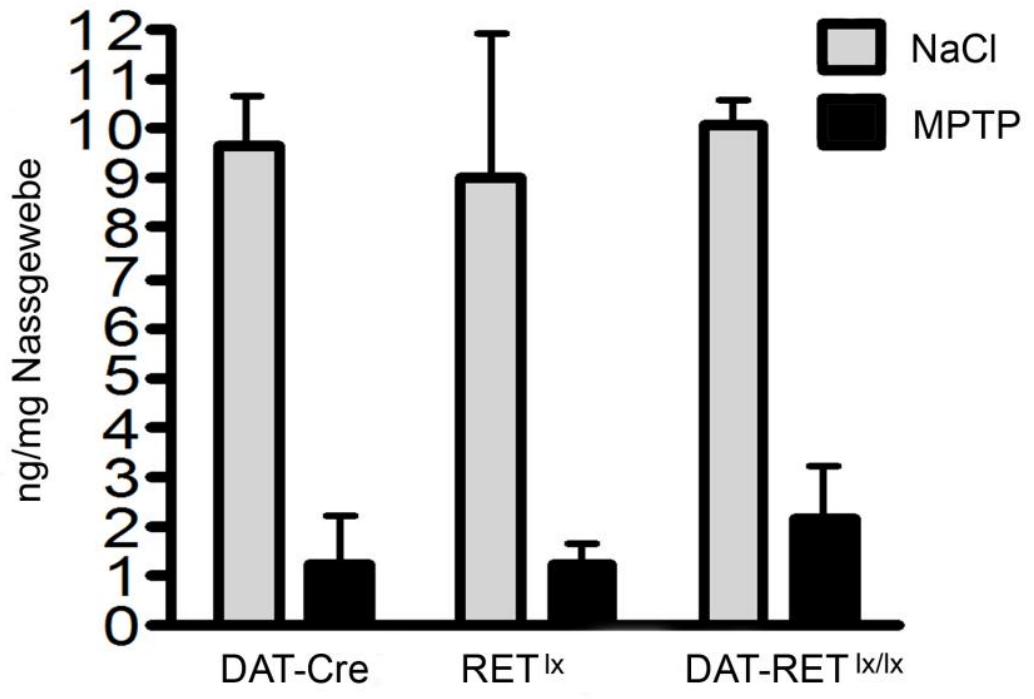

B) DOPAC

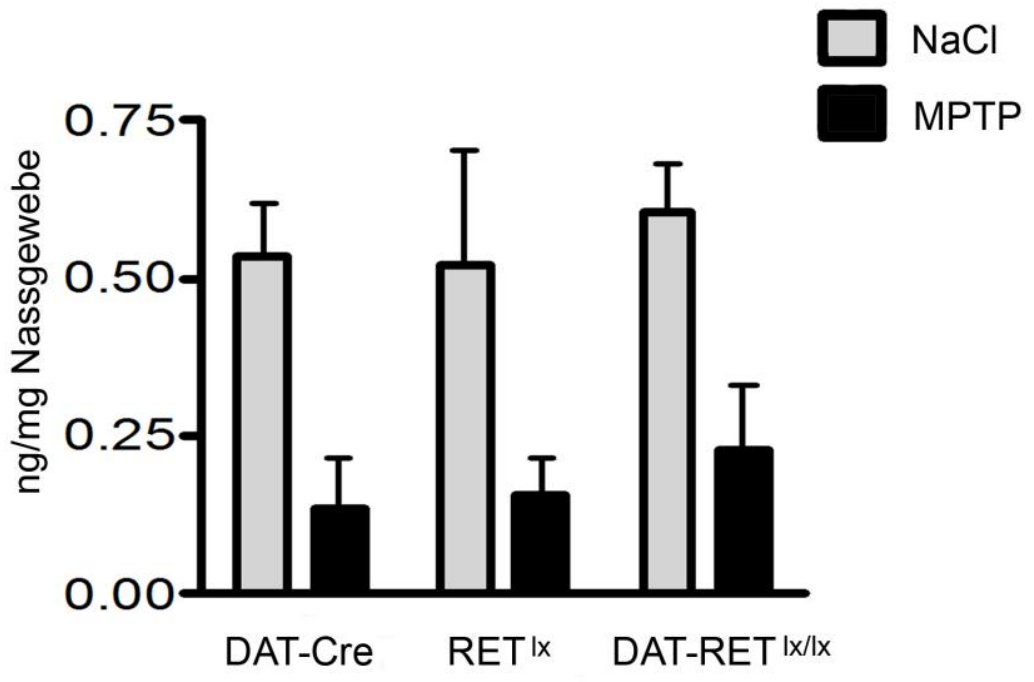


C) HVA

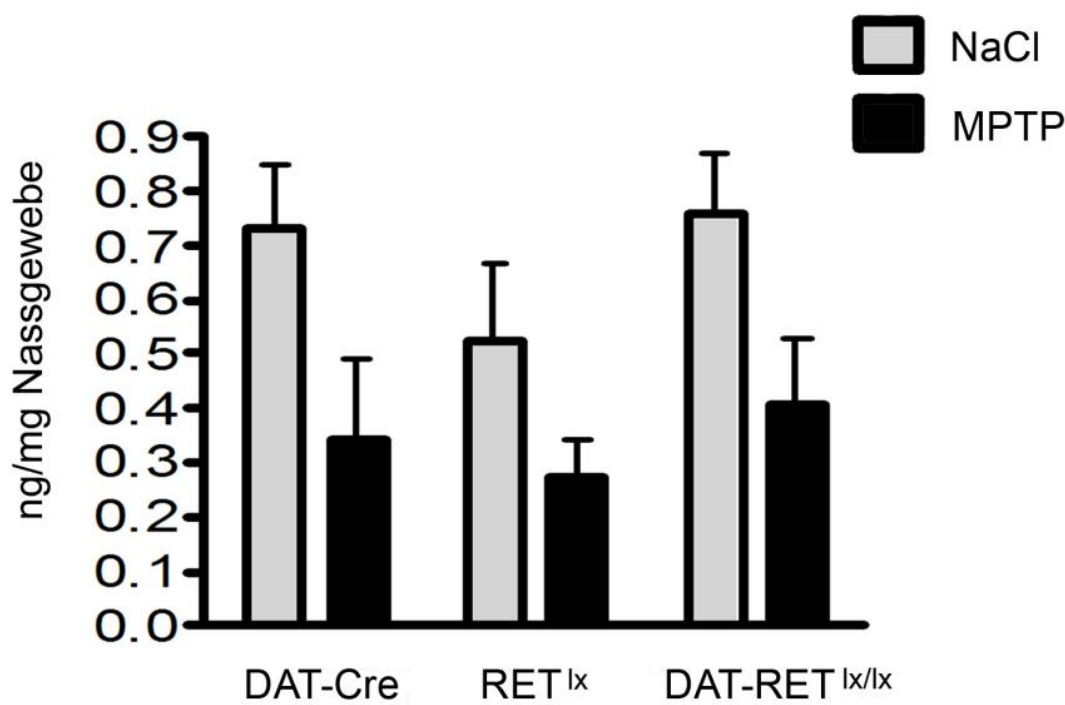

Abb. 9 Konzentrationen von Dopamin (A), DOPAC (B) und HVA (C) im Striatum Angegeben sind die Mittelwerte \pm Standardabweichung in $\mathrm{ng} / \mathrm{mg}$ Nassgewebe. 14 Tage nach MPTPInjektion kam es im Vergleich zu den $\mathrm{NaCl}$-behandelten Mäusen zu einer signifikanten Abnahme der Konzentrationen für Dopamin, DOPAC und HVA in allen drei Genotypen (ANOVA). Zwischen den MPTP-behandelten Genotypen konnte kein signifikanter Unterschied für Dopamin, DOPAC und HVA gemessen werden.

\subsubsection{Dopaminumsatz}

Läsionen des dopaminergen nigrostriatalen Systems, die mehr als $2 / 3$ der SNpc betreffen, führen zu einer erhöhten Synthese, Ausschüttung und Metabolisierung von Dopamin in den von der Schädigung nicht erfassten Neuronen. Ein Maß hierfür sind die erhöhten Dopaminmetabolite im Vergleich zum Dopamingehalt des Striatums (Hefti et al., 1980). Berechnet wird die Dopaminumsatzrate unter Berücksichtigung von DOPAC und HVA im Verhältnis zu Dopamin im Striatum.

\section{Dopaminumsatzrate $=[$ DOPAC $(\mathrm{ng} / \mathrm{mg})+\mathrm{HVA}(\mathrm{ng} / \mathrm{mg})] /$ Dopamin $(\mathrm{ng} / \mathrm{mg})$}

Die Auswertung ergab eine signifikante Erhöhung des Quotienten [DOPAC $(\mathrm{ng} / \mathrm{mg})+$ HVA (ng/mg)] / Dopamin (ng/mg) bei allen drei Genotypen DAT-Cre, RET ${ }^{1 \mathrm{x}}$ und DAT$\mathrm{RET}^{|x| x}$ nach MPTP-Behandlung (Abb. 10). Der Anstieg des striatalen 
Dopaminumsatzes ist ein Zeichen für den gesteigerten präsynaptischen Kompensationsmechanismus beim Verlust dopaminerger Neurone. Zwischen den einzelnen Genotypen bei NaCl- bzw. MPTP-Behandlung konnte kein signifikanter Unterschied aufgezeigt werden (ANOVA).

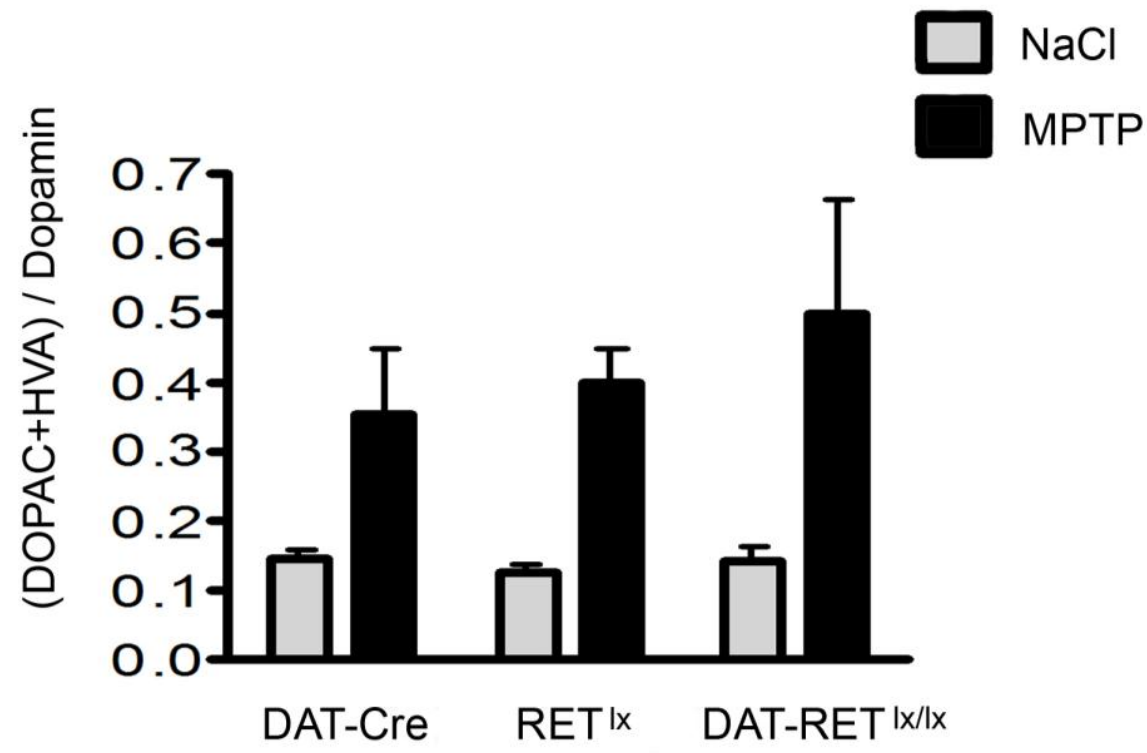

Abb. 10 Ergebnisse des Dopaminumsatzes der Genotypen DAT-Cre, RET ${ }^{1 \mathrm{x}}$ und DAT-RET ${ }^{\mathrm{Ix} / \mathrm{x}}$ Angegeben sind die Mittelwerte \pm Standardabweichung und werden aus den vorangegangenen Werten der HPLC-Messung (Dopamin, DOPAC und HVA) nach der Formel Dopaminumsatzrate = [DOPAC (ng/mg) + HVA (ng/mg)] / Dopamin (ng/mg) berechnet. Im Vergleich zur NaCl-Gruppe ergab die Auswertung der MPTP-behandelten Tiere eine signifikante Erhöhung des striatalen Dopaminumsatzes für die Genotypen DAT-Cre, RET ${ }^{\mid x}$ und DAT-RET $T^{|x| x}$ (ANOVA).

\subsubsection{Zusammenfassung}

MPTP führte zu einer deutlichen Verminderung von Dopamin und seinen Metaboliten im Striatum (Abb. 9) und zu einer Erhöhung der Dopaminumsatzrate (Abb. 10) als Ausdruck eines durch partielle Denervation ausgelösten, kompensatorisch erhöhten Dopaminumsatzes. Weiter bestand kein signifikanter Unterschied im Ausmaß der Erniedrigung der Katecholaminkonzentrationen und in der Erhöhung des striatalen Dopaminumsatzes zwischen den einzelnen Genotypen. 


\subsection{MPTP-Metabolismus}

Um mögliche Unterschiede im MPTP-Metabolismus zwischen den einzelnen Genotypen auszuschließen wurden $\mathrm{MPP}^{+}-$Messungen durchgeführt.

Tiere der verschieden Genotypen DAT-Cre, RET ${ }^{\mathrm{Ix}}$ und DAT-RET ${ }^{\mathrm{I} / \mathrm{Ix}}$ wurden mit 30 mg/kg KG MPTP i.p. injiziert. Die Detektion der striatalen MPP ${ }^{+}$-Level erfolgte mittels HPLC 90 Minuten nach MPTP-Injektion. Werte sind angegeben in ng pro $\mathrm{mg}$ Nassgewebe.

Bei den gemessen Konzentrationen von $\mathrm{MPP}^{+}$konnten zwischen den einzelnen Genotypen DAT-Cre $(n=4 ; 504 \pm 50,5), \operatorname{RET}^{1 x}(n=3 ; 544,6 \pm 53,8)$ und DAT-RET ${ }^{\mid x / x}$ $(n=3 ; 501 \pm 14,2)$ keine Unterschiede festgestellt werden (Tab. 6).

\begin{tabular}{|l|c|c|c|}
\cline { 2 - 4 } \multicolumn{1}{c|}{} & \multicolumn{1}{|c|}{ DAT-Cre } & RET $^{\text {Ix }}$ & \multicolumn{1}{c|}{ DAT-RET $^{\text {Ix/lx }}$} \\
\hline MPP $^{+}$ & $504 \pm 50,5$ & $544,6 \pm 53,8$ & $501 \pm 14,2$ \\
\hline
\end{tabular}

Tab. 6 Messung der MPP ${ }^{+}-$Konzentrationen

Angegeben sind die striatalen Konzentrationen von $\mathrm{MPP}^{+}$als $\mathrm{ng} / \mathrm{mg}$ Nassgewebe \pm Standardabweichung. Die Messung erfolgte 90 Minuten nach MPTP-Injektion mit 30 mg/kg KG.

Die Defizienz des RET-Rezeptors (DAT-RET $T^{\mid x / x}$ ) führte zu keinem Unterschied im MPTP-Metabolismus (Tab. 6) gegenüber den Genotypen DAT-Cre und RET ${ }^{\mid x}$. 


\section{Diskussion}

Zielsetzung der Arbeit war es zu ermitteln, ob der RET-Rezeptor und physiologische Konzentrationen des Neurotrophins GDNF die Toxizität von MPTP beeinflussen und dopaminerge Neurone vor MPTP schützen. Hierfür wurde das MPTP-Mausmodell verwendet. Die spezifische Deletion von RET (DAT-RET $T^{\mid x / x}$ ) in den dopaminergen Neuronen der SNpc machte es möglich, den Einfluss von GDNF unter physiologischen Bedingungen im in-vivo-Modell zu betrachten. GDNF gilt als potenter Wachstumsfaktor, der am Überleben und an der Ausdifferenzierung von dopaminergen Neuronen beteiligt ist (Airaksinen und Saarma 2002; Lin et al. 1993).

\subsection{RET-defiziente Mäuse zeigen kein Defizit in der Entwicklung von dopaminergen Neuronen}

Es konnte kein Unterschied in der Anzahl der dopaminergen Neurone der SNpc (Abb. 5 und Tab. 5), in der optischen Dichte (Abb. 6 und 7) und den Katecholaminkonzentrationen des Striatums (Abb. 9) zwischen den einzelnen Genotypen der NaCl-Mäuse beobachtet werden. Die spezifische Deletion des RETRezeptors (DAT-RET $T^{|x /| x}$ ) in dopaminergen Neuronen führte zu keinem spontanen Verlust dopaminerger Neurone und zu keinem Defizit in der Entwicklung. Auf den ersten Blick widerspricht dies den Befunden, GDNF sei ein wichtiger Wachstums(Oo et al. 2003) und postnataler-Überlebensfaktor (Krieglstein 2004; Sariola und Saarma 2003) für dopaminerge Neurone. Mäuse mit einer kompletten Deletion für RET sind nicht lebensfähig (Sariola und Saarma 2003). Mäuse mit einer selektiven RET-Defizienz zeigen bis zu einem Alter von 12 Monaten eine normale Ausbildung des dopaminergen Systems ohne Zellverlust. Nach dem 12. Lebensmonat kommt es zu einen progressiven Verlust von TH-positiven Neuronen in der SNpc und der nigrostriatalen Projektionen (Jain et al. 2006; Kramer et al. 2007). Um eine spontane Degeneration von dopaminergen Neuronen auszuschließen, wurden Tiere mit einem Lebensalter von 12-16 Wochen untersucht. Das Fehlen eines primären Unterschieds zwischen den Genotypen erleichtert zudem den Vergleich des MPTP-Effekts in 
dieser Arbeit. Der Verlust von dopaminergen Neuronen im höheren Lebensalter lässt vermuten, dass die Transduktion von GDNF über den RET-Rezeptor eher am Erhalt als am Aufbau des dopaminergen Systems beteiligt ist (Kowsky et al. 2007; Kramer et al. 2007).

Die Aktivierung des RET-Rezeptors durch GDNF benötigt die Anwesenheit von GFRa1 (Airaksinen et al. 1999; Baloh et al. 2000). Im gesamten Zentralnervensystem (ZNS) ist GFRa1 weitaus häufiger exprimiert als RET (Trupp et al. 1997; Yu et al. 1998). Es wird vermutet, dass GFRa1 durch ein weiteres transmembranes Protein, unabhängig von RET, an der Modulation von intrazellulären Signalkaskaden beteiligt ist (Poteryaev et al. 1999; Trupp et al. 1999). Die Aktivierung des Neural cell adhesion molecule (NCAM) durch GDNF in Verbindung mit GFRa1 führt zur Aktivierung RET-unabhängiger Signalkaskaden, die an der Migration von Schwann'schen Zellen sowie an der Modulation von axonalem und neuronalem Wachstum beteiligt sind (Paratcha et al. 2003). Ferner wird die präsynaptische GDNF-induzierte neuronale Differenzierung nicht von RET, sondern von GFRa1 vermittelt (Ledda et al. 2007). Diese Erkenntnisse erweitern die Diskussion, dass GDNF möglicherweise auch über andere Rezeptoren als RET Überlebenssignale vermittelt.

\subsection{RET-defiziente Mäuse zeigen keine erhöhte MPTP-Toxizität}

Die $\mathrm{MPP}^{+}$-Messungen zeigten eine gleichmäßige Aufnahme von MPTP in die dopaminergen Neurone (Tab. 6). Die gewebespezifische Deletion des RETRezeptors führte zu keinem Unterschied im MPTP-Metabolismus. Die Behandlung mit MPTP führte zu einem signifikanten Verlust dopaminerger Neurone in der SNpc, gemessen an der Erniedrigung von TH-positiven Zellen um ca. 50\% sowie der Erniedrigung von Nissl-positiven Zellen um ca. $53 \%$ bei allen verwendeten Genotypen (Tab. 5). Bei DAT-RET ${ }^{|x /| x}$ kommt es zu keiner erhöhten MPTP-Toxizität im Vergleich zu den Genotypen DAT-Cre und RET $T^{\mathrm{lx}}$. Bei einfachen Wildtypen mit einem vergleichbaren MPTP-Modell kam es ebenfalls zu einer ca. 50\%-igen Reduktion in der Anzahl TH-positiver Zellen und einer ca. 54\%-igen Reduktion von Nissl-positiven Zellen (Nagel et al. 2008). 
Eine Überexpression von TH-DAT kann zu einer erhöhten MPTP-Toxizität führen (Donovan et al. 1999). Der DAT-Promotor wurde für die selektive Deletion des RETRezeptors verwendet. Westernblot-Analysen und die Auszählung von DAT-positiven Fasern vor MPTP-Gabe zeigten keinen Unterschied zwischen den einzelnen Genotypen (Kowsky et al. 2007). Demnach ist es unwahrscheinlich, dass es Faktoren gab, die den MPTP-Metabolismus beeinflusst haben.

Es wird kontrovers diskutiert, ob MPTP zu einem Untergang von dopaminergen Neuronen führt oder ob es nur zu einer Atrophie und Dysfunktion dieser Zellen kommt (Ourednik et al. 2002). Als Degenerationsmarker für den nigralen Neuronenverlust gelten die Abnahme der TH-Immunreaktivität und die Abnahme der neuronen-spezifischen Nissl-Substanz. Beide Parameter müssen anfangs nicht zwingend miteinander korrelieren, da schwächer geschädigte Zellen ihre TH-Aktivität nur vorübergehend verlieren, sich aber während der nächsten Tage wieder erholen können (Jackson-Lewis et al. 1995). Das Maximum der Degeneration von nigralen Neuronen wird nach 2-7 Tagen erreicht (Sundstrom et al. 1988). Die Untersuchungen in dieser Arbeit ergaben eine gleichmäßige Erniedrigung von $\mathrm{TH}-$ positiven und NissI-positiven Zellen 14 Tage nach MPTP-Injektion bei allen verwendeten Genotypen. 90 Tage nach MPTP-Behandlung zeigten sich die TH- und Nissl-positiven Zellen weiterhin erniedrigt (Kowsky et al. 2007). Als zusätzlicher Degenerationsmarker gilt die Abnahme der Katecholaminkonzentrationen im Striatum nach MPTP-Behandlung. Die Erniedrigung der Katecholaminkonzentrationen nach MPTP-Injektion in dieser Arbeit korreliert mit dem Untergang der dopaminergen Neurone. Zusammenfassend zeigen diese Ergebnisse eine klare Degeneration der dopaminergen Neurone in der SNpc. Eine alleinige Abnahme der TH-Aktivität konnte somit ausgeschlossen werden.

\subsection{GDNF und der Rezeptor RET schützen nicht vor MPTP- induzierter Toxizität dopaminerger Neurone und ihrer striatalen Projektionen}

Die gleichmäßige Reduktion der dopaminergen Neurone, der optischen Dichte und der Katecholaminkonzentrationen im Striatum bei allen verwendeten Genotypen (DAT-Cre, RET $T^{\mid x}$ und DAT-RET $T^{|x| x}$ ) sind ein sicheres Indiz für eine MPTP-induzierte 
Neurodegeneration. Somit wird die MPTP-induzierte Degeneration von dopaminergen Neuronen in der SNpc und deren striatalen Projektionen nicht durch RET-abhängige Signalkaskaden moduliert. Die Aktivierung des RET-Rezeptors durch physiologische Konzentrationen von GDNF schützt dopaminerge Neurone und deren striatale Projektionen nicht vor MPTP. Im Falle einer über den RET-Rezeptor vermittelten Neuroprotektion durch GDNF wäre es zu einer erhöhten Vulnerabilität der DAT-RET ${ }^{|x| x}$-Mäuse gegenüber MPTP gekommen. Protektive Effekte von GDNF gegenüber 6-OHDA-induziertem und Axotomie-induziertem Verlust dopaminerger Neurone gelten als unumstritten (Beck et al. 1995; Bilang-Bleuel et al. 1997; ChoiLundberg et al. 1997). Es gibt jedoch nur wenige Studien, die einen protektiven Effekt von GDNF nach MPTP-Behandlung beschreiben (Kordower et al. 2000; Schober et al. 2007; Tomac et al. 1995). Ferner konnte nachgewiesen werden, dass die alleinige Anwesenheit von GDNF zu keinem protektiven Effekt führt. Die Protektion ist abhängig von der Anwesenheit des transforming growth factor- $B$ (TGFß) (Schober et al. 2007) und dessen Rekrutierung von GFRa1 (Peterziel et al. 2002). In Mäusen mit einem heterozygoten Knockout für GFRa1 kommt es vor und nach MPTP-Behandlung zu einem größeren Verlust von TH-positiven Neuronen und nigrostriatalen Projektionen im Vergleich zu Wildtypen (Boger et al. 2008). Dies verdeutlicht die Komplexizität dieses Systems.

Andere Studien zeigten keinen protektiven Effekt von GDNF bei MPTP-Gabe (Dietz et al. 2006; Eberhardt et al. 2000). Bei Untersuchungen an Mäusen mit einer adenoviralen GDNF-Expression im Striatum konnte kein vermehrtes Überleben von dopaminergen Neuronen gegenüber MPTP festgestellt werden (Eberhardt et al. 2000). Dennoch zeigte sich eine Protektion gegenüber MPTP-induzierter Erniedrigung der striatalen Katecholaminkonzentrationen. Verwendet wurde ein subchronisches MPTP-Modell von $5 \times 30 \mathrm{mg} / \mathrm{kg} \mathrm{KG}$, vergleichbar mit dieser Arbeit. Eine mögliche Erklärung für diesen Effekt wäre die Beteiligung von GDNF an der Erhaltung dopaminerger Terminalen im Striatum. Der Vergleich von Katecholaminen 14 und 90 Tage nach MPTP-Injektion zeigte einen Anstieg von Dopamin und seiner Metabolite bei den Genotypen DAT-Cre und RET ${ }^{1 x}$ (Kowsky et al. 2007). Dieser Anstieg ließ sich bei den DAT-RET ${ }^{|x| x}$ nicht feststellen. Dies lässt vermuten, dass GDNF eher an der Regeneration und der Langzeiterhaltung des dopaminergen Systems beteiligt ist als an einem Schutz der dopaminergen Neurone vor MPTPinduzierter Neurodegeneration. Diskrepanzen zwischen protektiven und nicht- 
protektiven Effekten verschiedener Studien beruhen möglicherweise auf den unterschiedlichen MPTP-Schemata zur Auslösung der Neurodegeneration. Tomac et. al. (1995) verwendeten zwei subkutane Injektionen mit je $40 \mathrm{mg} / \mathrm{kg} \mathrm{KG} \mathrm{MPTP.}$ Schober et. al. (2007) verwendeten Injektionen mit 3x20 mg/kg KG i.p., während bei Kordower et. al. (2000) mit einer $5 \times 30 \mathrm{mg} / \mathrm{kg} \mathrm{KG}$ und intraarteriellen Injektionsform gearbeitet wurde. Eine kurzfristige, hochdosierte MPTP-Gabe führt vermutlich zu einer geringeren MPTP-Toxizität, als die Verwendung eines subchronischen Injektionsregimes von $5 \times 30 \mathrm{mg} / \mathrm{kg} \mathrm{KG} \mathrm{MPTP}$ in dieser Arbeit. Diese Hypothese wird unterstützt durch eine Arbeit von Cheng und Kollegen (Cheng et al. 1998), die mit einem subchronischen MPTP-Schema (35 mg/kg KG) über sieben Tage und wiederholter intrastriataler GDNF-Applikationen nur einen kleinen protektiven Effekt auf den Verlust dopaminerger Neurone der SNpc beobachten konnten, während Tomac et. al. (1995) mit zwei subkutanen Injektionen (40 mg/kg KG) eine vollständige Protektion beobachten konnten. In mesenzephalen Kulturen konnte GDNF ebenfalls dopaminerge Neurone nicht vor MPP+ ${ }^{+}$-Toxizität schützen. Es kam jedoch zu einer Protektion vor weiterem Zellverlust nach Absetzten der MPP ${ }^{+}$ Behandlung und zu einer Wachstumsstimulation von dopaminergen Projektionen (Hou et al. 1996).

Neben GDNF werden noch weitere Neurotrophine für das Überleben und die Modulation von dopaminergen Neuronen verantwortlich gemacht. Der Brain-derived neurotrophic factor (BDNF) vermittelt seine Funktion über den TrkB-Tyrosin-Kinase Rezeptor und ist im gesamten ZNS, inklusive der dopaminergen Neurone und dem Striatum, weit verbreitet (Numan und Seroogy 1999; Seroogy et al. 1994). BDNF moduliert nigrostriatale Funktionen und schützt dopaminerge Neurone bei IPS angewandten Tiermodellen (Guillin et al. 2001; Krieglstein 2004; Levivier et al. 1995). Ferner können andere Neurotrophine wie der Conserved dopamine neurotrophic factor (CDNF) und der Mesencephalic astrocyte-derived neurotrophic factor (MANF) eine weitaus größere Rolle bei der Neuroprotektion von dopaminergen Neuronen spielen als bisher angenommen (Lindholm et al. 2007; Petrova et al. 2003).

In dieser Arbeit zeigte endogenes GDNF über den RET-Signalweg keine Protektion dopaminerger Neurone und deren striataler Projektionen im MPTP-Modell. Im Zusammenhang mit dieser Arbeit wäre es interessant, die Wirkung von exogen zugeführtem GDNF in RET-defizienten Mäuse zu untersuchen. 


\subsection{Das MPTP-Modell}

Die Ergebnisse aus dieser Arbeit gelten für das MPTP-Mausmodell und können im Vergleich zu anderen Modellen abweichen. Das 6-OHDA-Modell ist ebenfalls zur Erforschung des IPS geeignet. Die Behandlung mit 6-OHDA oder MPTP führen zu einem selektiven Untergang von dopaminergen Neuronen. Ihre Mechanismen sind jedoch unterschiedlich und protektive Effekte nach einer Behandlung nicht sicher miteinander vergleichbar (Eberhardt et al. 2000). Das 6-OHDA Modell eignet sich vor allem bei der Untersuchung medikamentöser Behandlungsprinzipien (Beal 2001).

Das MPTP-Mausmodell hat sich als sehr nützlich erwiesen (Heikkila und Sonsalla 1992), da es eine Vielzahl der irreversiblen klinischen, biochemischen und neuropathologischen Effekte des IPS vereinigt (Bloem et al. 1990). Es gilt daher als zuverlässiges Modell, um die Mechanismen der Degeneration von dopaminergen Neuronen zu untersuchen und Strategien zur Restauration von dopaminergen Neuronen zu entwickeln (Beal 2001; Dawson und Dawson 2002; Tatton und Kish 1997). Eine tägliche Applikation von MPTP über 5 Tage bei Mäusen führt zu einem apoptotischen Zelltod in der SNpc (Tatton und Kish 1997), während bei einer kurzfristigen Applikation (4 Injektionen im Abstand von 2 Stunden) keine apoptotischen Vorgänge gefunden werden können (Jackson-Lewis et al. 1995).

Tierexperimentelle Untersuchungen mit MPTP sind für die Grundlagenforschung unerlässlich, bleiben jedoch weiterhin ein Modell. Die Erkenntnisse aus diesen Untersuchungen machen es möglich klinische Studien zur Erforschung des IPS zu entwickeln und neue Therapieansätze zu finden.

\subsection{Klinische Studien mit GDNF}

Aufgrund der anfänglich positiven experimentellen Befunde über einen möglichen protektiven Effekt von GDNF auf dopaminerge Neurone wurden klinische Studien an Menschen mit intrakraniell verabreichtem GDNF durchgeführt.

In zwei kleineren Open-label-Studien wurde GDNF direkt in das Putamen appliziert. Dies führte zu einem signifikanten Anstieg der motorischen Funktionen der UPDRS (Gill et al. 2003; Slevin et al. 2005). Dies konnte in einer randomisierten Doppelblind- 
Studie nicht bestätigt werden und wurde teilweise bei einigen Patienten aufgrund von Komplikationen abgebrochen (Lang et al. 2006).

Pathologische post-mortem Untersuchungen eines Patienten mit multiplen intraventrikulären GDNF-Applikationen zeigten keine signifikante Regeneration von dopaminergen Neuronen in der SNpc (Kordower et al. 1999). Die intraventrikuläre Verabreichung von GDNF führte zu keiner Verbesserung der Symptome, sondern rief schwere Nebenwirkungen wie Übelkeit, Erbrechen, Depressionen und Halluzinationen hervor. Weitere Untersuchungen ergaben, dass die Freisetzung und Diffusion von GDNF ineffizient waren (Kordower et al. 1999; Nutt et al. 2003). Ferner sollten weitere Nebenwirkungen einer intrakraniellen GDNF-Applikation berücksichtigt werden. Bei einigen Patienten kam es zur Bildung von GDNFneutralisierenden Antikörpern sowie zu einer variablen, katheterabhängigen Diffusion von GDNF in das umliegende Gewebe (Sherer et al. 2006; Tatarewicz et al. 2007). Primaten, die einer hohen GDNF-Dosis ausgesetzt waren, zeigten unerwartete zerebelläre Neurodegenerationen (Hovland et al. 2007). Eine solche Neurotoxizität wurde in Patienten bisher noch nicht beobachtet. Für zukünftige Studien mit GDNFApplikationen ist es wichtig, die toxikologische Wirkweise zu kennen. Weiterhin wäre zu klären, inwieweit die Verabreichungsform von GDNF die Neuroprotektion beeinflusst. Die meisten GDNF-Studien beruhen auf intrakraniellen Injektionsformen. Diese Injektionsform birgt immer ein Verletzungsrisiko umliegender Strukturen und das Risiko einer Operation. Eine systemische Applikation ist schwierig, da GDNF aufgrund seiner Molekülgröße nicht durch die Blut-Hirn-Schranke penetrieren kann (Pardridge 2002). In einer Arbeit von Dietz et al. wurde eine Methode entwickelt, um dieses Problem zu umgehen. Dabei wurde GDNF mit einem CPP fusioniert und dadurch die Blut-Hirn-Schranke überwunden. Es kam zu einer Anreicherung von GDNF in dopaminergen Neuronen. Nach einer anschließenden MPTP-Injektion (5×28 $\mathrm{mg} / \mathrm{kg} \mathrm{KG)} \mathrm{konnte} \mathrm{jedoch} \mathrm{kein} \mathrm{neuroprotektiver} \mathrm{Effekt} \mathrm{von} \mathrm{dopaminergen}$ Neuronen beobachtet werden. Eine solche Verabreichungsform ist zudem immer durch die Löslichkeit des Proteins und dessen maximaler Volumendosis limitiert (Dietz et al. 2006). 


\subsection{Axonales Sprouting nach MPTP-Injektion}

Sprouting bezeichnet das Auswachsen von striatalen Axonkollateralen. Mögliche Hinweise für einen solchen Prozess lieferten die Untersuchungen an RET-defizienten Mäusen 90 Tage nach MPTP-Injektion (Kowsky et al. 2007). Die Genotypen DATCre und $\mathrm{RET}^{\mathrm{Ix}}$ zeigten einen Anstieg der striatalen TH-positiven Faserdichte und der striatalen Neurotransmitter Dopamin, DOPAC und HVA zwischen Tag 14 und Tag 90 nach MPTP-Gabe. Dieser Anstieg fehlte in RET-defizienten Mäusen (DAT-RET $T^{|x| x}$ ). Alle Genotypen zeigten jedoch eine gleichbleibende Erniedrigung von dopaminergen Neuronen und ihrer nigrostriatalen Projektionen rostral der SNpc zum Zeitpunkt von 14 und 90 Tagen nach MPTP-Injektion. Durch die Messung der nigrostriatalen Fasern rostral der SNpc konnte das Auswachsen neuer Axone von dopaminergen Neuronen der SNpc ausgeschlossen werden (Kowsky et al. 2007). GDNF vermittelt über den RET-Rezeptor die Aussprossung von Axonkollateralen im Striatum. Dies kann eine Erklärung für die Erhaltung von dopaminergen Terminalen bei adenoviraler GDNF-Überexpression sein (Eberhardt et al. 2000). Ob und welche Rolle ein solcher Sprouting-Prozess bei einem an IPS erkrankten Patienten spielt, bleibt bislang unklar.

\subsection{Mögliche weitere Therapieoptionen des IPS}

Die bisherige Therapie des IPS beschränkt sich auf die Behandlung der Symptome und die Herstellung einer weitgehend normalen physiologischen Funktion. Zur symptomatischen Therapie werden dabei heute u.a. L-DOPA, Dopaminagonisten, anticholinerge Substanzen, COMT- und MAO-B-Inhibitoren sowie NMDARezeptorantagonisten eingesetzt (siehe 1.3). Der degenerative Prozess von dopaminergen Neuronen kann durch diese symptomatischen Therapieformen nicht aufgehalten werden. Der Einsatz von Neurotrophinen weckt die Hoffnung den degenerativen Verlauf aufzuhalten und eine mögliche Neuroregeneration zu fördern. Es bedarf jedoch noch weiterer Grundlagenforschung, um diese Therapieoption beim Menschen anzuwenden. Obwohl in dieser Arbeit kein neuroprotektiver Effekt nachgewiesen werden konnte, zeigt ein GDNF-vermitteltes Sprouting (Kowsky et al. 2007) einen möglichen therapeutischen Ansatz. Da bisherige exogen zugeführte 
Verabreichungformen zu kontroversen Ergebnissen mit Nebenwirkungen führten, sollten diese verbessert werden. Eine weitere Möglichkeit wäre eine direkte Überexpression von Neurotrophinen im Gehirn, z.B. durch viralen Gentransfer. Rekombinante adenovirale Vektoren konnten effizient zu einer Langzeit-Expression von verschiedenen Proteinen führen ohne das Überleben, die elektrophysiologischen Funktionen und das Zytoskelett zu beeinflussen (Le Gal La Salle et al. 1993; Slack und Miller 1996). Gentherapeutische Transduktion des Neurotrophins NRTN mit einem adeno-associated type-2 vector-neurturin (AAV2-NRTN) an ParkinsonPatienten zeigte, dass die Behandlung sicher war, gut verträglich und zu einer Verbesserung der motorischen Funktionen führte (Marks et al. 2008). Diese Ergebnisse konnten in einer Doppelblind-Phase-2-Studie nicht bestätigt werden. Es kam zu keiner signifikanten Verbesserung der motorischen Funktionen. Zudem kam es bei 13 von 38 Patienten zu einem Auftreten von schwerwiegenden unerwünschten Ereignissen (Marks et al. 2010). Obwohl lentivirale Vektoren schon mit hoher biologischer und immunologischer Sicherheit konstruiert werden, verbleibt zusätzlich eine hohe psychologische Barriere, um diese bei Patienten einzusetzen (Debyser 2003).

Nach MPTP-Injektion bei Primaten führten lentivirale Vektoren mit einer Überexpression von GDNF zu einer Verbesserung der motorischen Symptome und verhinderten die nigrostriatale Degeneration (Kordower et al. 2000; Palfi et al. 2002). Dieser Effekt konnte bei MPTP-behandelten Mäusen nicht beobachtet werden (Eberhardt et al. 2000). In diesem Zusammenhang wäre es interessant, welchen Effekt eine adenovirale Überexpression von GDNF auf die Neurodegeneration von Mäusen mit einer selektiven Deletion des RET-Rezeptors hat. 


\section{$5 \quad$ Zusammenfassung}

Das idiopathische Parkinson-Syndrom (IPS) ist eine häufige altersassoziierte Erkrankung, die mit der Degeneration dopaminerger Neurone in der Substantia nigra pars compacta (SNpc) einhergeht. Der Verlust dieser Neurone führt im Verlauf zu den typischen Symptomen Akinese, Tremor, Rigor sowie posturaler Instabilität. Die derzeitige Therapie beschränkt sich auf die Behandlung der Symptome, die Degeneration der Neurone kann bisher nicht aufgehalten werden.

Endogene neurotrophe Faktoren regulieren physiologische Apoptosen während der neuronalen Entwicklung, fördern das Wachstum von neuronalen Strukturen und sind an dem postnatalen Erhalt von neuronalen Netzwerken beteiligt.

Die Aktivierung des RET (rearranged during transfection)-Rezeptors durch das Neurotrophin Glial cell line-derived neurotrophic factor (GDNF) wurde in präklinischen Untersuchungen als wichtiger Überlebensfaktor von dopaminergen Neuronen identifiziert. Klinische Studien mit GDNF führten zu widersprüchlichen Resultaten. Um die Wirkungsweise von GDNF über den RET-Rezeptor im Zusammenhang mit neuroprotektiven Eigenschaften genauer zu untersuchen, wurden tierexperimentelle Untersuchungen in einem Parkinson-Modell durchgeführt. Hierfür wurde das Neurotoxin MPTP (1-Methyl-4-Phenyl-1,2,3,6-Tetrahydropyridin) verwendet, welches am besten die neurodegenerativen Vorgänge des IPS reproduziert. Verwendet wurden Mäuse mit einer selektiven RET-Defizienz in dopaminergen Neuronen. Hierzu wurden Mäuse mit einem gefloxten Allel für RET $\left(R E T^{\mid x}\right)$ mit einer Mauslinie verkreuzt, die die Cre-Rekombinase unter Kontrolle des Dopamintransporter (DAT)-Promotors (DAT-Cre) exprimiert. Das Resultat ist eine gewebespezifische Deletion des RET-Rezeptors in dopaminergen Neuronen (DAT$\left.\operatorname{RET}^{|x| x}\right)$.

Die Versuchstiere wurden gewichtsadaptiert an fünf aufeinander folgenden Tagen mit $30 \mathrm{mg} / \mathrm{kg} \mathrm{KG} \mathrm{MPTP}$ oder mit einem äquivalenten Volumen 0,9\% NatriumchloridLösung ( $\mathrm{NaCl}$ ) behandelt. Um die akuten Effekte von GDNF über den RET-Rezeptor auf die dopaminergen Neurone der SNpc im MPTP-Modell bewerten zu können, wurden die Mäuse 14 Tage nach MPTP-Injektion getötet. Es folgte die Bestimmung der dopaminergen Neurone in der SNpc, der optischen Faserdichte und der 
Katecholaminkonzentrationen im Striatum sowie die Anzahl der striatalen Projektionen rostral der SNpc.

Die durchgeführten Untersuchungen zeigten, dass Mäuse mit einer selektiven RETDefizienz keine initialen Defizite oder spontane Degeneration von dopaminergen Neuronen aufwiesen. MPTP führte 14 Tage nach der letzten Injektion zu einem ausgeprägten Verlust dopaminerger Neurone in der SNpc, zu einer deutlichen Erniedrigung der Katecholaminkonzentrationen und der optischen Dichte im Striatum sowie zu einem Verlust von nigrostriatalen Projektionen rostral der SNpc bei allen Genotypen. Zwischen den einzelnen Genotypen bestand kein Unterschied. Die Anwesenheit von RET in den Kontrollen schützt die dopaminergen Neurone daher nicht im Vergleich zu den RET-defizienten Tieren. Daraus lässt sich folgern, dass RET-abhängige Signalkaskaden keine Protektion gegen MPTP-induzierte Degeneration dopaminerger Neurone in der SNpc vermitteln. Die Aktivierung des RET-Rezeptors durch endogenes GDNF reichte nicht aus, um dopaminerge Neurone und deren striatale Projektionen gegenüber MPTP zu schützen.

Zusammenfassend lässt sich sagen, dass der GDNF-Rezeptor RET in dem hier angewendeten MPTP-Mausmodell keine Neuroprotektion vermittelte. Dieses Ergebnis kann möglicherweise helfen, die negativen klinischen Effekte von GDNF bei Patienten mit IPS zu erklären. 


\section{$6 \quad$ Abbildungsverzeichnis}

Abb. 1 Modifizierte Darstellung der Basalganglien nach Lang und Lozano (1998), S.1132

Abb. 2 Modifizierte Darstellung der Basalganglien beim IPS nach Lang und

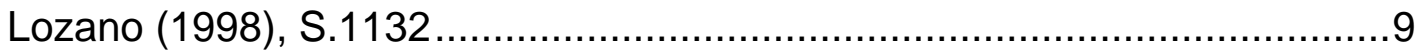

Abb. 3 Schematische Darstellung des Injektionszyklus .19

Abb. 4 Modifizierte Darstellung des Mausgehirns von ventral (A) mit Resektionsanteilen der Gewebeentnahme (B)

Abb. 5 MPTP-induzierter Verlust von TH-positiv gefärbten Zellen in der SNpc ......40

Abb. 6 TH-gefärbte striatale Gehirnschnitte zur Messung der optischen Dichte.....43

Abb. 7 Bestimmung der optischen Dichte von TH-positiven Fasern des Striatums

Abb. 8 Bestimmung der Anzahl (A) und Fläche (B) nigrostriataler Projektionen rostral der SNpc

Abb. 9 Konzentrationen von Dopamin (A), DOPAC (B) und HVA (C) im Striatum .48

Abb. 10 Ergebnisse des Dopaminumsatzes der Genotypen DAT-Cre, RET ${ }^{\mathrm{x}}$ und DAT-RET $T^{\mid x / x}$ 


\section{Tabellenverzeichnis}

Tab. 1 Tabellarische Darstellung der TH-Färbung der SNpc.........................27

Tab. 2 Tabellarische Darstellung der Nissl-Färbung der SNpc..........................29

Tab. 3 Tabellarische Darstellung der striatalen TH-Färbung .............................31

Tab. 4 Tabellarische Darstellung der Entwässerungsreihe von TH-gefärbten

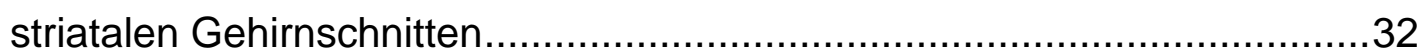

Tab. 5 Stereologische Quantifizierung von TH-positiven und Nissl-positiven Zellen in der SNpc....................................................................... 40

Tab. 6 Messung der MPP ${ }^{+}-$Konzentrationen .................................................. 50 


\section{Publikationen}

Kowsky $\mathrm{S}^{*}$, Poeppelmeyer $\mathrm{C}^{*}$, Kramer ER*, Falkenburger $\mathrm{BH}$, Kruse A, Klein R, Schulz JB (2007): RET signaling does not modulate MPTP toxicity but is required for regeneration of dopaminergic axon terminals. Proc Natl Acad Sci U S A 104, 20049-20054

*gleichberechtigte Erstautoren

Nagel F, Falkenburger BH, Tonges L, Kowsky S, Poeppelmeyer C, Schulz JB, Bahr M, Dietz GP (2008): Tat-Hsp70 protects dopaminergic neurons in midbrain cultures and in the substantia nigra in models of Parkinson's disease. $J$ Neurochem $\underline{105}$, 853-864 


\section{$9 \quad$ Literaturverzeichnis}

Airaksinen MS, Saarma M (2002): The GDNF family: signalling, biological functions and therapeutic value. Nat Rev Neurosci $\underline{3}$, 383-394

Airaksinen MS, Titievsky A, Saarma M (1999): GDNF family neurotrophic factor signaling: four masters, one servant? Mol Cell Neurosci 13, 313-325

Akerud P, Canals JM, Snyder EY, Arenas E (2001): Neuroprotection through delivery of glial cell line-derived neurotrophic factor by neural stem cells in a mouse model of Parkinson's disease. J Neurosci 21, 8108-8118

Alexander GE, Crutcher MD (1990): Functional architecture of basal ganglia circuits: neural substrates of parallel processing. Trends Neurosci 13, 266-271

Andressoo JO, Saarma M (2008): Signalling mechanisms underlying development and maintenance of dopamine neurons. Curr Opin Neurobiol $\underline{18}$, 297-306

Arenas E, Trupp M, Akerud P, Ibanez CF (1995): GDNF prevents degeneration and promotes the phenotype of brain noradrenergic neurons in vivo. Neuron $\underline{15}$, 1465-1473

Baloh RH, Enomoto H, Johnson EM, Jr., Milbrandt J (2000): The GDNF family ligands and receptors - implications for neural development. Curr Opin Neurobiol $\underline{10}$, 103-110

Baudet C, Pozas E, Adameyko I, Andersson E, Ericson J, Ernfors P (2008): Retrograde signaling onto Ret during motor nerve terminal maturation. $J$ Neurosci 28, 963-975

Beal MF (2001): Experimental models of Parkinson's disease. Nat Rev Neurosci $\underline{\text {, }}$ 325-334 
Beck KD, Valverde J, Alexi T, Poulsen K, Moffat B, Vandlen RA, Rosenthal A, Hefti F (1995): Mesencephalic dopaminergic neurons protected by GDNF from axotomy-induced degeneration in the adult brain. Nature $\underline{373}, 339-341$

Benamer TS, Patterson J, Grosset DG, Booij J, de Bruin K, van Royen E, Speelman JD, Horstink MH, Sips HJ, Dierckx RA, et al. (2000): Accurate differentiation of parkinsonism and essential tremor using visual assessment of [123I]-FP-CIT SPECT imaging: the [123I]-FP-CIT study group. Mov Disord 15, 503-510

Bergman H, Wichmann T, DeLong MR (1990): Reversal of experimental parkinsonism by lesions of the subthalamic nucleus. Science $\underline{249}, 1436-1438$

Bernheimer H, Birkmayer W, Hornykiewicz O, Jellinger K, Seitelberger F (1973): Brain dopamine and the syndromes of Parkinson and Huntington. Clinical, morphological and neurochemical correlations. J Neurol Sci $\underline{20}$, 415-455

Bilang-Bleuel A, Revah F, Colin P, Locquet I, Robert JJ, Mallet J, Horellou P (1997): Intrastriatal injection of an adenoviral vector expressing glial-cell-line-derived neurotrophic factor prevents dopaminergic neuron degeneration and behavioral impairment in a rat model of Parkinson disease. Proc Natl Acad Sci U S A $\underline{94}, 8818-8823$

Bindoff LA, Birch-Machin M, Cartlidge NE, Parker WD, Jr., Turnbull DM (1989): Mitochondrial function in Parkinson's disease. Lancet $\underline{2}, 49$

Bloem BR, Irwin I, Buruma OJ, Haan J, Roos RA, Tetrud JW, Langston JW (1990): The MPTP model: versatile contributions to the treatment of idiopathic Parkinson's disease. J Neurol Sci $\underline{97}$, 273-293

Boger HA, Middaugh LD, Zaman V, Hoffer B, Granholm AC (2008): Differential effects of the dopamine neurotoxin MPTP in animals with a partial deletion of the GDNF receptor, GFR alpha1, gene. Brain Res $\underline{1241}$, 18-28

Bohlen und Halbach Ov, Dermietzel R (1999): Methoden der Neurohistologie. 1. Auflage; Spektrum Akademischer Verlag, Heidelberg/Berlin 
Bower JH, Maraganore DM, McDonnell SK, Rocca WA (1999): Incidence and distribution of parkinsonism in Olmsted County, Minnesota, 1976-1990. Neurology $\underline{52}, 1214-1220$

Bowling AC, Beal MF (1995): Bioenergetic and oxidative stress in neurodegenerative diseases. Life Sci $\underline{56}, 1151-1171$

Braak H, Del Tredici K, Rub U, de Vos RA, Jansen Steur EN, Braak E (2003): Staging of brain pathology related to sporadic Parkinson's disease. Neurobiol Aging 24, 197-211

Bravi D, Mouradian MM, Roberts JW, Davis TL, Sohn YH, Chase TN (1994): Wearing-off fluctuations in Parkinson's disease: contribution of postsynaptic mechanisms. Ann Neurol $\underline{36}, 27-31$

Brocks DR (1999): Anticholinergic drugs used in Parkinson's disease: An overlooked class of drugs from a pharmacokinetic perspective. J Pharm Pharm Sci $\underline{2}$, 3946

Burke RE, Cadet JL, Kent JD, Karanas AL, Jackson-Lewis V (1990): An assessment of the validity of densitometric measures of striatal tyrosine hydroxylasepositive fibers: relationship to apomorphine-induced rotations in 6hydroxydopamine lesioned rats. J Neurosci Methods $\underline{35}, 63-73$

Burns RS, Chiueh CC, Markey SP, Ebert MH, Jacobowitz DM, Kopin IJ (1983): A primate model of parkinsonism: selective destruction of dopaminergic neurons in the pars compacta of the substantia nigra by N-methyl-4-phenyl-1,2,3,6tetrahydropyridine. Proc Natl Acad Sci U S A $\underline{80}$, 4546-4550

Cepeda C, Buchwald NA, Levine MS (1993): Neuromodulatory actions of dopamine in the neostriatum are dependent upon the excitatory amino acid receptor subtypes activated. Proc Natl Acad Sci U S A $\underline{90}$, 9576-9580

Chan P, DeLanney LE, Irwin I, Langston JW, Di Monte D (1991): Rapid ATP loss caused by 1-methyl-4-phenyl-1,2,3,6-tetrahydropyridine in mouse brain. $J$ Neurochem $\underline{57}$, 348-351 
Cheng FC, Ni DR, Wu MC, Kuo JS, Chia LG (1998): Glial cell line-derived neurotrophic factor protects against 1-methyl-4-phenyl-1,2,3,6tetrahydropyridine (MPTP)-induced neurotoxicity in C57BL/6 mice. Neurosci Lett 252, 87-90

Chiueh CC, Rauhala P (1998): Free radicals and MPTP-induced selective destruction of substantia nigra compacta neurons. Adv Pharmacol 42, 796800

Choi-Lundberg DL, Lin Q, Chang YN, Chiang YL, Hay CM, Mohajeri H, Davidson BL, Bohn MC (1997): Dopaminergic neurons protected from degeneration by GDNF gene therapy. Science $\underline{275}, 838-841$

Cleeter MW, Cooper JM, Schapira AH (1992): Irreversible inhibition of mitochondrial complex I by 1-methyl-4-phenylpyridinium: evidence for free radical involvement. J Neurochem $\underline{58}, 786-789$

Cosi C, Marien M (1998): Decreases in mouse brain NAD+ and ATP induced by 1 methyl-4-phenyl-1, 2,3,6-tetrahydropyridine (MPTP): prevention by the poly(ADP-ribose) polymerase inhibitor, benzamide. Brain Res $\underline{809}, 58-67$

Cotzias GC, Papavasiliou PS, Gellene R (1969): L-DOPA in parkinson's syndrome. N Engl J Med 281, 272

Cummings JL (1999): Understanding Parkinson disease. JAMA 281, 376-378

Dauer W, Przedborski S (2003): Parkinson's disease: mechanisms and models. Neuron 39, 889-909

Dawson TM, Dawson VL (2002): Neuroprotective and neurorestorative strategies for Parkinson's disease. Nat Neurosci 5 Suppl, 1058-1061

Debyser Z (2003): Biosafety of lentiviral vectors. Curr Gene Ther $\underline{3}$, 517-525

DeLong MR (1990): Primate models of movement disorders of basal ganglia origin. Trends Neurosci 13, 281-285 
DeRijk MC, Launer LJ, Berger K, Breteler MM, Dartigues JF, Baldereschi M, Fratiglioni L, Lobo A, Martinez-Lage J, Trenkwalder C, et al. (2000): Prevalence of Parkinson's disease in Europe: A collaborative study of population-based cohorts. Neurologic Diseases in the Elderly Research Group. Neurology $\underline{54}$, S21-23

Dexter DT, Sian J, Rose S, Hindmarsh JG, Mann VM, Cooper JM, Wells FR, Daniel SE, Lees AJ, Schapira AH, et al. (1994): Indices of oxidative stress and mitochondrial function in individuals with incidental Lewy body disease. Ann Neurol $\underline{35}, 38-44$

Diener HC, Putzki N (2008): Leitlinien für die Diagnostik und Therapie in der Neurologie. 4. überarb. Auflage; Georg Thieme Verlag, Stuttgart

Dietz GP, Valbuena PC, Dietz B, Meuer K, Mueller P, Weishaupt JH, Bahr M (2006): Application of a blood-brain-barrier-penetrating form of GDNF in a mouse model for Parkinson's disease. Brain Res 1082, 61-66

Donovan DM, Miner LL, Perry MP, Revay RS, Sharpe LG, Przedborski S, Kostic V, Philpot RM, Kirstein CL, Rothman RB, et al. (1999): Cocaine reward and MPTP toxicity: alteration by regional variant dopamine transporter overexpression. Brain Res Mol Brain Res $\underline{73}$, 37-49

Durbec P, Marcos-Gutierrez CV, Kilkenny C, Grigoriou M, Wartiowaara K, Suvanto P, Smith D, Ponder B, Costantini F, Saarma M, et al. (1996): GDNF signalling through the Ret receptor tyrosine kinase. Nature $\underline{381}, 789-793$

Eberhardt O, Schulz JB (2003): Apoptotic mechanisms and antiapoptotic therapy in the MPTP model of Parkinson's disease. Toxicol Lett 139, 135-151

Eberhardt O, Coelln RV, Kugler S, Lindenau J, Rathke-Hartlieb S, Gerhardt E, Haid S, Isenmann S, Gravel C, Srinivasan A, et al. (2000): Protection by synergistic effects of adenovirus-mediated X-chromosome-linked inhibitor of apoptosis and glial cell line-derived neurotrophic factor gene transfer in the 1-methyl-4phenyl-1,2,3,6-tetrahydropyridine model of Parkinson's disease. J Neurosci $\underline{20}, 9126-9134$ 
Elizan TS, Yahr MD, Moros DA, Mendoza MR, Pang S, Bodian CA (1989): Selegiline as an adjunct to conventional levodopa therapy in Parkinson's disease. Experience with this type B monoamine oxidase inhibitor in 200 patients. Arch Neurol 46, $1280-1283$

Engelender S, Kaminsky Z, Guo X, Sharp AH, Amaravi RK, Kleiderlein JJ, Margolis RL, Troncoso JC, Lanahan AA, Worley PF, et al. (1999): Synphilin-1 associates with alpha-synuclein and promotes the formation of cytosolic inclusions. Nat Genet 22, 110-114

Fahn S (1999): Parkinson disease, the effect of levodopa, and the ELLDOPA trial. Earlier vs Later L-DOPA. Arch Neurol $\underline{56}, 529-535$

Fahn S, Cohen G (1992): The oxidant stress hypothesis in Parkinson's disease: evidence supporting it. Ann Neurol $\underline{32}$, 804-812

Fahn S, Sulzer D (2004): Neurodegeneration and neuroprotection in Parkinson disease. NeuroRx $\underline{1}, 139-154$

Fahn S, Oakes D, Shoulson I, Kieburtz K, Rudolph A, Lang A, Olanow CW, Tanner C, Marek K (2004): Levodopa and the progression of Parkinson's disease. $N$ Engl J Med 351, 2498-2508

Fearnley JM, Lees AJ (1991): Ageing and Parkinson's disease: substantia nigra regional selectivity. Brain $\underline{114}, 2283-2301$

Forno LS, DeLanney LE, Irwin I, Langston JW (1993): Similarities and differences between MPTP-induced parkinsonsim and Parkinson's disease. Neuropathologic considerations. Adv Neurol $\underline{60}$, 600-608

Gash DM, Zhang Z, Ovadia A, Cass WA, Yi A, Simmerman L, Russell D, Martin D, Lapchak PA, Collins F, et al. (1996): Functional recovery in parkinsonian monkeys treated with GDNF. Nature $\underline{380}, 252-255$

Gasser T (2005): Genetics of Parkinson's disease. Curr Opin Neurol 18, 363-369 
Gelb DJ, Oliver E, Gilman S (1999): Diagnostic criteria for Parkinson disease. Arch Neurol $\underline{56}$, 33-39

Gerfen CR, Engber TM, Mahan LC, Susel Z, Chase TN, Monsma FJ, Jr., Sibley DR (1990): D1 and D2 dopamine receptor-regulated gene expression of striatonigral and striatopallidal neurons. Science 250, 1429-1432

Gerlach M, Youdim MB, Riederer P (1996): Pharmacology of selegiline. Neurology $\underline{47}, \mathrm{~S} 137-145$

German DC, Nelson EL, Liang CL, Speciale SG, Sinton CM, Sonsalla PK (1996): The neurotoxin MPTP causes degeneration of specific nucleus A8, A9 and A10 dopaminergic neurons in the mouse. Neurodegeneration $\underline{5}, 299-312$

Gibb WR, Lees AJ (1988): The relevance of the Lewy body to the pathogenesis of idiopathic Parkinson's disease. J Neurol Neurosurg Psychiatry 51, 745-752

Gill SS, Patel NK, Hotton GR, O'Sullivan K, McCarter R, Bunnage M, Brooks DJ, Svendsen CN, Heywood P (2003): Direct brain infusion of glial cell linederived neurotrophic factor in Parkinson disease. Nat Med $\underline{9}$, 589-595

Guillin O, Diaz J, Carroll P, Griffon N, Schwartz JC, Sokoloff P (2001): BDNF controls dopamine D3 receptor expression and triggers behavioural sensitization. Nature $\underline{411}, 86-89$

Hartmann A, Hunot S, Michel PP, Muriel MP, Vyas S, Faucheux BA, Mouatt-Prigent A, Turmel H, Srinivasan A, Ruberg M, et al. (2000): Caspase-3: A vulnerability factor and final effector in apoptotic death of dopaminergic neurons in Parkinson's disease. Proc Natl Acad Sci U S A $\underline{97}$, 2875-2880

Hefti F, Melamed E, Wurtman RJ (1980): Partial lesions of the dopaminergic nigrostriatal system in rat brain: biochemical characterization. Brain Res $\underline{195}$, 123-137

Heikkila RE, Sonsalla PK (1992): The MPTP-treated mouse as a model of parkinsonism: how good is it? Neurochem Int 20 Suppl, 299S-303S 
Heikkila RE, Nicklas WJ, Vyas I, Duvoisin RC (1985): Dopaminergic toxicity of rotenone and the 1-methyl-4-phenylpyridinium ion after their stereotaxic administration to rats: implication for the mechanism of 1-methyl-4-phenyl1,2,3,6-tetrahydropyridine toxicity. Neurosci Lett $\underline{62}, 389-394$

Heinonen EH, Rinne UK (1989): Selegiline in the treatment of Parkinson's disease. Acta Neurol Scand Suppl $\underline{126}, 103-111$

Henderson CE, Phillips HS, Pollock RA, Davies AM, Lemeulle C, Armanini M, Simmons L, Moffet B, Vandlen RA, Simpson LC, et al. (1994): GDNF: a potent survival factor for motoneurons present in peripheral nerve and muscle. Science 266, 1062-1064

Hou JG, Lin LF, Mytilineou C (1996): Glial cell line-derived neurotrophic factor exerts neurotrophic effects on dopaminergic neurons in vitro and promotes their survival and regrowth after damage by 1-methyl-4-phenylpyridinium. $J$ Neurochem $\underline{66}, 74-82$

Hovland DN, Jr., Boyd RB, Butt MT, Engelhardt JA, Moxness MS, Ma MH, Emery MG, Ernst NB, Reed RP, Zeller JR, et al. (2007): Six-month continuous intraputamenal infusion toxicity study of recombinant methionyl human glial cell line-derived neurotrophic factor ( $r$-metHuGDNF in rhesus monkeys. Toxicol Pathol 35, 1013-1029

Hughes AJ, Ben-Shlomo Y, Daniel SE, Lees AJ (2001): What features improve the accuracy of clinical diagnosis in Parkinson's disease: a clinicopathologic study. 1992. Neurology 57, S34-38

Jackson-Lewis V, Jakowec M, Burke RE, Przedborski S (1995): Time course and morphology of dopaminergic neuronal death caused by the neurotoxin 1methyl-4-phenyl-1,2,3,6-tetrahydropyridine. Neurodegeneration 4, 257-269

Jain S, Golden JP, Wozniak D, Pehek E, Johnson EM, Jr., Milbrandt J (2006): RET is dispensable for maintenance of midbrain dopaminergic neurons in adult mice. J Neurosci 26, 11230-11238 
Janetzky B, Hauck S, Youdim MB, Riederer P, Jellinger K, Pantucek F, Zochling R, BoissI KW, Reichmann H (1994): Unaltered aconitase activity, but decreased complex I activity in substantia nigra pars compacta of patients with Parkinson's disease. Neurosci Lett $\underline{169}$, 126-128

Javitch JA, D'Amato RJ, Strittmatter SM, Snyder SH (1985): Parkinsonism-inducing neurotoxin, N-methyl-4-phenyl-1,2,3,6 -tetrahydropyridine: uptake of the metabolite $\mathrm{N}$-methyl-4-phenylpyridine by dopamine neurons explains selective toxicity. Proc Natl Acad Sci U S A $\underline{82}, 2173-2177$

Javoy-Agid F, Agid Y (1980): Is the mesocortical dopaminergic system involved in Parkinson disease? Neurology $\underline{30}, 1326-1330$

Jenner P, Olanow CW (2006): The pathogenesis of cell death in Parkinson's disease. Neurology $\underline{66}$, S24-36

Joel D, Weiner I (1997): The connections of the primate subthalamic nucleus: indirect pathways and the open-interconnected scheme of basal gangliathalamocortical circuitry. Brain Res Brain Res Rev 23, 62-78

Johnson RG, Jr. (1988): Accumulation of biological amines into chromaffin granules: a model for hormone and neurotransmitter transport. Physiol Rev $\underline{68}, 232-307$

Kaplan DR, Miller FD (2000): Neurotrophin signal transduction in the nervous system. Curr Opin Neurobiol 10, 381-391

Kawaguchi Y, Wilson CJ, Augood SJ, Emson PC (1995): Striatal interneurones: chemical, physiological and morphological characterization. Trends Neurosci $\underline{18}, 527-535$

Kebabian JW, Calne DB (1979): Multiple receptors for dopamine. Nature 277, 93-96

Kirik D, Georgievska B, Bjorklund A (2004): Localized striatal delivery of GDNF as a treatment for Parkinson disease. Nat Neurosci $\underline{7}, 105-110$ 
Kordower JH, Palfi S, Chen EY, Ma SY, Sendera T, Cochran EJ, Mufson EJ, Penn R, Goetz CG, Comella CD (1999): Clinicopathological findings following intraventricular glial-derived neurotrophic factor treatment in a patient with Parkinson's disease. Ann Neurol $\underline{46}, 419-424$

Kordower JH, Emborg ME, Bloch J, Ma SY, Chu Y, Leventhal L, McBride J, Chen EY, Palfi S, Roitberg BZ, et al. (2000): Neurodegeneration prevented by lentiviral vector delivery of GDNF in primate models of Parkinson's disease. Science $\underline{290}, 767-773$

Kornhuber J, Weller M (1997): Psychotogenicity and N-methyl-D-aspartate receptor antagonism: implications for neuroprotective pharmacotherapy. Biol Psychiatry $\underline{41}, 135-144$

Kowall NW, Hantraye P, Brouillet E, Beal MF, McKee AC, Ferrante RJ (2000): MPTP induces alpha-synuclein aggregation in the substantia nigra of baboons. Neuroreport $\underline{11}, 211-213$

Kowsky S, Poppelmeyer C, Kramer ER, Falkenburger BH, Kruse A, Klein R, Schulz JB (2007): RET signaling does not modulate MPTP toxicity but is required for regeneration of dopaminergic axon terminals. Proc Natl Acad Sci U S A $\underline{104}$, 20049-20054

Kramer ER, Knott L, Su F, Dessaud E, Krull CE, Helmbacher F, Klein R (2006): Cooperation between GDNF/Ret and ephrinA/EphA4 signals for motor-axon pathway selection in the limb. Neuron $\underline{50}$, 35-47

Kramer ER, Aron L, Ramakers GM, Seitz S, Zhuang X, Beyer K, Smidt MP, Klein R (2007): Absence of Ret signaling in mice causes progressive and late degeneration of the nigrostriatal system. PLoS Biol $\underline{5}$, e39

Krieglstein K (2004): Factors promoting survival of mesencephalic dopaminergic neurons. Cell Tissue Res $\underline{318}, 73-80$

Lang AE, Lozano AM (1998): Parkinson's disease. Second of two parts. N Engl J Med $\underline{339}, 1130-1143$ 
Lang AE, Gill S, Patel NK, Lozano A, Nutt JG, Penn R, Brooks DJ, Hotton G, Moro E, Heywood P, et al. (2006): Randomized controlled trial of intraputamenal glial cell line-derived neurotrophic factor infusion in Parkinson disease. Ann Neurol $\underline{59}, 459-466$

Langston JW, Ballard P (1984): Parkinsonism induced by 1-methyl-4-phenyl-1,2,3,6tetrahydropyridine (MPTP): implications for treatment and the pathogenesis of Parkinson's disease. Can J Neurol Sci 11, 160-165

Langston JW, Ballard P, Tetrud JW, Irwin I (1983): Chronic Parkinsonism in humans due to a product of meperidine-analog synthesis. Science 219 , 979-980

Langston JW, Forno LS, Tetrud J, Reeves AG, Kaplan JA, Karluk D (1999): Evidence of active nerve cell degeneration in the substantia nigra of humans years after 1-methyl-4-phenyl-1,2,3,6-tetrahydropyridine exposure. Ann Neurol $\underline{46}$, 598605

Larkin M (1999): Parkinson's disease research moves on briskly. Lancet 353, 566

Le Gal La Salle G, Robert JJ, Berrard S, Ridoux V, Stratford-Perricaudet LD, Perricaudet M, Mallet $J$ (1993): An adenovirus vector for gene transfer into neurons and glia in the brain. Science 259, 988-990

Ledda F, Paratcha G, Sandoval-Guzman T, Ibanez CF (2007): GDNF and GFRalpha1 promote formation of neuronal synapses by ligand-induced cell adhesion. Nat Neurosci 10, 293-300

Levi-Montalcini R (1987): The nerve growth factor 35 years later. Science 237, 11541162.

Levivier M, Przedborski S, Bencsics C, Kang UJ (1995): Intrastriatal implantation of fibroblasts genetically engineered to produce brain-derived neurotrophic factor prevents degeneration of dopaminergic neurons in a rat model of Parkinson's disease. J Neurosci $\underline{15}, 7810-7820$ 
Lin LF, Doherty DH, Lile JD, Bektesh S, Collins F (1993): GDNF: a glial cell linederived neurotrophic factor for midbrain dopaminergic neurons. Science $\underline{260}$, 1130-1132

Lindholm P, Voutilainen MH, Lauren J, Peranen J, Leppanen VM, Andressoo JO, Lindahl M, Janhunen S, Kalkkinen N, Timmusk T, et al. (2007): Novel neurotrophic factor CDNF protects and rescues midbrain dopamine neurons in vivo. Nature $\underline{448}, 73-77$

Maher NE, Currie LJ, Lazzarini AM, Wilk JB, Taylor CA, Saint-Hilaire MH, Feldman RG, Golbe LI, Wooten GF, Myers RH (2002): Segregation analysis of Parkinson disease revealing evidence for a major causative gene. Am J Med Genet $\underline{109}, 191-197$

Marini AM, Lipsky RH, Schwartz JP, Kopin IJ (1992): Accumulation of 1-methyl-4phenyl-1,2,3,6-tetrahydropyridine in cultured cerebellar astrocytes. $J$ Neurochem $\underline{58}, 1250-1258$

Markey SP, Johannessen JN, Chiueh CC, Burns RS, Herkenham MA (1984): Intraneuronal generation of a pyridinium metabolite may cause drug-induced parkinsonism. Nature 311, 464-467

Marks WJ, Jr., Ostrem JL, Verhagen L, Starr PA, Larson PS, Bakay RA, Taylor R, Cahn-Weiner DA, Stoessl AJ, Olanow CW, et al. (2008): Safety and tolerability of intraputaminal delivery of CERE-120 (adeno-associated virus serotype 2neurturin) to patients with idiopathic Parkinson's disease: an open-label, phase I trial. Lancet Neurol $\underline{7}, 400-408$

Marks WJ, Jr., Bartus RT, Siffert J, Davis CS, Lozano A, Boulis N, Vitek J, Stacy M, Turner D, Verhagen L, et al. (2010): Gene delivery of AAV2-neurturin for Parkinson's disease: a double-blind, randomised, controlled trial. Lancet Neurol $\underline{9}, 1164-1172$

Mayer RA, Kindt MV, Heikkila RE (1986): Prevention of the nigrostriatal toxicity of 1methyl-4-phenyl-1,2,3,6-tetrahydropyridine by inhibitors of 3,4dihydroxyphenylethylamine transport. J Neurochem 4ㄱ, 1073-1079 
Mayeux R, Denaro J, Hemenegildo N, Marder K, Tang MX, Cote LJ, Stern Y (1992): A population-based investigation of Parkinson's disease with and without dementia. Relationship to age and gender. Arch Neurol $\underline{49}$, 492-497

Merello M, Lees AJ, Webster R, Bovingdon M, Gordin A (1994): Effect of entacapone, a peripherally acting catechol-O-methyltransferase inhibitor, on the motor response to acute treatment with levodopa in patients with Parkinson's disease. J Neurol Neurosurg Psychiatry $\underline{57}$, 186-189

Myllyla VV, Kultalahti ER, Haapaniemi H, Leinonen M (2001): Twelve-month safety of entacapone in patients with Parkinson's disease. Eur J Neurol $\underline{8}, 53-60$

Nagel F, Falkenburger BH, Tonges L, Kowsky S, Poppelmeyer C, Schulz JB, Bahr M, Dietz GP (2008): Tat-Hsp70 protects dopaminergic neurons in midbrain cultures and in the substantia nigra in models of Parkinson's disease. $J$ Neurochem $\underline{105}, 853-864$

Nicklas WJ, Youngster SK, Kindt MV, Heikkila RE (1987): MPTP, MPP+ and mitochondrial function. Life Sci $\underline{40}, 721-729$

Numan S, Seroogy KB (1999): Expression of trkB and trkC mRNAs by adult midbrain dopamine neurons: a double-label in situ hybridization study. J Comp Neurol 403, 295-308

Nutt JG, Burchiel KJ, Comella CL, Jankovic J, Lang AE, Laws ER, Jr., Lozano AM, Penn RD, Simpson RK, Jr., Stacy M, et al. (2003): Randomized, double-blind trial of glial cell line-derived neurotrophic factor (GDNF) in PD. Neurology $\underline{60}$, $69-73$

O'Callaghan JP, Miller DB, Reinhard JF, Jr. (1990): Characterization of the origins of astrocyte response to injury using the dopaminergic neurotoxicant, 1-methyl-4phenyl-1,2,3,6-tetrahydropyridine. Brain Res $\underline{521}, 73-80$

Obeso JA, Rodriguez-Oroz MC, Rodriguez M, Lanciego JL, Artieda J, Gonzalo N, Olanow CW (2000): Pathophysiology of the basal ganglia in Parkinson's disease. Trends Neurosci $\underline{23}$, S8-19 
Oertel WH, Wolters E, Sampaio C, Gimenez-Roldan S, Bergamasco B, Dujardin M, Grosset DG, Arnold G, Leenders KL, Hundemer HP, et al. (2006): Pergolide versus levodopa monotherapy in early Parkinson's disease patients: The PELMOPET study. Mov Disord 21, 343-353

Olanow CW (2007): The pathogenesis of cell death in Parkinson's disease--2007. Mov Disord 22 Suppl 17, S335-342

Oo TF, Kholodilov N, Burke RE (2003): Regulation of natural cell death in dopaminergic neurons of the substantia nigra by striatal glial cell line-derived neurotrophic factor in vivo. J Neurosci $\underline{23}, 5141-5148$

Ourednik J, Ourednik V, Lynch WP, Schachner M, Snyder EY (2002): Neural stem cells display an inherent mechanism for rescuing dysfunctional neurons. Nat Biotechnol 20, 1103-1110

Palfi S, Leventhal L, Chu Y, Ma SY, Emborg M, Bakay R, Deglon N, Hantraye P, Aebischer P, Kordower JH (2002): Lentivirally delivered glial cell line-derived neurotrophic factor increases the number of striatal dopaminergic neurons in primate models of nigrostriatal degeneration. J Neurosci $\underline{22}, 4942-4954$

Paratcha G, Ledda F, Ibanez CF (2003): The neural cell adhesion molecule NCAM is an alternative signaling receptor for GDNF family ligands. Cell 113, 867-879

Pardridge WM (2002): Neurotrophins, neuroprotection and the blood-brain barrier. Curr Opin Investig Drugs $\underline{3}, 1753-1757$

Paxinos G, Franklin KBJ (2004): The Mouse Brain in Stereotaxic Coordinates. Second Edition; Elsevier Science, San Diego, USA

Pennathur S, Jackson-Lewis V, Przedborski S, Heinecke JW (1999): Mass spectrometric quantification of 3-nitrotyrosine, ortho-tyrosine, and o,o'dityrosine in brain tissue of 1-methyl-4-phenyl-1,2,3, 6-tetrahydropyridinetreated mice, a model of oxidative stress in Parkinson's disease. J Biol Chem $\underline{274}, 34621-34628$ 
Peterziel $\mathrm{H}$, Unsicker $\mathrm{K}$, Krieglstein $\mathrm{K}$ (2002): TGFbeta induces GDNF responsiveness in neurons by recruitment of GFRalpha1 to the plasma membrane. J Cell Biol 159, 157-167

Petrova P, Raibekas A, Pevsner J, Vigo N, Anafi M, Moore MK, Peaire AE, Shridhar V, Smith DI, Kelly J, et al. (2003): MANF: a new mesencephalic, astrocytederived neurotrophic factor with selectivity for dopaminergic neurons. $J \mathrm{Mol}$ Neurosci 20, 173-188

Poteryaev D, Titievsky A, Sun YF, Thomas-Crusells J, Lindahl M, Billaud M, Arumae U, Saarma M (1999): GDNF triggers a novel ret-independent Src kinase family-coupled signaling via a GPI-linked GDNF receptor alpha1. FEBS Lett $\underline{463}, 63-66$

Przedborski S, Jackson-Lewis V (1998): Mechanisms of MPTP toxicity. Mov Disord 13 Suppl 1, 35-38

Przedborski S, Vila M (2003): The 1-methyl-4-phenyl-1,2,3,6-tetrahydropyridine mouse model: a tool to explore the pathogenesis of Parkinson's disease. Ann NY Acad Sci 991, 189-198

Przedborski S, Jackson-Lewis V, Djaldetti R, Liberatore G, Vila M, Vukosavic S, Almer G (2000): The parkinsonian toxin MPTP: action and mechanism. Restor Neurol Neurosci 16, 135-142

Przedborski S, Jackson-Lewis V, Naini AB, Jakowec M, Petzinger G, Miller R, Akram $M$ (2001): The parkinsonian toxin 1-methyl-4-phenyl-1,2,3,6-tetrahydropyridine (MPTP): a technical review of its utility and safety. $J$ Neurochem $\underline{76}, 1265-$ 1274

Ramsay RR, Krueger MJ, Youngster SK, Gluck MR, Casida JE, Singer TP (1991): Interaction of 1-methyl-4-phenylpyridinium ion (MPP+) and its analogs with the rotenone/piericidin binding site of $\mathrm{NADH}$ dehydrogenase. J Neurochem $\underline{56}$, 1184-1190 
Ransom BR, Kunis DM, Irwin I, Langston JW (1987): Astrocytes convert the parkinsonism inducing neurotoxin, MPTP, to its active metabolite, MPP+. Neurosci Lett $\underline{75}$, 323-328

Rascol O, Goetz C, Koller W, Poewe W, Sampaio C (2002): Treatment interventions for Parkinson's disease: an evidence based assessment. Lancet $\underline{359}$, 15891598

Rascol O, Payoux P, Ory F, Ferreira JJ, Brefel-Courbon C, Montastruc JL (2003): Limitations of current Parkinson's disease therapy. Ann Neurol 53 Suppl 3, S312; discussion S12-15

Riddle EL, Fleckenstein AE, Hanson GR (2005): Role of monoamine transporters in mediating psychostimulant effects. AAPS J $\underline{7}$, E847-851

Rinne JO, Laihinen A, Rinne UK, Nagren K, Bergman J, Ruotsalainen U (1993): PET study on striatal dopamine D2 receptor changes during the progression of early Parkinson's disease. Mov Disord $\underline{8}, 134-138$

Rinne JO, Laihinen A, Nagren K, Bergman J, Solin O, Haaparanta M, Ruotsalainen U, Rinne UK (1990): PET demonstrates different behaviour of striatal dopamine D-1 and D-2 receptors in early Parkinson's disease. J Neurosci Res $\underline{27}, 494-499$

Rossetti ZL, Sotgiu A, Sharp DE, Hadjiconstantinou M, Neff NH (1988): 1-Methyl-4phenyl-1,2,3,6-tetrahydropyridine (MPTP) and free radicals in vitro. Biochem Pharmacol 37, 4573-4574

Ruottinen HM, Rinne UK (1996): Entacapone prolongs levodopa response in a one month double blind study in parkinsonian patients with levodopa related fluctuations. J Neurol Neurosurg Psychiatry $\underline{60}, 36-40$

Russ H, Staust K, Martel F, Gliese M, Schomig E (1996): The extraneuronal transporter for monoamine transmitters exists in cells derived from human central nervous system glia. Eur J Neurosci $\underline{8}$, 1256-1264 
Salach JI, Singer TP, Castagnoli N, Jr., Trevor A (1984): Oxidation of the neurotoxic amine 1-methyl-4-phenyl-1,2,3,6-tetrahydropyridine (MPTP) by monoamine oxidases $A$ and $B$ and suicide inactivation of the enzymes by MPTP. Biochem Biophys Res Commun 125, 831-835

Saporito MS, Thomas BA, Scott RW (2000): MPTP activates c-Jun NH(2)-terminal kinase (JNK) and its upstream regulatory kinase MKK4 in nigrostriatal neurons in vivo. J Neurochem $\underline{75}, 1200-1208$

Saporito MS, Brown EM, Miller MS, Carswell S (1999): CEP-1347/KT-7515, an inhibitor of $\mathrm{c}$-jun $\mathrm{N}$-terminal kinase activation, attenuates the 1-methyl-4phenyl tetrahydropyridine-mediated loss of nigrostriatal dopaminergic neurons In vivo. J Pharmacol Exp Ther 288, 421-427

Sariola H, Saarma M (2003): Novel functions and signalling pathways for GDNF. J Cell Sci 116, 3855-3862

Schapira AH, Cooper JM, Dexter D, Clark JB, Jenner P, Marsden CD (1990): Mitochondrial complex I deficiency in Parkinson's disease. J Neurochem $\underline{54}$, 823-827

Schiel SJ (2004): Untersuchung eines möglichen Neuroprotektiven Effektes der Kainsäure- und Chinolinsäureläsion des Nucleus subthalamicus auf dopaminerge Neurone der Substantia nigra im 6-Hydroxydopamin- und im 3Nitropropionsäure-Parkinson-Tiermodell der Ratte. Med. Diss. Marburg

Schober A, Peterziel H, von Bartheld CS, Simon H, Krieglstein K, Unsicker K (2007): GDNF applied to the MPTP-lesioned nigrostriatal system requires TGF-beta for its neuroprotective action. Neurobiol Dis $\underline{25}, 378-391$

Schrag A, Ben-Shlomo Y, Quinn N (2002): How valid is the clinical diagnosis of Parkinson's disease in the community? J Neurol Neurosurg Psychiatry $\underline{73}$, 529-534

Schulz JB (2006): Anti-apoptotic gene therapy in Parkinson's disease. J Neural Transm Suppl 467-476 
Schulz JB, Falkenburger BH (2004): Neuronal pathology in Parkinson's disease. Cell Tissue Res $\underline{318}, 135-147$

Schulz JB, Lindenau J, Seyfried J, Dichgans J (2000): Glutathione, oxidative stress and neurodegeneration. Eur J Biochem 267, 4904-4911

Schulz JB, Klockgether T, Petersen D, Jauch M, Muller-Schauenburg W, Spieker S, Voigt K, Dichgans J (1994): Multiple system atrophy: natural history, MRI morphology, and dopamine receptor imaging with 123IBZM-SPECT. J Neurol

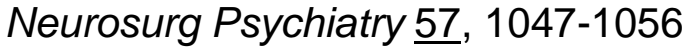

Schulz JB, Skalej M, Wedekind D, Luft AR, Abele M, Voigt K, Dichgans J, Klockgether T (1999): Magnetic resonance imaging-based volumetry differentiates idiopathic Parkinson's syndrome from multiple system atrophy and progressive supranuclear palsy. Ann Neurol $\underline{45}, 65-74$

Schwarz J, Tatsch K, Arnold G, Ott M, Trenkwalder C, Kirsch CM, Oertel WH (1993): 123l-iodobenzamide-SPECT in 83 patients with de novo parkinsonism. Neurology $\underline{43}$, S17-20

Scotcher KP, Irwin I, DeLanney LE, Langston JW, Di Monte D (1990): Effects of 1methyl-4-phenyl-1,2,3,6-tetrahydropyridine and 1-methyl-4-phenylpyridinium ion on ATP levels of mouse brain synaptosomes. J Neurochem $\underline{54}, 1295-1301$

Seroogy KB, Lundgren KH, Tran TM, Guthrie KM, Isackson PJ, Gall CM (1994): Dopaminergic neurons in rat ventral midbrain express brain-derived neurotrophic factor and neurotrophin-3 mRNAs. J Comp Neurol 342, 321-334

Sherer TB, Fiske BK, Svendsen CN, Lang AE, Langston JW (2006): Crossroads in GDNF therapy for Parkinson's disease. Mov Disord 21, 136-141

Sian J, Gerlach M, Youdim MB, Riederer P (1999): Parkinson's disease: a major hypokinetic basal ganglia disorder. J Neural Transm 106, 443-476 
Singer TP, Salach JI, Castagnoli N, Jr., Trevor A (1986): Interactions of the neurotoxic amine 1-methyl-4-phenyl-1,2,3,6-tetrahydropyridine with monoamine oxidases. Biochem J $\underline{235}, 785-789$

Singleton AB, Farrer M, Johnson J, Singleton A, Hague S, Kachergus J, Hulihan M, Peuralinna T, Dutra A, Nussbaum R, et al. (2003): alpha-Synuclein locus triplication causes Parkinson's disease. Science $\underline{302}, 841$

Slack RS, Miller FD (1996): Viral vectors for modulating gene expression in neurons. Curr Opin Neurobiol $\underline{6}, 576-583$

Slevin JT, Gerhardt GA, Smith CD, Gash DM, Kryscio R, Young B (2005): Improvement of bilateral motor functions in patients with Parkinson disease through the unilateral intraputaminal infusion of glial cell line-derived neurotrophic factor. J Neurosurg $\underline{102}, 216-222$

Smith AD, Bolam JP (1990): The neural network of the basal ganglia as revealed by the study of synaptic connections of identified neurones. Trends Neurosci $\underline{13}$, 259-265

Spillantini MG, Schmidt ML, Lee VM, Trojanowski JQ, Jakes R, Goedert M (1997): Alpha-synuclein in Lewy bodies. Nature $\underline{388}, 839-840$

Sugama S, Yang L, Cho BP, DeGiorgio LA, Lorenzl S, Albers DS, Beal MF, Volpe BT, Joh TH (2003): Age-related microglial activation in 1-methyl-4-phenyl1,2,3,6-tetrahydropyridine (MPTP)-induced dopaminergic neurodegeneration in C57BL/6 mice. Brain Res $\underline{964}, 288-294$

Sundstrom E, Luthman J, Goldstein M, Jonsson G (1988): Time course of MPTPinduced degeneration of the nigrostriatal dopamine system in C57 BL/6 mice. Brain Res Bull 21, 257-263

Sveinbjornsdottir S, Hicks AA, Jonsson T, Petursson H, Gugmundsson G, Frigge ML, Kong A, Gulcher JR, Stefansson K (2000): Familial aggregation of Parkinson's disease in Iceland. N Engl J Med $\underline{343}, 1765-1770$ 
Tatarewicz SM, Wei X, Gupta S, Masterman D, Swanson SJ, Moxness MS (2007): Development of a maturing T-cell-mediated immune response in patients with idiopathic Parkinson's disease receiving $r$-metHuGDNF via continuous intraputaminal infusion. J Clin Immunol 27, 620-627

Tatton NA, Kish SJ (1997): In situ detection of apoptotic nuclei in the substantia nigra compacta of 1-methyl-4-phenyl-1,2,3,6-tetrahydropyridine-treated mice using terminal deoxynucleotidyl transferase labelling and acridine orange staining. Neuroscience $\underline{77}$, 1037-1048

Tatton NA, Maclean-Fraser A, Tatton WG, Perl DP, Olanow CW (1998): A fluorescent double-labeling method to detect and confirm apoptotic nuclei in Parkinson's disease. Ann Neurol 44, S142-148

Thanvi BR, Lo TC (2004): Long term motor complications of levodopa: clinical features, mechanisms, and management strategies. Postgrad Med J $\underline{80}, 452-$ 458

Thomas B, Beal MF (2007): Parkinson's disease. Hum Mol Genet 16 Spec No. 2, R183-194

Tomac A, Lindqvist E, Lin LF, Ogren SO, Young D, Hoffer BJ, Olson L (1995): Protection and repair of the nigrostriatal dopaminergic system by GDNF in vivo. Nature $\underline{373}, 335-339$

Trimmer PA, Smith TS, Jung AB, Bennett JP, Jr. (1996): Dopamine neurons from transgenic mice with a knockout of the p53 gene resist MPTP neurotoxicity. Neurodegeneration $\underline{5}$, 233-239

Trupp M, Belluardo N, Funakoshi H, Ibanez CF (1997): Complementary and overlapping expression of glial cell line-derived neurotrophic factor (GDNF), cret proto-oncogene, and GDNF receptor-alpha indicates multiple mechanisms of trophic actions in the adult rat CNS. J Neurosci 17, 3554-3567

Trupp M, Scott R, Whittemore SR, Ibanez CF (1999): Ret-dependent and independent mechanisms of glial cell line-derived neurotrophic factor signaling in neuronal cells. J Biol Chem 274, 20885-20894 
Trupp M, Ryden M, Jornvall H, Funakoshi H, Timmusk T, Arenas E, Ibanez CF (1995): Peripheral expression and biological activities of GDNF, a new neurotrophic factor for avian and mammalian peripheral neurons. $J$ Cell Biol $\underline{130}, 137-148$

Trupp M, Arenas E, Fainzilber M, Nilsson AS, Sieber BA, Grigoriou M, Kilkenny C, Salazar-Grueso E, Pachnis V, Arumae U (1996): Functional receptor for GDNF encoded by the c-ret proto-oncogene. Nature 381, 785-789

Twelves D, Perkins KS, Counsell C (2003): Systematic review of incidence studies of Parkinson's disease. Mov Disord $\underline{18}, 19-31$

Varastet M, Riche D, Maziere M, Hantraye P (1994): Chronic MPTP treatment reproduces in baboons the differential vulnerability of mesencephalic dopaminergic neurons observed in Parkinson's disease. Neuroscience $\underline{63}$, 4756

Varrone A, Marek KL, Jennings D, Innis RB, Seibyl JP (2001): [(123)I]beta-CIT SPECT imaging demonstrates reduced density of striatal dopamine transporters in Parkinson's disease and multiple system atrophy. Mov Disord $\underline{16}, 1023-1032$

Vila M, Jackson-Lewis V, Vukosavic S, Djaldetti R, Liberatore G, Offen D, Korsmeyer SJ, Przedborski S (2001): Bax ablation prevents dopaminergic neurodegeneration in the 1-methyl- 4-phenyl-1,2,3,6-tetrahydropyridine mouse model of Parkinson's disease. Proc Natl Acad Sci U S A $\underline{98}, 2837-2842$

Volkmann J (2004): Deep brain stimulation for the treatment of Parkinson's disease. J Clin Neurophysiol $\underline{21}, 6-17$

Warner TT, Schapira AH (2003): Genetic and environmental factors in the cause of Parkinson's disease. Ann Neurol 53 Suppl 3, S16-23; discussion S23-15

West MJ (1993): New stereological methods for counting neurons. Neurobiol Aging $\underline{14}, 275-285$ 
West MJ, Slomianka L, Gundersen HJ (1991): Unbiased stereological estimation of the total number of neurons in thesubdivisions of the rat hippocampus using the optical fractionator. Anat Rec 231, 482-497

Wichmann T, DeLong MR (1993): Pathophysiology of parkinsonian motor abnormalities. Adv Neurol $\underline{60}, 53-61$

Wichmann T, Bergman H, DeLong MR (1994): The primate subthalamic nucleus. III. Changes in motor behavior and neuronal activity in the internal pallidum induced by subthalamic inactivation in the MPTP model of parkinsonism. $J$ Neurophysiol $\underline{72}, 521-530$

Yoritaka A, Hattori N, Uchida K, Tanaka M, Stadtman ER, Mizuno Y (1996): Immunohistochemical detection of 4-hydroxynonenal protein adducts in Parkinson disease. Proc Natl Acad Sci U S A $\underline{93}$, 2696-2701

Yu T, Scully S, Yu Y, Fox GM, Jing S, Zhou R (1998): Expression of GDNF family receptor components during development: implications in the mechanisms of interaction. J Neurosci $\underline{18}$, 4684-4696

Zhou FM, Wilson CJ, Dani JA (2002): Cholinergic interneuron characteristics and nicotinic properties in the striatum. J Neurobiol $\underline{53}, 590-605$

Zimprich A, Biskup S, Leitner P, Lichtner P, Farrer M, Lincoln S, Kachergus J, Hulihan M, Uitti RJ, Calne DB, et al. (2004): Mutations in LRRK2 cause autosomal-dominant parkinsonism with pleomorphic pathology. Neuron $\underline{44}$, 601-607 


\section{Danksagung}

Ein besonderer Dank gilt Prof. Dr. med. Jörg B. Schulz für die Bereitstellung meines Dissertationsthemas und die Unterstützung im Erlernen und Anwenden von eigenständigem wissenschaftlichen Arbeiten.

Ebenfalls bedanke ich mich herzlich bei Dr. med. Björn Falkenburger für die exzellente Betreuung während der gesamten Dissertation. Das unermüdliche Engagement und die Unterstützung auf allen Ebenen machten diese Arbeit erst möglich.

Ich möchte mich bei Dr. Edgar R. Kramer (Max-Planck Institut für Neurobiologie, Martinsried, Deutschland) für die Bereitstellung der Versuchstiere und für die gute und freundliche Zusammenarbeit bei der Erstellung der veröffentlichten Arbeit bedanken.

Es gilt ein großer Dank den Mitarbeitern des Instituts für Neurodegeneration und Neurorestaurationsforschung, insbesondere Cathy Ludwig, Dr. rer. nat. Ellen Gerhardt, Christiane Fahlbusch, Annette Bennemann, Dr.med. Arno Reich für das angenehme Arbeitsklima und die Unterstützung während der wissenschaftlichen Laborarbeit.

Als letztes gebührt ein großer Dank Charlotte Pöppelmeyer für die gute Zusammenarbeit während des Projektes und der gemeinsamen Veröffentlichung. 
